\title{
PASSING ON THE MONOPOLY OVERGHARGE: A COMPREHENSIVE POLICY ANALYSIS
}

\section{Robert G. Harris † and Lawrence A. Sullivan $\dagger$}

Technological development and increasing specialization in the American economy have fostered structural complexity. Consequently (and despite considerable vertical integration), most transformations from basic inputs to finished products involve a series of transactions in a lengthy production-distribution chain. Monopoly power can be exercised at or near the top of the chain as well as farther down; indeed, it often is. Because retail, service, and wholesale markets are generally competitive except when market power is created by restrictive distribution policies of firms higher on the chain, variations from the competitive ideal are more frequently encountered at the manufacturing, mining, and processing levels. ${ }^{1}$

When monopolization or cartelization takes place, participating firms gain market power ${ }^{2}$ and can price their products in excess of competitive levels. ${ }^{3}$ The difference between such an enhanced price and a competitive price is called a "monopoly overcharge," or simply the "overcharge." * An overcharge exacted high on the dis-

+ Assistant Professor of Business Administration, University of California, Berkeley. B.A. 1965, M.A. 1973, Michigan State University; Ph.D. 1977, University of California, Berkeley.

t† Earl Warren Professor of Public Law, University of California, Berkeley. A.B. 1948, University of California, Los Angeles; J.D. 1951, Harvard University.

We wish to acknowledge the helpful comments of our colleagues, Professors Michael Conant, George Evans, and Thomas Jorde, on an earlier draft of this Article.

1 See generally the brief studies of thirteen industries in W. ADAMs, ThE STructure of AMERTCAN INDUSTRT (4th ed. 1971). See also F. Scherker, INDUStrial Market Structure and Economic Performance (1970) (see especially chapters $3,4, \& 9$ ).

2 Market power can be defined as "the power of a firm to affect the price which will prevail on the market in which the firm trades." L. SULrivaN, HaNDBOOK of THE LAW OF ANTITRUST $\$ 8$ (1977).

3 A simple, theoretical description of the differences between competitive and monopoly pricing is found in Gellhorn, An Introduction to Antitrust Economics, 1975 Duse L.J. 1, 33-35.

4 This terminology has become customary. See, e.g., House COMM. ON THE Judictary, Report to ACCOMPANy H.R. 11942, H.R. Rep. No. 95-1397, pt. 1, 95th Cong., $2 d$ Sess. 3 (1978) [hereinafter cited as 1978 House REPORT]. 
tribution chain need not remain there. Firms which buy from a monopolist or cartel member may simply mark up the price of products they sell by all or part of (or even more than) the overcharge, thus passing it on to buyers farther down the chain. The complexity of the production-distribution chain and the fact that a monopoly overcharge exacted at one level may be transmitted to another give rise to the "passing on" problem which has been vexing antitrust litigation for over a decade. ${ }^{5}$

Two Supreme Court decisions, Hanover Shoe, Inc. v. United Shoe Machinery Corp. ${ }^{6}$ and Illinois Brick Co. v. Illinois, ${ }^{7}$ are of dominating significance. Hanover Shoe, decided in 1968, was a suit against a monopolist by one of its customers seeking to recover three times the amount of an alleged overcharge. The Court held that an antitrust violator may not, as a rule, defend such a suit by proving that the customer passed on all or part of the illegal overcharge to its own customer. ${ }^{8}$ The Court reasoned that to allow the defense would unduly complicate overcharge litigation and might result in a violator retaining the fruits of its illegal conduct.9 Illinois Brick, decided in 1977, involved down-chain plaintiffs suing members of a cartel. The Court held that an antitrust plaintiff may not recover

5 Passing on is the subject of considerable case law. E.g., Illinois Brick Co. v. Illinois, 431 U.S. 720 (1977); Hanover Shoe, Inc. v. United Shoe Mach. Corp., 392 U.S. 481 (1968); In re Western Liquid Asphalt Cases, 487 F.2d 191 (9th Cir. 1973), cert. denied, 415 U.S. 919 (1974); West Va. v. Chas. Pfizer \& Co., 440 F.2d 1079 (2d Cir.), cert. denied, 404 U.S. 87I (1971). There is also extensive legal literature. E.g., Berger \& Bernstein, An Analytical Framework for Antitrust Standing, 86 Y ALE L.J. 809 (1977); McGuire, The Passing-On Defense and the Right of Remote Purchasers to Recover Treble Damages Under Hanover Shoe, 33 U. Prrr. L. Rev. 177 (1971); Pollock, Automatic Treble Damages and the PassingOn Defense: The Hanover Shoe Decision, 13 ANTrrrust BuLL. 1183 (1968). There is also some economic commentary. E.g., Schaefer, Passing-On Theory in Antitrust Treble Damage Actions: An Economic and Legal Analysis, 16 WM. \& MARy L. Rev. 883 (1975).

6392 U.S. 481 (1968).

7431 U.S. 720 (1977).

8392 U.S. at 494 . Dicta in the opinion carve out a limited exception under which the passing-on defense would be available when passing on takes place pursuant to a pre-existing cost-plus contract. Id.

In In re Beef Indus. Antitrust Litig., 600 F.2d 1148, 1163-67 (5th Cir. 1979), the court interpreted this exception to be wider than we have supposed, thus indicating that both policy analysis and institutionally based economic analysis may appropriately be brought to bear by courts in applying the exception. In an opinion by Judge Wisdom, the court said that the "cost-plus" exception may apply to any transaction constituting the "functional equivalent of the cost-plus contract case." Id. 1163 . The court also said that functional equivalence was established whenever the impact of a price change at one level upon the pricing decisions of firms at the next level could be determined in advance, without regard to the interactions of supply and demand, and it intimated that proof of the existence of a well-established and consistently applied markup pricing system might meet this standard.

9392 U.S. at 494. 
an illegal overcharge passed on to the plaintiff by an intermediate firm which had in turn purchased from a cartel member.10 The Court noted that Hanover Shoe precluded the defensive use of passing on, and that a symmetrical rule precluding its offensive use was needed to protect defendants from the risk of duplicative trebledamage liability. ${ }^{11}$ It also reiterated the Hanover Shoe concern about complexity and stressed the limited capacity of courts to deal with passing-on issues. ${ }^{12}$ Indeed, Hanover Shoe was expressive of an asserted tradition under which courts award damages only to the party immediately injured, thus terminating analysis at the "first step." 13 Finally, the Court in Illinois Brick took the view that the deterrent effect of the antitrust laws would be maximized by assigning the cause of action for an overcharge to the direct purchaser only, whether or not that purchaser was in fact injured. ${ }^{14}$

These decisions, far from settling the passing-on question, have triggered intensive congressional involvement. Legislation to overrule Illinois Brick, supported by state officials ${ }^{15}$ and federal antitrust-enforcement officials, ${ }^{16}$ but opposed by business groups, ${ }^{17}$ has been introduced in two successive sessions of Congress. ${ }^{18}$ In the first session of the ninety-sixth Congress, such legislation, sponsored by Senator Kennedy and Congressman Rodino, headed the antitrust.

10 Like Hanover Shoe, the opinion suggests the possibility of limited exceptions. See 431 U.S. at 736 n.16, 745-46.

11 Id. $730-31$.

12 Id. 731-33.

13 See Southern Pac. Co. v. Darnell-Taenzer Lumber Co., 245 U.S. 531, 533; (1918), in which Justice Holmes asserted that the "general tendency of the law, in regard to damages at least, is not to go beyond the first step."

14431 U.S. at 745-47.

15 State officials took leading roles in the efforts to override Illinois Brick in both the 95th and 96th Congresses. See Restoring Effective Enforcement of the Antitrust Laws: Hearings on H.R. 2060 and H.R. 2204 and Other Proposals Before the Subcomm. on Monopolies and Commercial Law of the House Comm. on the Judiciary, 96th Cong., lst Sess. 44-79 (1979) (support of Nat'l Governors Ass'n). [hereinafter cited as 1979 House Hearings]; Effective Enforcement of the Antitrust Laws: Hearings on H.R. $8359 B$ Before the Subcomm. on Monopolies and Commercial Law of the House Comm. on the Judiciary, 95th Cong., 1st Sess. 23-71 (1978) (support of Nat'l Ass'n of Attorney Generals) [hereinafter cited as 1978 House Hearings]; Fair and Effective Enforcement of the Antitrust Laws: Hearings on S. 1874 Before the Senate Comm. on the Judiciary, 95th Cong., Ist Sess. 92-96, 101-28 (1978) [hereinafter cited as 1978 Senate Hearings].

16 See 1979 House Hearings, supra note 15, at 14-40; 1978 House Hearings, supra note 15, at 6-23; 1978 Senate Hearings, supra note 15, pt. 1, at 17-29.

17 See, e.g., 1979 House Hearings, supra note 15, at 149-94; 1978 Senate Hearings, supra note 15, pt. 1 , at 141-49, 161-69; 1978 House Hearings, supra note15 , at $489-500$.

18 See Senate Conm. on the Judrctary, Report to Accompany S. 300, S. REP. No. 96-239, 96th Cong., Ist Sess. 61 (1979) [hereinafter cited as 1979 SENATe. REPORT]. 
agenda in both houses. ${ }^{19}$ There seems to be little doubt that if it fails to pass now, it will be introduced again next session. ${ }^{20}$

This pending legislation addresses the controversial issues raised in Hanover Shoe and Illinois Brick. One concern is duplicative liability, or, more broadly conceived, compensatory justice. If a monopolist or cartelist is not protected against the possibility of successful overcharge suits by successive purchasers at different levels of distribution, it would be liable more than once for three times the amount of the overcharge, a potential liability exceeding the damages Congress has mandated ${ }^{21}$ and which imagination easily stretches to ruinous amounts. ${ }^{22}$ To assign the cause of action to the direct purchaser only, however, as the Court did in Illinois Brick, strains against another compensatory concern: to the extent that the direct purchaser passes the overcharge on, a damage award to it is a windfall, and some purchaser farther down the chain is left with an uncompensated loss. ${ }^{23}$

Factual complexity and judicial capacity are also difficult issues. If one supposes, as the Court perhaps has done, that each decision about passing on by each sequential price-setter is sui generis, the prospect of using adjudication to trace a particular overcharge down its particular chain is a daunting one. ${ }^{24}$ Further, despite what others have argued, a general theoretical analysis alone does not necessarily simplify the problem. ${ }^{25}$ Nonetheless, there are realms of inquiry that stand between open-ended, unguided exploration of each specific situation and application of unbounded, universal theoretical principles. It may be possible to narrow the theoretical universe in ways that suggest useful presumptions. ${ }^{26}$ Moreover, it

19 See, e.g., Senate Committee Approves Bill to Overrule Illinois Brick Rale, [1979] 913 ANTitrust \& Trade Reg. Rep. (BNA) A-7 to -9.

20 We draw this inference on the basis of the support for the legislation from state officials, antitrust enforcement officials, and the leadership of the relevant congressional committees. See notes 16-18 supra.

21 Section 4 of the Clayton Act provides that any person injured in his business or property by a violation of the antitrust laws may recover three times the damage sustained. 15 U.S.C. $\$ 15$ (1976). views).

221979 Senate Report, supra note 18, at 149-52 (minority and additional

23 The potential, uncompensated losses, though difficult to quantify, are certainly exceedingly large. See 1979 Senate REPORT, supra note 18, at 16-17.

24 Such complexity is envisaged by those opposed to legislation to overrule Illinois Brick. See 1979 SenAte Report, supra note 18, at 157-59 (minority and additional views).

25 See, e.g., 1978 House Hearings, supra note 15, at 192-95 (statement of Richard A. Posner).

26 Presumptive rules and guidelines in antitrust are based upon such a process of deriving practice from theory. See, e.g., Dep't of Justice Merger Guidelines, [1968] I Trade REg. Rep. (CCH) $\Uparrow 4510$. 
may also be possible to make institutionally based, middle-level generalizations which will make inquiry into particular situations more manageable. ${ }^{27}$

Deterrence is also a troublesome question. First, there is little theoretical or empirical information to help one decide whether direct or more remote purchasers are more likely to challenge overcharges. Second, matters of complexity and judicial capacity obviously also bear on the matter, though not in any direct way. ${ }^{28}$ Finally, it may ultimately be necessary to make some trade-off between maximizing compensatory justice and maximizing deterrence. Yet, policy judgments about deterrence should be informed by empirical and institutional factors.

This Article attempts a comprehensive analysis of these issuesmore comprehensive in several respects than anything now in the literature. In part I we draw on microeconomics to do a theoretical analysis of passing on. We show that the extent of passing on in a particular market depends mainly upon the elasticities of demand and supply. ${ }^{29}$ While this general approach informs some of the legislative testimony ${ }^{30}$ and scholarly commentary ${ }^{31}$ already available, our analysis contains three new contributions, each of significance in policy formulation. First, on the basis of both analytical and empirical factors, we identify from the range of possible analytical models the particular variants most likely to be encountered in markets in which antitrust overcharges are likely to occur. Abstract models, if carefully selected, can offer insights which may transcend, and thereby aid in the understanding of, specific cases. Such models, however, if not chosen with skill and judgment, can obscure or mislead. Those who have used this kind of approach in the past have stressed the wide range of possible results and have implied that judgments about the extent of passing on are difficult. ${ }^{32}$ By narrow-

27 By "institutionally based" generalizations, we mean those that rely not solely upon theory but also upon relevant industrial custom, practice, and procedures.

28 In general, the more confident one was that courts could easily and accurately decide passing-on issues, the less convincing one would find the contention that deterrence would be enhanced by excluding passing-on evidence.

29 The elasticity concept (in relation to demand) is explained in Gellhorn, supra note 3, at 19-22. See also note 44 infra \& accompanying text.

30 See 1978 Senate Hearings, supra note 15, pt. 2, at 89-101 (statement of Betty Bock). Compare id., pt. 2, at 311-19 (statement of Dorsey D. Ellis) with id., pt. 2, at 51-54 (statement of Richard A. Posner). A less thorough, preliminary version of the analysis completed in this Article was presented in Congress by one of the authors at 1979 House Hearings, supra note 15, at 119-30.

31 For an excellent pre-Illinois Brick review of the economics of passing on, see Schaefer, supra note 5.

32 See, e.g., 1978 Senate Hearings, supra note 15 (statement of Betty Bock), especially pt. 2 , at 91 . 
ing the theoretical range, we provide a basis for more confident prediction about what is likely to occur in markets in which passing on is likely. Second, we focus sharply on the dimension of time. We show that the extent of passing on is likely to be high in the long run even when it is low in the short run. Third, we emphasize the greater significance of supply factors over demand factors in passing-on analysis and, in so doing, sharpen the policy perspective. In its entirety, our analysis suggests that in markets in which monopoly overcharges are likely to be found, a high degree of passing on almost always occurs eventually and is likely to occur quite rapidly.

Without the enrichment of an empirical analysis, even a sensitive theoretical analysis may provide a weak basis for inferences about real-world situations. Having concluded that, in theory, passing on is likely in monopolized or cartelized markets, we turn, in part II, to institutional material. From the extensive marketing literature about actual commercial pricing practices, we identify two widely utilized pricing methods. We show both how these affect the likelihood of passing on and how they provide a manageable way to determine whether and to what extent passing on has occurred in particular cases. This study confirms that a high degree of passing on (sometimes exceeding $100 \%$ ) is frequent. More important, it serves to demystify questions about how passing on can be traced.

In part III we focus on the limited differences between the theoretical and institutional analyses and seek to reconcile them. Specifically, we identify the mechanisms through which prices set by methods not deliberately attuned to marginal costs may nevertheless be brought into congruence with marginal costs. We also note the limits of these mechanisms.

We draw in part IV upon these theoretical and institutional analyses and their reconciliation to identify two separate, yet harmonious, methodologies that could be used to determine the extent of passing on in particular cases. The first draws upon the theoretical analysis and the reconciliation to identify several simplified structural factors-all readily identifiable in markets in which they occur-that will be useful in making estimates about the extent of passing on in particular cases. This methodology requires only a modest amount of empirical information and thus could save time and expense. The estimates ought to be highly accurate in most cases-certainly accurate enough to serve as presumptions subject to rebuttal by detailed evidence of the pricing methods used and 
their passing on consequences. The second method is a direct and precise (and carefully structured) empirical inquiry into what is actually occurring in the particular market. This method, informed primarily by the institutional analysis, requires more data and is even more accurate.

Part $V$ constitutes a demonstration section, a workshop. We evaluate the sixty-five price-fixing cases brought and won by the Department of Justice Antitrust Division between 1963 and 1972. Then, drawing upon the prior analysis and, in particular, upon the structural factors discussed in part IV(A), we illustrate how judgments about passing on can be made from available data. We specify the recurrent situations in which the first purchaser will absorb the overcharge and we show that these can readily be identified. In all other situations, some passing on has occurred. In some of these, it may not be possible to determine either the class or the individual purchasers to whom the overcharge has been passed on; in others, it will be possible to determine the class but not the individual firms; in still others, both the class and the individual victims will be readily determinable. In each of the last two categories, it will in most cases be easy to determine whether or not there is a great probability that a high percentage of the overcharge has been passed on. In sum, we use this part to illustrate specific, manageable inquiries through which a court can investigate and resolve passing-on questions with reasonable confidence and dispatch.

In part VI we return to the policy issues raised by Hanover Shoe and Illinois Brick, which have been debated extensively in Congress. We seek to show that where it is possible to trace passing on, the best balance between concerns about compensatory justice and about deterrence is achieved by allowing both the offensive use of passing-on evidence and also its defensive use when reasonably necessary to avoid the risk of duplicative recovery. By contrast, the case for rejecting proof of passing on is strong when its extent is highly speculative and when the defendant, as a practical matter, faces no significant risk of duplicative recovery.

\section{The Economic Theory of Passing ON}

Economic theory relating to passing on, formally known as "incidence theory," ${ }^{33}$ draws upon the standard tools and utilizes

33 For an excellent treatment of tax-incidence theory, see R. MUSGRave \& P. Musgrave, Public Finance in Theory and Practice (1973) (see especially chapter 19). The cause of the price increase makes no difference to the analysis; 
the conventional assumptions of neoclassical microeconomics. Other studies using this approach have focused on short-run analysis, emphasized the wide range of possibilities suggested by the models (from no passing on to total passing on), and stressed that the extent of a pass on is a function of elasticity relationships which are hard to measure in actual markets. ${ }^{34}$ Thus, such studies have often concluded that the existence and extent of passing on are indeterminable. ${ }^{35}$ The utility of a general, theoretical analysis, however, is seldom that it directly shows what is happening in particular cases; ${ }^{36}$ rather, its value is that it can identify central tendencies. In what follows, we utilize long- as well as short-run analysis and stress supply factors which are customarily of greater relevance to passing on than are demand factors. In addition, we first utilize and then vary the usual assumption that markets downstream from the cartelized or monopolized one are all perfectly competitive. In sum, we provide a fuller theoretical analysis than is typical.

Moreover, we use this material to gauge the scope of the passing-on problem. Through simple analytic models we show that in a multiple-level chain of distribution, passing on monopoly overcharges is not the exception: it is the rule. This analysis then addresses one of the central policy issues regarding the standing of indirect purchasers-compensatory justice. If in most situations indirect purchasers ultimately bear the costs of monopoly over-

although we are assuming it is a monopoly overcharge, it could be a tax, price fixing, or general inflation. This form of analysis was developed initially as "tax incidence theory," which is concerned with who ultimately pays various forms of taxes. Because a monopoly overcharge, resulting from noncompetitive structure or collusive conduct, is theoretically analogous to an excise tax (that is, a sales tax on a specific product), our analysis follows closely the incidence theory as applied to excise taxes.

Not only is the theoretical literature on tax incidence well developed, but there is also an extensive body of empirical studies of incidence by public-finance economists. E.g., Brownlee \& Perry, The Effect of the 1965 Federal Excise Tax Reduction on Prices, 20 NAT'L TAX J. 235 (1967). In most cases the complexities of tax incidence make empirical analysis exceedingly more difficult than it is likely to be in most antitrust passing-on cases. For an extensive survey of tax incidence theory and empirical studies, see Break, The Incidence and Economic Effects of Taxation, in The Economics of Publtc Finance 119 (1974).

34 See, e.g., Illinois Brick Co. v. Illinois, 431 U.S. 720, 742 (1977); 1978 Senate Hearings, supra note 15 , pt. 2 , at $90-94$ (statement of Betty Bock). But see Schaefer, supra note 5, at 915 (such measurements "do not present insurmountable obstacles"). Bock).

35 See 1978 Senate Hearings, supra note 15, pt. 2, at 90-94 (statement of Betty

36 One of the potential misuses of a theoretical analysis is to move from the blackboard to the marketplace without any basis for supposing that the theoretical presuppositions are found in the marketplace. Another is to suppose that theoretical referents such as "marginal cost" can be used as the building blocks for an operative legal rule, even though the theoretical referent has no marketplace analogue. 
charges, then denying them redress and granting it to others not in fact injured is inequitable. We also use the theoretical inquiry as a source of concepts which, along with others drawn from institutional sources, can be used as the basis for useful presumptions about passing on. Thus, these models bear upon whether proof of passing on is too difficult for courts. This theoretical analysis also pertains to the policy of deterrence. Supporters of Illinois Brick have argued that disallowing both the offensive and defensive use of passing on would increase the deterrent effect of private actions by providing a strong incentive to direct purchasers to sue. The economic model shows, however, that, because direct purchasers often suffer little economic loss, their incentive to seek out and sue antitrust violators may be relatively weak.

In the sections which follow, we consider the extent of passing on in the short run in situations in which downstream markets are competitive, deal with long-run adjustments in such markets, and finally, examine structures in which market power is exercised downstream as well as at the level at which the overcharge is initially imposed.

\section{A. Short-Run Analysis When All Downstream Markets are Competitive}

To begin, let us introduce some terminology. Assume a threestep production-distribution chain: a manufacturing level, a reselling level, and a consumer level. ${ }^{37}$ We refer to the manufacturers as $M$, resellers as $R$, and consumers as $C$. Because the $M$ firms sell their output to firms at level $R$, who in turn sell to final usersfirms or households at $C$-we classify $R$ as direct purchasers and $C$ as indirect purchasers. We refer to any given output of $M$ as $Q_{\mathrm{m}}$ and the price for this output as $P_{m}$; for the reseller, output is specified as $Q_{\mathrm{r}}$, price as $P_{\mathrm{r}}$. Throughout part $I$, we make the standard neoclassical assumption that all firms are profit-maximizing, which means they set the price so that marginal cost is equal to marginal revenue. ${ }^{38}$

37 We employ a three-level chain of production and distribution for the purposes of graphical and expositional simplicity. The analytical models are general, applying as well to any n-level chain of production. Perhaps the most important source of simplification in our model is the assumption that the direct purchaser only resells the manufacturers' product to consumers without transforming the product physically. Again, the model is general and is applicable to cases in which an intermediary is a manufacturer who uses the product of $M$ as an input into its production process.

38 See Gellhorn, supra note 3, at 22-35. 
The existence of a monopoly overcharge at the manufacturing level implies that the $M$ level is noncompetitive. We will assume an effective cartel operating at that level, though the results would be essentially the same if $M$ were occupied by one firm, a monopolist. ${ }^{39} R$, the resale level, is assumed to be perfectly competitive. This implies that each firm at $R$ faces a perfectly elastic demand curve, which means that it can sell at one and only one price-the competitive price. (For the $R$ level as a whole, the supply curve is equivalent to the short-run marginal-cost curve.) Elasticity is a measure of the responsiveness of demand (or supply) to changes in price: given an increase in the price of a product, how much less of the product will consumers be willing to purchase? If the price of bread increases by $10 \%$ and consumers buy $5 \%$ fewer loaves, the elasticity of demand is equal to -.5. Elasticity, usually symbolized by $e$, is defined as the percentage change in quantity divided by the percentage change in price. Note that the higher the elasticity of demand, the more responsive consumers are to price changes. At the limits, perfectly elastic demand would mean that any increase in price would cause consumers to buy none of the product; by contrast, perfectly inelastic demand would mean that consumers would buy the same amount even though the price increased.

Our concern is with the effect upon $P_{r}$, the price charged by firms at level $R$, when $M$ imposes a monopoly overcharge which causes $P_{\mathrm{m}}$, the price charged by $M$, to increase. If $P_{\mathrm{m}}$ goes up by a certain amount (to which we refer as $\Delta P_{\mathrm{m}}$ ), what will happen to $P_{\mathrm{r}}$, the price paid for the product by the ultimate consumers?

We begin with a short-run analysis of the case in which $R$ is a perfectly competitive level. ${ }^{40}$ In this context, the short run means a period of time shorter than that within which firms at level $R$ could adjust capacity through, for example, changes in plant or capital equipment in order to respond to the increase imposed by $M$. In the short run, then, firms must respond to a price increase without

39 An effective cartel, like a monopolist, would exercise power to raise price above the competitive level although the cartelized price would still be lower than a pure monopoly price. See generally $F$. SCHERER, supra note 1 , at 158-82.

40 The "short run" in economic theory refers to a time period in which investment level (or, alternatively, production capacity) is fixed, so that producers must meet any increase in demand by increasing the rate at which existing capacity is used rather than by increasing capacity. In the "long run" all factors of production are variable, which means that producers have sufficient time to plan, construct, and begin operating additional facilities. The length of time to which the long run refers depends upon the particular industry. In the steel industry, for example, it might take five or ten years to build a new mill, whereas a retailer might expand capacity in a matter of months. 
altering their levels of investment. How long the short run may be will vary, of course, from industry to industry. Some capacity adjustments can be made very quickly; others may take months or years. To make discussion more concrete, we suggest that one year be viewed as a demarcation point. Based on institutional factors such as those discussed in part II, it is our sense that in most industries long-run adjustments would have begun, and in some cases been completed, within a year after a significant increase in a factor cost was imposed. By contrast, short-run adjustments, which are likely to be made by the next time that prices are changed, will frequently be completed within weeks and seldom, if ever, take longer than a year.

\section{Monopoly Overcharge on a "Fixed Cost" Item}

Figure 1 shows two contrasting equilibrium prices and outputs ${ }^{41}$ in the market between $R$ and $C,{ }^{42}$ before and after $M$ imposes a monopoly overcharge which increases $R$ 's costs. The question is how much of the overcharge will be passed on by the $R$ firms when they resell to the $C$ firms or households. The answer depends upon whether the cost to the $R$ firms of the product purchased from $M$ is a variable or a fixed cost. In our model, firms at level $R$ are not final consumers. They use the products they buy from firms at level $M$ as inputs into their own production, distribution, or service functions which are then sold to $C$. Thus, prices charged by $M$ on sales to $R$ are one element of the overall cost incurred by $R$ in producing the item or service it sells to $C$. Economists subdivide these input costs into two categories, fixed costs and variable costs.

Suppose, for example, that $R$ firms are sporting goods stores and that $M$ firms produce and sell to $R$ firms machines used to string tennis and squash rackets. Then, for $R$, the cost of $M^{\prime}$ 's product is a fixed cost in that it will not vary directly with the sales of tennis rackets or racket-stringing services. Thus, the increase in $M$ 's price that results from the monopoly overcharge has no effect upon the supply curve of $R$ : because $R$ firms cannot reduce their costs by supplying less at the current market price for their products

41 In dynamic economies, markets are constantly in motion, changing in response to factors like shifting preferences, technology, entry and exit of firms, and development of new products. The "equilibrium" is an abstraction used to portray the results of market competition (in terms of price and output levels) if the market were to come to rest. A simple physical analogue is the pendulum: its equilibrium point is the bottom of the arc through which it swings, whether or not the pendulum ever comes to rest there.

42 The model could be extended from a three-level chain to an n-level chain without altering the analysis. See note 37 supra. 
Figure 1. Passing-On in the Short-Run, Competitive Case.*

A. Increase in $R$ 's Fixed Costs

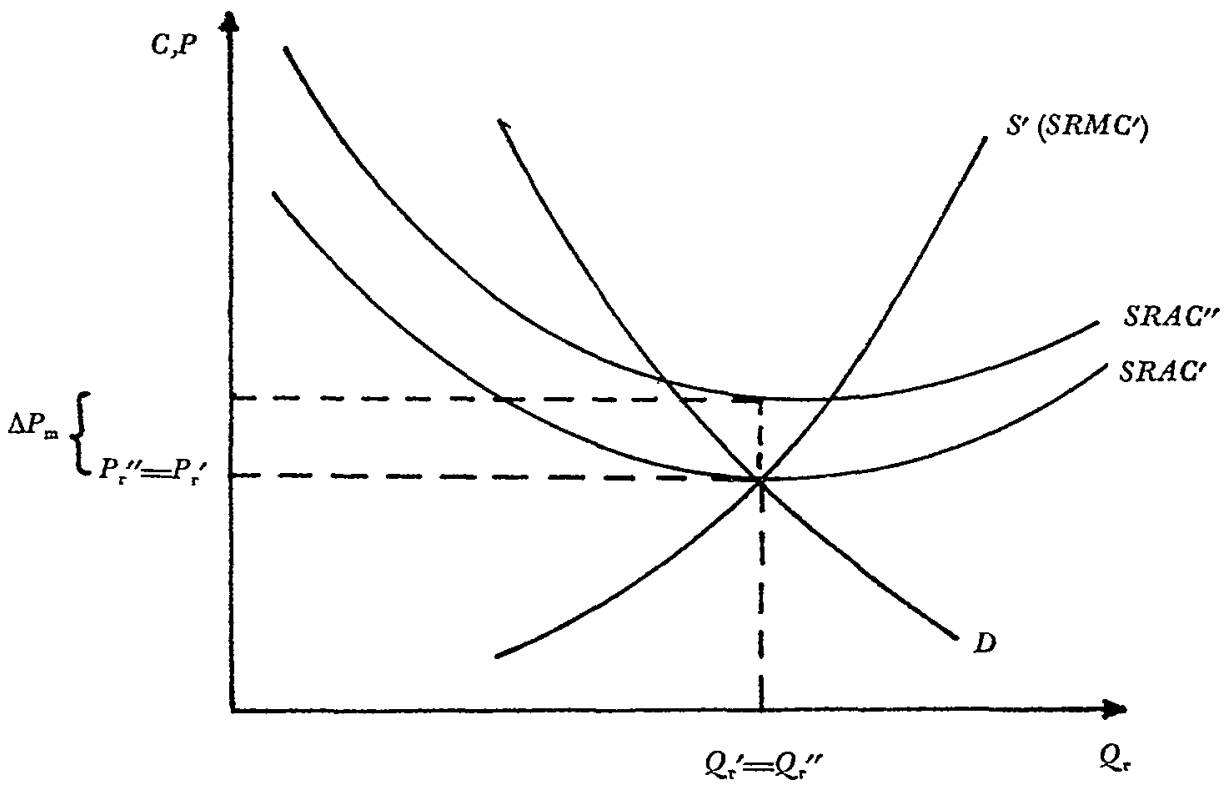

B. Increase in $R$ 's Variable Costs

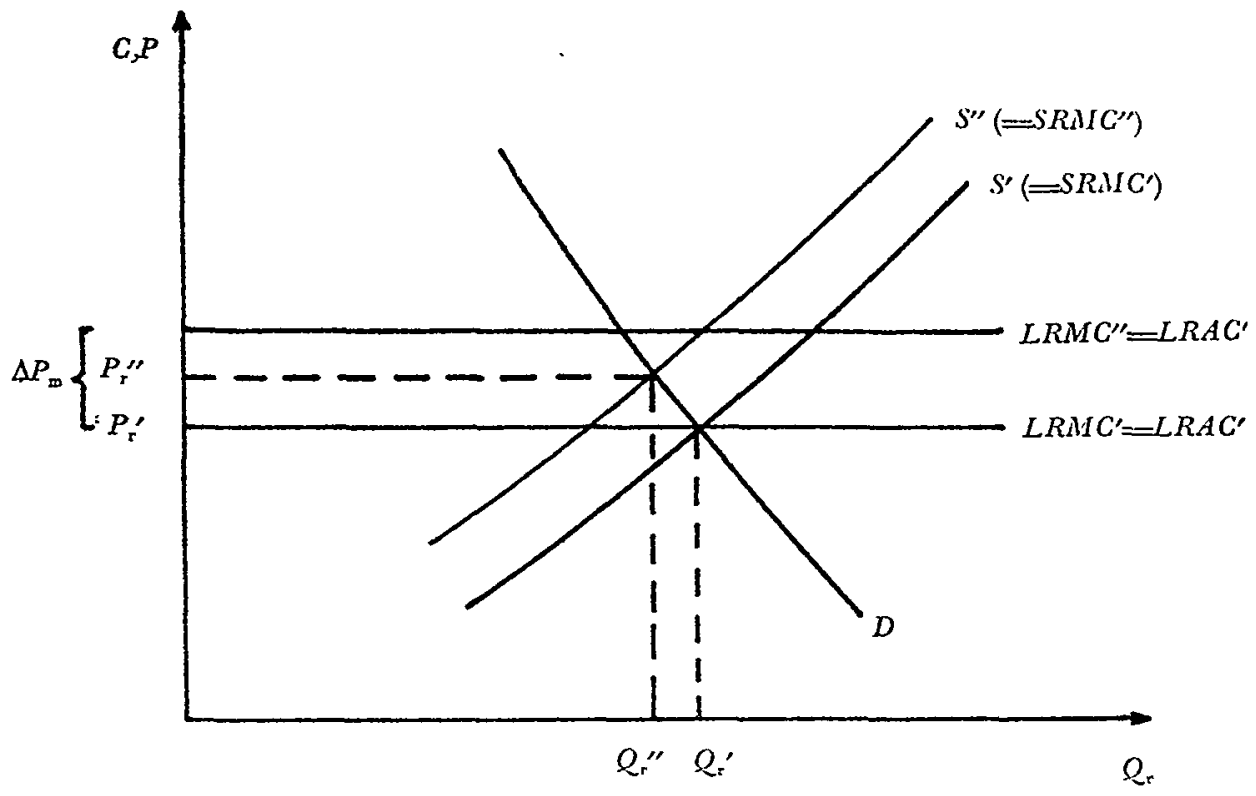

In this and succeeding figures 2,3 , and 4, the supply and demand curves represent those of the industry $R$ as a whole; not of individual $R$ firms. 
and services, they have no reason to supply either more or less than they were supplying before the overcharge was imposed upon them. This is shown graphically in Figure I(A), where the supply curve is unchanged by the increase in $P_{m}$; that is, $S^{\prime}=S^{\prime \prime}$ (for a competitive industry, the supply curve is equivalent to the short-run marginalcost curve, which we abbreviate $S R M C$ ).

There is, of course, an increase in the average costs of $R$ firms, who must pay more for the racket-stringing equipment. This is shown in Figure $1(\mathrm{~A})$ as a shift in the short-run average-cost curve $(S R A C)$ from $S R A C^{\prime}$ to $S R A C^{\prime \prime}$. In spite of this increase in average costs, though, the equilibrium price is unchanged by $M$ 's price fixing because $R$ 's supply curve remains the same-graphically, $P_{r}^{\prime}=$ $P_{r}^{\prime \prime}$. In the short run, the resellers, $R$, bear all of the monopoly overcharge on such a fixed-cost item, passing on none of it. Because average costs now exceed the price $\left(P_{\mathrm{m}}^{\prime \prime}<S R A C^{\prime \prime}\right.$ at $\left.Q_{\mathrm{r}}{ }^{\prime \prime}\right), R$ firms will earn less profit than at the precartelization price.

Additional examples of fixed costs for which $R$ would have to bear the monopoly overcharge in the short run are easily imagined: at the retail level, refrigeration equipment for a butcher or grocer; in service businesses, tables and chairs bought by a restaurant; at the wholesale level, warehouse shelving; in manufacturing, production machinery such as stitching equipment bought by a shoemaker. In each of these cases and all those like them, any monopoly overcharge resulting in an increase in fixed costs will be borne-in the short run -entirely by the direct purchasers.

\section{Monopoly Overcharge on a "Variable Cost" Item}

When a monopoly overcharge increases the price of a variable factor, the results are quite different. Suppose again that $R$ firms are sporting goods stores but that the $M$ firms make tennis rackets and sell them to these retailers. When $M$ increases $P_{\mathrm{m}}$ to monopoly levels, this results in an increase in short-run marginal costs for firms at $R$ level. The cost of the tennis rackets that $R$ buys from $M$ varies directly with $R$ 's own output-its retail sales of tennis rackets. Because the price charged by $M$ has gone up, each additional unit of production by $R$ will now cost more than it did before, by an amount equal to the monopoly overcharge. Because the short-run marginal-cost curve defines the supply curve for firms selling in a competitive market, the overcharge imposed by $M$ results in an upward shift of the supply curve for firms at $R$. To maximize their profits (or minimize their losses), these firms will now supply less, at any given resale price (dictated by the competitive market in which 
they sell), than they would have supplied before the overcharge by $M$ increased their costs. This is illustrated by a vertical shift of $S^{\prime}$ to $S^{\prime \prime}$ in Figure $1(B)$. Thus, the overcharge imposed by the cartel at $M$ causes a change in the equilibrium price and output in the market between $R$ and $C$, from $P_{\mathrm{r}}{ }^{\prime}$ to $P_{\mathrm{r}}{ }^{\prime \prime}$ and $Q_{\mathrm{r}}{ }^{\prime}$ to $Q_{\mathrm{r}}{ }^{\prime \prime}$. As a consequence of the increase, $\Delta P_{\mathrm{m}}$, consumers pay more to, and buy less from, the resellers at level $R$. This is the so-called short-run equilibrium result: an increase in the price of a variable factor of production shifts the supply curve, inducing a new equilibrium. In this situation $R$ firms will in the short run pass on a substantial part of the overcharge.

In Figure $1(B)$, note that the rate of passing on is determined by the relative elasticities of the demand and supply curves. The steeper the demand curve relative to the supply curve, ${ }^{43}$ the larger the share of the manufacturer's price increase, $\Delta P_{m}$, that will be passed on to the indirect purchasers, $C$, in the form of a higher price, $P_{\mathbf{r}}{ }^{\prime \prime}$. As a rule, we define the passing-on rate as the change in the reseller's price divided by the change in the manufacturer's price. ${ }^{44}$ Note also on the basis of Figure $1(B)$ that there are two important effects of the anticompetitive practice of $M$ in the market between $R$ and $C . .^{45}$ The allocative effect is the decrease in output from $Q_{r}^{\prime}$ to $Q_{r}^{\prime \prime}$ : consumers are worse off because, at the higher price, they buy less of the reseller's (and, in turn, the manufacturer's) product. ${ }^{46}$ The distributive, or equity, effect is that consumers pay an artificially high price for what they buy, yielding

43 Strictly speaking, elasticity is not equivalent to the slope of a curve. As a rule, though, the slope of a curve is indicative of elasticity: the steeper the curve, the less elasticity it indicates, and the flatter the curve, the more elasticity it indicates.

44 Algebraically, the passing-on rate is defined as $\frac{\Delta P r}{\Delta \bar{P} m}$.

45 There is a third effect of the overcharge closely connected to the reduction in output (the allocative effect) which is distributive in nature. Because consumers buy less of $R$ 's product at the monopoly-overcharge-induced higher price, the $R$ firms may suffer losses from the overcharge even if they pass on all of the. overcharge on the products they continue to sell. The economic loss to the $R$ firms would not amount to the total value of the lost sales revenues. The loss would be only that share of those revenues that would have accrued as profit to $R$ firms. This reduction is likely to be significant only if $R$ 's investment is relatively immobile (that is, cannot be used to sell other products to make up for the lost sales) and the elasticity of demand is high (so that the reduction in sales is substantial). In any event, our analysis is concerned only with the passing on of the monopoly overcharge on sales that actually occur, not with any losses due to foregone sales.

46 The allocative effect is measured by the "welfare triangle" shown as the area bounded by $P r^{\prime}$ on the bottom, $Q r^{\prime \prime}$ on the left, and the demand curve on the right. The shift in supply induces a price increase and reduction in consumption, causing a "deadweight" loss of economic welfare. The loss is deadweight because it inures to no one. 
what amounts to a transfer of income from consumers to manufacturers. ${ }^{47}$

\section{The Significance of Elasticities}

Because the percentage of the overcharge on a variable-cost item that will be passed on in the short run depends upon the relationship between supply and demand elasticities, it is useful to focus on the possible range of this relationship. Figure 2 displays the four extreme types of supply-demand relationships-the limit cases, as it were. We have assumed in each that the price increase by $M$ raises variable costs-that is, it shifts the supply curve upward. We continue to assume that $R$ is a competitive industry and that each firm maximizes profit.

In Figure 2(A), the supply curve for industry $R$ is perfectly elastic throughout the relevant range, ${ }^{48}$ thus indicating that these firms can expand output without any increase in the unit costs of the items produced. While perfect elasticity of supply would never prevail indefinitely, no matter how great the increase, this particular limit case is one which is often encountered in real markets within the range of expansion or contraction that firms are likely to consider seriously. For example, a retail trade (say, sporting goods) might greatly expand or contract sales of a particular product (say, tennis rackets) with no change in per-unit, variable costs. ${ }^{49}$ Manufacturers of tennis rackets stand ready to meet large or small orders at list price. The same would be true, for example, of a grocery store ordering canned goods.

In such situations, when perfect supply elasticity prevails over the relevant range, all of any monopoly overcharge imposed by manufacturers is passed on to consumers. Because the overcharge increases the cost of a variable item, the supply curve (as established above) will in the short run move up from $S^{\prime}$ to $S^{\prime \prime}$ by an amount equal to the overcharge. Because at both the old and the new level $R$ can supply any amount within the relevant range without

47 The redistribution from consumers to producers is measured, in Figure 1(B), as the rectangle bounded by $P r^{\prime}$ on the bottom, $P r^{\prime \prime}$ on the top, the vertical axis on the left, and $Q r^{\prime \prime}$ on the right.

48 Perfect elasticity (or perfect inelasticity) need not apply to the entire length of the supply or demand curves. All that is relevant for the present analysis is the elasticity within the observed range of price and output (for example, the elasticity between $P_{r^{\prime}}$ and $\left.P r^{\prime \prime}\right)$.

49 When the costs of a product are "invoice costs," as is often the case in retailing, the firm can presumably buy all it wants at the same price (at least up to some reasonable limit). In fact, retailers often obtain special discounts for buying large quantities, in which case the supply curve of $R$ would slope downward. 
Figure 2. Comparison of Short-Run, Competitive Results for EXtreme Types of SUPPLy-Demand RELationships.

A. Perfectly Elastic Supply

B. Perfectly Elastic Demand
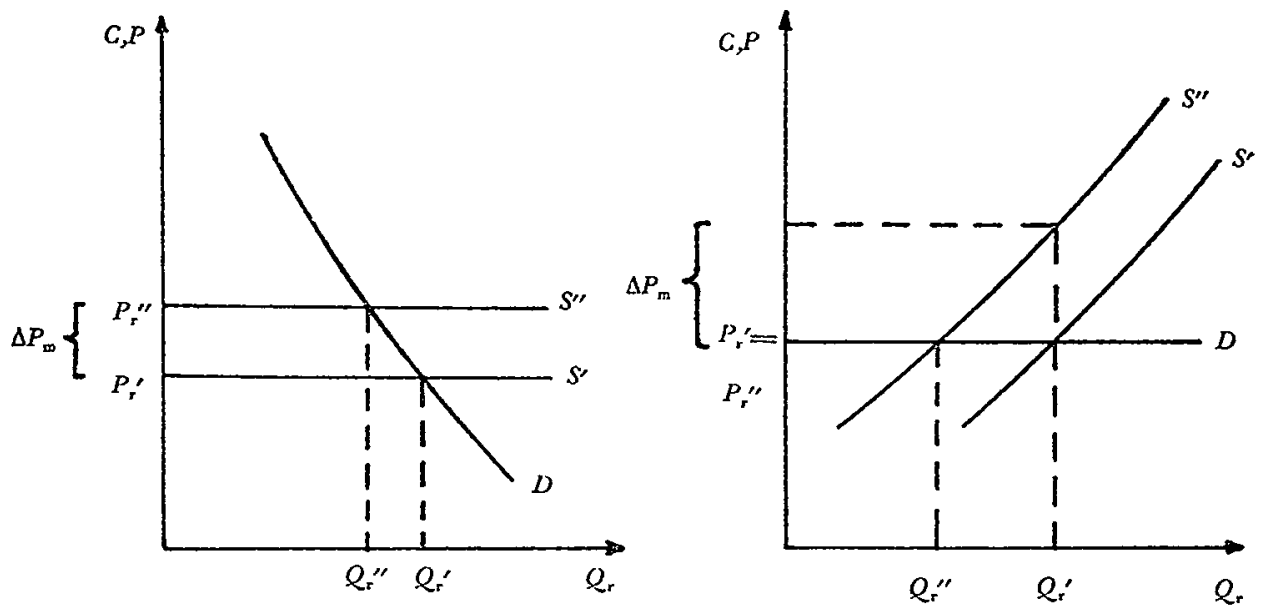

C. Perfectly Inelastic Supply

D. Perfectly Inelastic Demand
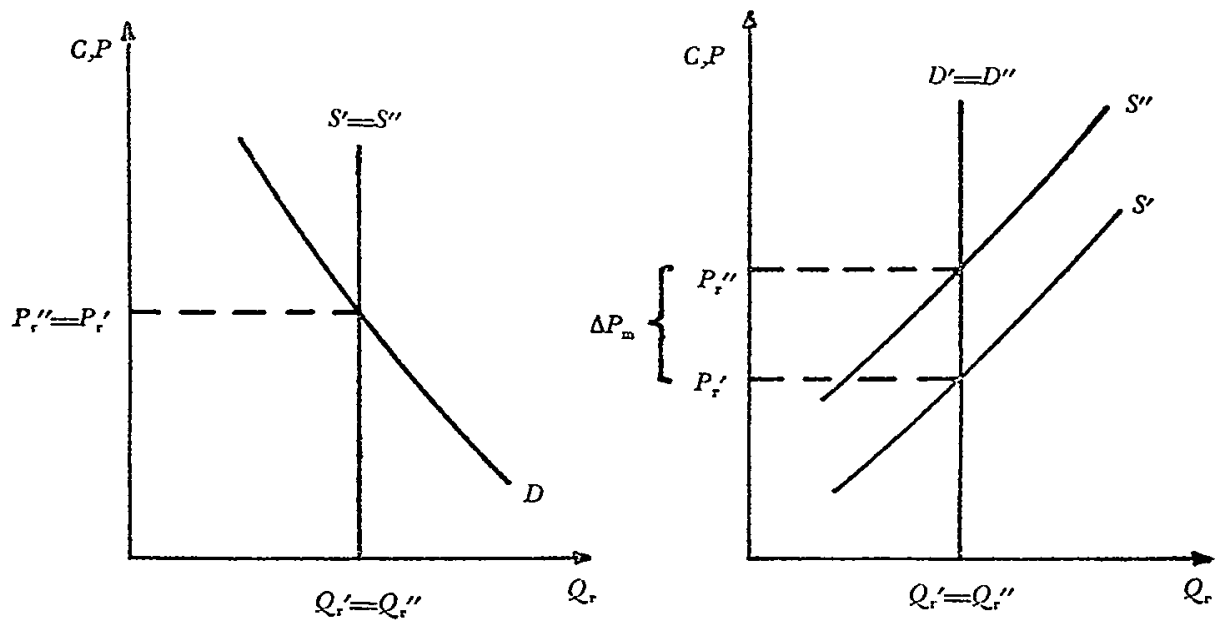
affecting its unit cost (because both $S^{\prime}$ and $S^{\prime \prime}$ are flat, given perfect supply elasticity within the relevant range), the entire overcharge imposed by $M$ is reflected in the price charged by firms at $R$ when they sell to firms or households at $C$. The change in $P_{x}$ is equal to the change in the manufacturer's price, $\Delta P_{\mathrm{m}}$. The overcharge is thus passed on in full.

It is important to notice that this result obtains regardless of the shape (or elasticity) of the demand curve. When the supply curve is flat, the elasticity of demand will affect the extent to which sales are reduced as price goes up, but it will not affect the extent to which an overcharge is passed on. In this limit case, or cases approaching it, supply is the factor crucial to passing on. Demand has no impact on the rate of passing on here and little impact in cases approaching the limit.

In the second limit case, shown in Figure 2(B), demand, rather than supply, is perfectly elastic within the relevant range; hence, the demand curve is flat. If the industry increases its price at all, it will lose all sales. Because the resellers, $R$, cannot raise their price even though $M$ 's overcharge has increased $P_{\mathrm{m}}$, none of $M$ 's price increase will be passed on to $C$. Here, the slope of the supply curve determines the reduction in output, from $Q_{r}^{\prime}$ to $Q_{r}^{\prime \prime}$, but has no impact on the rate of passing on.

This limit case, unlike the last one, is not likely to be encountered in any real market. Individual firms may face a perfectly elastic demand curve; indeed, our analysis assumes that the $R \mathrm{~s}$ do face perfectly elastic demand curves (which, in economic theory, are a necessary condition for perfectly competitive markets). By definition, though, an industry does not face a perfectly elastic demand curve, in that an industry is defined (over product, geography, and time) in terms of intra- and inter-industry cross-elasticities of demand. ${ }^{50}$ In short, a perfectly elastic demand curve for an industry implies that there is a nearly perfect substitute for the product of that industry. A near-perfect substitute, however, means that the cross-elasticity of demand between the two products is very high (that is, a price change in one product will raise sales of the other significantly), so that both products ought to be defined as part of

$50[F]$ irms .... in any sector tend to fall roughly into subgroups ... so that in each subgroup the outputs are relatively close substitutes for each other and relatively distant substitutes for all other outputs. Each subgroup is thus also a group of sellers potentially in more or less direct competition with each other. Any such subgroup may be called an industry.

J. BAIN, Industrial Organization 6 (2d ed. 1968) (emphasis in original). 
the same industry in the first place. We conclude, therefore, that if the industry has been properly defined, the demand curve will be neither perfectly elastic nor nearly so. Hence, the second limit case is merely a theoretical possibility. ${ }^{51}$

In our third limit case, Figure 2(C), the supply curve for the industry is perfectly inelastic. The equilibrium will be unaffected by a monopoly overcharge which increases $P_{m}$. Perfect inelasticity of supply supposes a product so limited in availability that no matter what the price, the same quantity will always reach the market. In such cases, the resellers would bear all of the price increase: the rate of passing on would be zero. Note also that the level of output is unchanged $\left(Q_{\mathrm{r}}{ }^{\prime}=Q_{\mathrm{r}}{ }^{\prime \prime}\right)$. Here, again, relevant realworld examples are infrequent, though nearly perfect inelasticity of supply can be illustrated by the existing stock of paintings of a deceased master.

In our final limit case, Figure $2(D)$, the demand curve facingindustry $R$ is perfectly inelastic. Here, all of the overcharge that increases $P_{\mathrm{m}}$ will be passed on to $C$, regardless of the elasticity of supply. Perfectly inelastic demand implies that within the relevant range of prices, consumers will buy a fixed quantity of the product regardless of any increase or decrease in price. Hence, even if a reseller were to increase its price from $P_{\mathrm{r}}^{\prime}$ to $P_{\mathbf{r}}^{\prime \prime}$, it would sell the same quantity: the equilibrium output remains unchanged $\left(Q_{r}^{\prime}=\right.$ $\left.Q_{r}^{\prime \prime}\right)$. In this situation, if $M$ imposes a monopoly overcharge, shifting $R^{\prime}$ 's supply curve from $S^{\prime}$ to $S^{\prime \prime}$ all of that price increase will be passed on by firms at $R$ to $C$.

51 There are two potential exceptions to this statement. First, suppose that the cartelization among $M$ firms is less than complete, so that not all $R$ firms are paying. the monopoly overcharge. Then, the firms that are paying the overcharge must nevertheless continue to charge a market price determined by those that are not because consumers would not pay a higher price when they could buy the same product at a lower price. There is no reason why the $R$ firms buying from cartel members would not, in these circumstances, seek out and purchase from $M$ firms that are not members of the cartel.

The second possibility arises from different production technologies within the same industry (as defined in terms of output). Suppose that $R$ firms manufacture a product, $Z$, and that some $R$ firms use $X$ as the basic input while others use $Y$ (for instance, the product might be wrapping materials, produced either from aluminum or petrochemicals). In that event, a price-fixing conspiracy among the makers of $X$ would raise the costs of some $R$ firms but not affect the costs of the others. If the $Z$ produced from $Y$ is a very close substitute for $Z$ produced from $X$, the $R(X)$ firms would face a highly elastic demand curve and, in the short run at least, would have to absorb the monopoly overcharge rather than pass it on. If this were the case, though, there would then be a significant drop in the sales of the $R(X)$ firms (who would be operating at a loss), which would in turn mean a drop in sales of the firms producing (and fixing the price of) $X$. Since cartels are likely to occur when elasticity of demand (in our example, for $X$ ) is low, cases such as these are not likely to occur frequently. See note 54 infra \& accompanying text. 
While perfectly inelastic demand curves may be uncommon, highly inelastic demand is not. One can imagine no more poignant example than the Organization of Petroleum Exporting Countries (OPEG) cartel: virtually all of the derivative products of crude petroleum-gasoline, diesel fuel, kerosene (for jet aircraft), and home heating oil have highly inelastic demand. Indeed, it is precisely because demand is so inelastic that OPEC has been able to raise its prices so high with so little effect upon the quantity of petroleum sold.

\section{Probable Monopoly Market Characteristics}

Under the conditions assumed here-that $R$ is on a competitive level with profit-maximizing firms-the rate of passing on in the short run is a function of the relative elasticities of supply and demand. ${ }^{62}$ The higher the elasticity of supply relative to demand, the greater is the percentage of the overcharge which will be passed on by the direct purchaser to indirect purchasers; conversely, the lower the elasticity of supply relative to demand, the lower is the percentage passed on. Given that the models allow for extreme results (varying from no passing on to total passing on) and that the results depend upon elasticities (about which there is seldom precise data), it is sometimes argued that the theoretical analysis demonstrates the difficulty of handling passing-on issues through the judicial process.

This contention-that proving passing on in an actual case is difficult and costly at best-is deficient on three distinct grounds. First, in emphasizing the wide range of results obtained from hypothetically possible supply-demand relationships, the argument ignores the probable relationship between supply and demand in markets in which monopoly overcharges are likely to occur and passing-on problems are likely to be presented. Second, in focusing on short-run analysis, the argument takes no account of the adjustments made by producers and consumers over time. As we show in the next section, long-run analysis changes the picture dramat-

52 The rate of passing on, $R P O$, is defined as

$$
R P O=\frac{e_{S}}{e_{S}+e_{D}},
$$

where $e_{S}$ is the elasticity of supply and $e_{D}$ is the elasticity of demand. Thus, to refer to Figure 2 once again, supply is perfectly elastic in case $2(A)$, so $e=\infty \rightarrow R P O=1.00$ (100\%). Likewise, when demand is perfectly inelastic $S$

(Figure $2(\mathrm{D})$ ), $e_{D}=0$, so whatever the value of $e_{S_{\text {: }}}, R P O=1.00$. 
ically, and in many market situations, even long-run (that is, capitalinvestment or capacity) adjustments can be made quite rapidlycertainly, in markets such as the retail industry, well within the time span over which a monopoly or successful cartel might maintain an overcharge. Third, that elasticities are relevant to the theoretical analysis does not mean that precise measurement of elasticities is the only way that passing on can be identified. In part II we show that there are empirical indicia of passing on, and in part III we demonstrate that these, along with plausible judgments about the general level of elasticities, can be used to develop reasonable presumptions about passing on. First, though, let us remain within the present theoretical universe and examine the probable short-run relationship between supply and demand in situations. in which monopoly overcharges are likely to be encountered.

Remember that we are dealing with at least a three-level chain of distribution: manufacturers, resellers, and consumers. In this situation, the direct purchasers have a derived demand for the output of $M$-that is, $R$ 's demand for $Q_{\mathrm{m}}$ is derived from the demand of the final consumers, $C .{ }^{53}$ Accordingly, the elasticity of demand by $R$ firms for $Q_{\mathrm{m}}$ depends upon the elasticity of demand by $C$ households or firms for $Q_{r}$. When the product sold in the two sequential markets is identical (say, bread sold first by a commercial bakery to a retailer and then by the retailer to households), there is a near identity between the respective elasticities. Even when the product is transformed physically by the intermediary (say, flour sold to a retail baker and bread products sold by the baker to households), there remains a strong functional relationship between the elasticities of direct and derived demand..$^{54}$

Remember also that the initial price increase, $P_{\mathrm{m}}$, is the result of an antitrust violation: it is an exercise of power by a cartel (or a monopolist) to raise $P_{\mathrm{m}}$ above the competitive level. The profit-

53 "Consumers purchase commodities because they derive satisfaction from them. Inputs are purchased for the sake of the contribution they make to production." J. Hendernson \& R. Quandt, Mxcroeconomir Theory 127 (2d ed. 1971). "The producer's input demands are derived from the underlying demand for the commodity which he produces." Id. 69. When the "producer" is merely a reseller, the "input" is identical to the "commodity which he produces."

54 The demand factor which is most important to the relationship between direct and derived demand is the degree of factor substitutability. If there are readily available substitutes for an input, the producer has a very elastic demand for that input even though the final demand for its output is very inelastic. If, for example, a producer can easily substitute plastic fasteners in the production process, its demand for metal fasteners would be high, whatever the elasticity of demand for its finished product. Again, in the case of a reseller, the input is the output, which means a very low rate of substitutability. 
ability of such an anticompetitive practice depends upon the elasticity of demand confronting the would-be violators; the less elastic the demand, the more profitable will be cartelization (or monopolization); the more elastic the demand, the less profitable it will be. This is because the demand elasticity at the current competitive price specifies the rate at which the cartel or monopolist at $M$ will lose sales as prices for the product are raised above competitive levels. Indeed, in the limit case in which the demand for $Q_{m}$ is perfectly elastic, it is theoretically impossible for the firm or firms at $M$ to raise the price above the competitive level because there is one, and only one, price at which manufacturers will be able to sell their product at all.

No antitrust passing-on problem can exist unless a cartel (or monopolist) has succeeded in raising prices above the competitive level-that is, unless there is a monopoly overcharge which may or may not be passed on. Given the relationship between elasticities and the potential for and profitability of cartelization or monopolization, however, the very existence of a supracompetitive price forcefully implies that the elasticity of demand for $Q_{\mathrm{m}}$ is not high. Because that elasticity derives from the elasticity of demand for $Q_{r}$, we know that in all probability the demand curve facingfirm at $R$ is not highly elastic either. In short, the case portrayed in Figure 2(B), or any case approaching this limit, is highly unlikely to occur in any market in which a monopoly overcharge is being imposed. As a practical matter, situations in which direct rather than indirect purchasers bear all or most of the costs of an increase in $P_{\mathrm{m}}$ because of demand-supply relationships like those identified in Figure 2(B) will simply not occur when the cause of the price increase is a monopoly overcharge.

On the other hand, although perfectly inelastic demand curves, as shown in Figure 2(D), do sometimes exist, the point here is more general. Cartelization and monopolization-and, hence, monopoly overcharges-are most likely to be achieved and to persist in intermediate markets characterized by relatively inelastic demand because the potential for supracompetitive profits is greatest in these markets. It is in precisely these markets, however, that the higher prices paid by direct purchasers will, as a rule, be passed on to indirect purchasers, even in the short run.

The other limit case in which, according to the short-run variable-cost analysis, direct purchasers pass on none of the price increase by $M$ is that depicted in Figure 2(C), in which the supply curve is perfectly inelastic. Situations at or near this limit can be 
imagined-for example, Picasso paintings and Ming Dynasty artifacts-but, as a practical matter, supply curves even approaching the vertical seldom occur in the commercial world which concerns us here. ${ }^{55}$ So, again, the extreme case in which indirect purchasers bear little or none of an increase in variable costs through passing on is little more than a theoretical nicety.

Although inelastic supply curves are uncommon, highly elastic supply curves which approach the limit case in Figure 2(A) are very common. All that a highly elastic supply curve implies is that the reseller can increase sales with no significant increase in costs. That will often be true for retailers and wholesalers because they can typically buy larger quantities at the same price (or, with volume discounts, a lower price). Since cases like or approaching that in Figure 2(A) entail a high rate of passing on, even in the short run, it appears that supply elasticities conducive to passing on are also those most likely to be encountered in many real-world markets. When cartelization or monopolization occurs in manufacturing or processing, it will be precisely these resellers-the ones most likely to be able to pass on-who will be the direct purchasers and firstlevel indirect purchasers through whom the monopolized products will pass from the cartel or monopoly to the final consumer.

Let us summarize the short-run results when the reseller operates in a competitive market. If the monopoly overcharge increasing $P_{\mathrm{m}}$ raises the fixed costs of $R$ but does not affect variable costs, the model indicates that the price increase will not be passed on to $C$. When $P_{\mathrm{m}}$ affects variable costs (that is, shifts the supply curve upward), the rate of passing on depends upon the relationship between supply and demand. Given the probable elasticities of supply and demand in markets in which monopoly overcharges are likely to be encountered, the model suggests that, even in the short run, the rate of passing on is likely to be high in most instances.

\section{B. Long-Run Analysis When All Downstream Markets Are Competitive}

The results of the preceding section indicate that in many situations a high degree of passing on is likely to occur even in the short

55 Even "Picassos" are not strictly limited in supply (that is, the supply curve is not perfectly inelastic). As is widely known among art dealers and collectors, rising prices of even deceased artists have the almost certain effect of increasing the supply of his or her work, or, shall we say, of "close substitutes."

There is an important restriction that induces inelasticity of supply. In a case in which there is a scarcity of natural resources (for example, land and fossil fuels) and in which those resources represent a large share of the total cost of production, the supply curve is likely to be less than perfectly elastic. 
run. In other cases, however, direct purchasers may bear all or part of the monopoly overcharge. The analysis above, however, takes no account of the long-run adjustments likely to be made by producers and consumers in response to a monopoly overcharge. This is no small fault, considering that discovering, prosecuting, and remedying antitrust violations is a time-consuming process and that successful cartelization or monopolization often endures over a very long period. ${ }^{56}$ Continuing to assume that $R$ is a competitive market with profit-maximizing firms, we turn, therefore, to an examination of long-run equilibrium.

It is a basic axiom of economic theory that the elasticity of supply or demand is time-dependent. As time passes, firms at all levels and ultimate consumers have greater opportunities to respond to changes in prices, substitutes, technology, or tastes and have greater flexibility in doing so. Over the long run, consumers gain additional information regarding price, quality, and availability of substitutes. Consequently, elasticity of ultimate (and related derived) demand becomes increasingly elastic as the time dimension is extended. In response to an increase in the price of gasoline, for example, consumers might respond initially by buying the same quantity, but consumption would likely be reduced in the long run as consumers switched to smaller and more fuel-efficient automobiles. In that case, demand for gasoline is highly inelastic in the short run but more elastic in the long run.

Similarly, supply elasticity is highly time-dependent. Just as the short-run marginal-cost curve in a competitive market represents the short-run supply curve, so the long-run marginal-cost curve in such a market represents the long-run supply curve. In the long run, however, all production costs are variable: the producer can adjust capacity, production techniques, and marketing strategy in response to changing market conditions. For this reason, supply will, in the long run, be highly elastic, while the supply curve will be flat, or nearly so. ${ }^{57}$ This is not a matter of idle speculation or

56 An empirical analysis of 49 price-fixing cases brought and won by the Antitrust Division in the period from 1971 to 1976 found the average duration of those conspiracies to be 5.5 years. By any reasonable standard, five-and-a-half years is the long run, in terms of the appropriate economic model. M. Block, H. Demmert \& F. Nold, An Empirical Investigation of the Determinants and Impact of Class Action Activity: A Proposal (1979) (Center for Econometric Studies of the Justice System, Hoover Institution, Stanford University).

57 But see J. Henderson \& R. Quandr, supra note 53, at 118 ("Long run supply curves are not always horizontal. The supply curve will be upward sloping if firms do not have identical cost functions and there are no offsetting external economies."). If an industry does not face constant costs, the factor of increasing costs can be readily added to the inquiry. See part IV $(A)(4)$ infra. 
abstract theorizing; virtually every empirical study of industry cost functions has found that, in most industries, marginal and average costs are equal and identical over the relevant range of output in the long run. ${ }^{58}$

In Figure 3 we have illustrated the long-run adjustments by $R$ in response to a monopoly overcharge imposed by $M$. Figure 3(A) indicates both the short- and long-run supply curves of firms at level $R$. (We have shown an upward-sloped short-run supply curve; if the short-run supply curve were flat, $100 \%$ of $\Delta P_{\mathrm{m}}$ would be passed on, so we would not need to examine the long-run results.) Note that $\Delta P_{\mathrm{m}}$, the overcharge imposed by $M$, shifts both the short- and long-run supply curves, but that, in the short run, the equilibrium price and output are determined by the intersection of $S^{\prime \prime}$ and $D$. The rate of passing on is, in the short run, less than $100 \%$ because $\Delta P_{\mathrm{r}}$ is less than $\Delta P_{\mathrm{m}}$. That result will not continue over the long run, however. In the short run, the $R$ firms find that at $Q_{r}{ }^{\prime \prime}, P_{\mathrm{r}}^{\prime \prime}$ is less than the long-run average cost, so they are operating at a loss. In order to stop the resulting losses, the $R$ firms will make adjustments that will bring costs into line with the market-clearing price. These adjustments may include reduction in inventory or in investment level, and hence in capacity. Exit from the industry may even be necessary if no lesser adjustment will stanch the flow of losses.

The long-run equilibrium result is shown in Figure 3(B). ${ }^{50}$ In accordance with our comments regarding the time elasticity of demand, the demand curve has been shown to be more elastic in the long-run illustration. Nevertheless, when the long-run supply curve is flat, ${ }^{60}$ the elasticity of demand is irrelevant to the rate of passing

58 The classic study of industry-cost relationships is J. BAIN, BARRIEns To NEw COMPETITION (1956). It is important to distinguish between firm and industry costs. Many observers have speculated (though little empirical substantiation has been presented) that, because of "managerial diseconomies of scale," the long-run cost curve of an individual firm may increase at some point. Our analysis depends upon the cost curve of an entire industry, to which, presumably, managerial diseconomies do not apply.

59 By showing the change in the long-run marginal-cost curve from $L R M C^{\prime}$ to $L R M C^{\prime \prime}$ as exactly equal to the monopoly overcharge, $\Delta P m$, we have implicitly assumed away the possibility of factor substitution by $R$. It is conceivable that, by modifying the production process to use less $Q m$ to produce a given quantity of $Q r$, the change in $L R M C$ would be less than $\triangle P m$. The possibility of significant factor substitution by $R$ implies an elastic demand curve between $R$ and $M$, in which case monopolistic pricing is highly improbable. Hence, it is reasonable to assume that factor substitution is relatively low in passing-on cases.

60 When the long-run supply curve is only nearly flat, the elasticity of demand is relevant to determining the rate of passing on. See part IV(A)(5) infra. 
on, which will, in any event, be complete. ${ }^{61}$ Note also that the reduction in output in the long run is greater than in the short run because of the higher elasticity of both supply and demand in the long run. Thus, in the long run both the allocative effects (reduced output) and the distributive effects (excessive prices) are more onerous for final consumers.

Notice that in both the short- and long-run analysis, supply elasticity tends to be of great importance. Indeed, in the long run it is of dominating importance. This rather striking implication of standard economic theory as applied to passing on has been commonly overlooked by analysts who have insisted that both supply and demand factors must be considered, ${ }^{61 a}$ and who seem to have supposed that both could vary through the complete range from perfect elasticity to perfect inelasticity, yielding innumerable permutations affecting the passing-on rate. What our emphasis on the supply side shows is that, in most cases, demand factors are relatively unimportant. Given what is known about the nature of cost functions in most industries, we can state categorically that, as a general rule, all monopoly overcharges to direct purchasers who simply resell the manufactured product will in the long run be passed on to the indirect purchasers who consume the product. Inasmuch as anticompetitive practices of short duration are seldom discovered, much less prosecuted, this generalization can be taken to cover all or most cases in which overcharge litigation occurs. For purposes of antitrust enforcement, it is the longer run that matters most, and the longer the run, the more likely that the rate of passing on will be $100 \%$.

61 The long-run equilibrium price and output are shown as $P r^{\prime \prime}$ and $Q r^{\prime \prime}$. Because $\operatorname{Pr}^{\prime \prime}-\operatorname{Pr}^{\prime}=\Delta P m$, the rate of passing on is $100 \%$. Note that this result applies whether the price increase from $M$ affects fixed or variable costs. In either case, the long-run marginal-cost curve will shift up by an amount exactly equal to the change in $P_{m}$. Put simply, there are no fixed costs in the long run; if all costs are variable and constant per unit of output, the effect of $\Delta P m$ will be the same whether the product is a capital asset or an input that is consumed during the production of one unit of output.

61a Editors' note: The lettered footnotes contain some of the material added by the authors to take account of an economic analysis of the rule of Illinois Brick, Landes \& Posner, Should Indirect Purchasers Have Standing to Sue Under the Antitrust Laws? An Economic Analysis of the Rule of Illinois Brick, 46 U. CrI. L. REv. 602 (1979), published just before this Atticle went to press.

In Landes \& Posner, supra, it is argued that empirical analysis of passing on is always difficult because estimates of elasticities of both supply and demand are always required. In fact, when either elasticity takes an extreme value, knowledge of the other elasticity is not required, as shown in our discussion in part $I(A)(3)$ supra. Landes and Posner compound this error by presenting only a short-run analysis. Because in the long run supply is likely to be perfectly elastic (and when it is not, it will be readily apparent), an estimate of elasticity of demand will rarely be required for a long-run analysis. 


\section{Short- and Long-Run Analysis When All Downstream Markets Are Not Competitive}

Up to this point, we have assumed in both the short-run and long-run analyses that competition prevails among the resellers, signifying that profit maximization by a firm at the $R$ level induces marginal-cost pricing. If, instead, the reseller possesses some degree of market power, its marginal-revenue curve will lie below the demand curve, ${ }^{62}$ in which case the profit-maximizing price will exceed marginal cost. In short, if the reseller has market power, the supply curve is not equivalent to the short-run marginal-cost curve, and the analysis must be modified.

Figure 4 shows the short-run and long-run equilibria when $R$ is a single-firm monopoly. ${ }^{63}$ The monopolist maximizes profit by choosing the output level at which marginal cost is equal to marginal revenue and then charging "what the market will bear" for that level of output. Price is thus set at the level determined by the intersection of the quantity line and the demand curve. The more inelastic the demand, the greater is the divergence of price from marginal cost.

In Figure $4(\mathrm{~A})$, the original equilibrium price and output are $P_{\mathrm{r}}{ }^{\prime}$ and $Q_{\mathrm{r}}{ }^{\prime}$. Assuming a shift in the reseller's short-run marginalcost curve, from $S R M C^{\prime}$ to $S R M C^{\prime \prime}$, due to an overcharge by $M$ affecting the variable costs, the reseller reduces output to $Q_{r}{ }^{\prime \prime}$ and raises price to $P_{\mathrm{r}}^{\prime \prime}$ in the short run. The rate of passing on is considerably less than $100 \%$ because $P_{r}^{\prime \prime}$ minus $P_{r}^{\prime}$ is much less than $\Delta P_{\mathrm{m}}$.

In the long run, when the marginal-cost curve is perfectly elastic (Figure 4(B)), or nearly so, the monopolist, $R$, passes on a larger share of the price increase, but still less than $100 \%{ }^{64}$ The irony of monopoly power at two levels is that whereas the competitive reseller is forced by market pressures to pass on all or most of

$62 \mathrm{~A}$ demand curve is equivalent to an average-revenue curve: for a given level of output, the average revenue is equal to the total revenue from the sale of that output, divided by the units of output. The marginal-revenue curve represents the additional revenues that would be received by selling one more unit of output. If, and only if, the average-revenue curve is flat (demand is perfectly elastic), marginal revenue is equal to average revenue. If the demand curve is downward sloping, the marginal-revenue curve will lie below it.

63 The results shown in Figure 4 are generalizable to cases in which there is more than one firm, but each possesses some degree of market power. The critical assumption is that each individual firm in the industry $R$ faces a demand curve that is not perfectly elastic, as it is in the competitive case.

64 The long-run equilibrium positions for the monopolist are shown in Figure $4(B)$ as $P r^{\circ}$ and $Q r^{\circ}$. Because $P r^{*}-P r^{\prime}<\Delta P m$, the rate of passing on is less than 100\%. 
Figure 4. Comparison of SHORT-Run and Long-Run Equilibria, MoNopoly CASE.

A. Short-Run Results

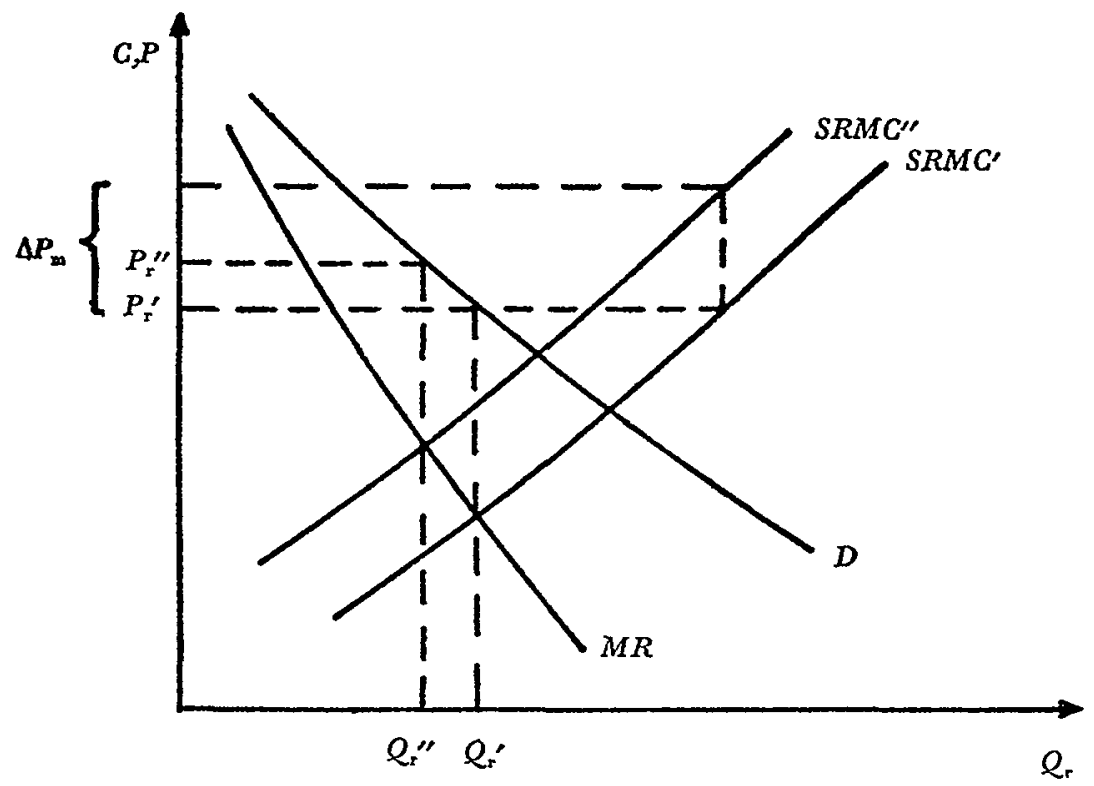

B. Long-Run Results

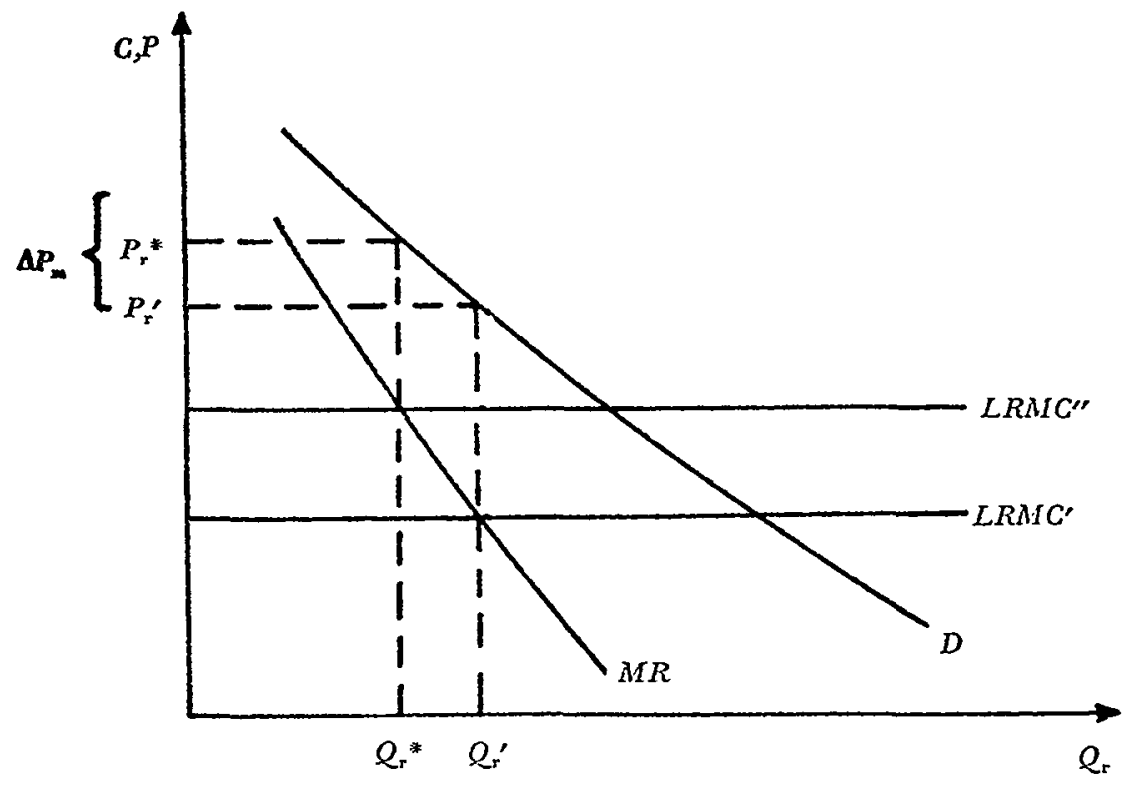


the price increase, the profit-maximizing monopolist-reseller may rationally absorb a part of the overcharge first imposed by the cartel or monopolist at a higher level.

Although in particular cases one can judge these matters on the basis of industry structure, it is difficult to generalize about the probable existence of market power held by a direct purchaser in potential passing-on situations. In many production-distribution chains, as we have noted earlier, resellers will be wholesalers or retailers who are unlikely to wield very much market power. Resellers in more complex chains, however, may include manufacturers, processors, and others who may cartelize, or may already have cartelized, to obtain market power.

Nevertheless, there is reason to believe that, other things being equal, the greater the market power of direct purchasers at level $R$, the more difficult it will be for firms at level $M$ to impose a monopoly overcharge in the first instance. Power at level $R$ which could be used when selling to level $C$ would in most cases imply countervailing power which could be used defensively against $M$ 's effort to impose an overcharge. Hence, price fixing and other anticompetitive practices by sellers high on the chain may be less likely when resellers lower on the chain themselves have sufficient power to impose an overcharge. Indeed, one must conclude that, at the very least, the amount of the overcharge imposed high on the chain in such situations will be smaller than it would have been if no countervailing power were encountered. This would also be the result of a "bargain" between firms with power at each level concerning sharing of the proceeds of the total, profit-maximizing overcharge imposed on consumers. In some cases, of course, market power at the intermediate level reflects vertical restraints imposed at the prior level. ${ }^{65}$ In those cases, we would also expect some degree of joint profit-maximizing by the two levels of the distribution chain.

Although the possibility that power at the resale level may in particular cases reduce the rate of passing on achieved at that level, on the whole those business entities most likely to stand between consumers and cartelists (or monopolists)-that is, retail stores, wholesalers, contractors, and service firms-tend to be highly competitive (if unaided by vertical restraints or collusive practices which themselves violate antitrust laws). So, although monopoly may result from incomplete passing on in some cases, these cases can be

65 These restraints may not by themselves violate the antitrust laws; consider, for example, exclusive wholesaling territories imposed by manufacturers. See Continental T.V., Inc. v. GTE Sylvania Inc., 433 U.S. 36 (1977). 
expected to be a distinct minority and to display structural features differentiating them from the more typical case.

\section{Analysis of Passing Back}

There remains one last exercise in our theoretical review: an analysis of the effects of a damage award to a direct purchaser upon the price charged to indirect purchasers. This analysis is relevant to the issue of compensatory justice in antitrust policy: to the extent that an overcharge is passed on to indirect purchasers, these purchasers should justly receive a corresponding share of overcharge damages collected from the violator. If one were to conclude, however, that an award of overcharge damages to the direct purchaser would be "passed back" down the distribution chain, in much the same pattern as the overcharge has been passed on, then this goal of compensatory justice could be met by assigning the entire cause of action to the first purchaser. Unfortunately, analysis persuades that this will not occur. If indirect purchasers are to be compensated, other mechanisms must in most instances be found.

Again, we draw upon tax-incidence theory for the analysis. Interestingly enough, the award of damages by a court is exactly analogous to a "lump-sum tax," which is a tax that is not related to any specific measure of economic performance. ${ }^{66}$ The lump-sum tax has the advantage-unique among all known forms of taxationof not inducing any allocative inefficiency because it does not affect price or levels of output. The burden of a lump-sum tax, then, is directly upon the payer of the tax: there is no mechanism for shifting the tax to someone else. The result is similar with a "lump-sum damage award": subject to one minor qualification, it is virtually certain that no part of the award will find its way to the indirect purchasers who bore part or all of the offensive price increase. ${ }^{67}$

66 The most commonly cited example of a lump-sum tax is the "head tax" a tax levied on each individual regardless of income or wealth. Lump-sum taxes "are of considerable analytical interest since they do not give rise to an 'excess burden,' but they are not of major quantitative importance. Nor should they be since they are not acceptable on equity grounds." R. MUSGRAve and P. MUSGRAve, supra note 33 , at 211 .

67 "Passing back" is zero because the damage award has no effect whatsoever upon marginal costs, either in the short or long run. As a consequence, the profitmaximizing price for the firm, whether competitive or monopolistic, is unchanged by the award. If the direct purchaser passed on a significant share of the price increase, the damage award is a "windfall profit." (The minor qualification refers to publicly regulated utilities or similar enterprises, which might be required by. administrative action to pass "windfall gains" back to their customers.)

This argument is critical to an understanding of the compensatory injustice of Illinois Brick, and has been misapprehended by other commentators. See, e.g., Landes \& Posner, supra note 6la. Landes and Posner, for example, claim that 
Regardless of the rate of passing on, the rate of passing back will be zero.

The theoretical analysis is now complete. Its most salient results bear directly on the policy issues faced by the Supreme Court and Congress in dealing with passing on. The analysis demonstrates that in markets likely to be characterized by monopoly overcharges, direct purchasers who are not final consumers seldom bear any significant part of the costs of antitrust-law violations. Direct purchasers may be "closer" to the violation in some superficial sense, but markets are highly interdependent. Furthermore, part II will show that when we relax some of the restrictive assumptions required for the preceding analytical models and thus account for actual commercial pricing practices, these implications about the frequency of passing on are strengthened rather than weakened. To that matter we now turn.

\section{Commercial Pricing Practice and Passing On}

When one is aggregating across a sufficiently large number of firms, marginal analysis of the kind employed in part $\mathrm{I}$ can be a useful tool for understanding business pricing behavior. It need not be literally true that each and every firm instantaneously adjusts price to marginal costs. If the "law of large numbers" is applicable and pertinent models are carefully selected, the profit-maximizing, marginal-cost-pricing assumptions of neoclassical theory can simplify analysis and reduce the amount of information required about the behavior of individual enterprises while still providing useful insights about the likely experience of most individual firms. Thus, theory like that discussed in part $I$ is indicative of the general scope of the passing-on problem and could provide the basis for making rebuttable presumptions about the extent of passing on in particular cases.

\footnotetext{
"indirect purchasers are compensated for relinquishing their legal claims [under the Illinois Brick rule] by being charged lower prices [by direct purchasers]." Id. 606 . Unfortunately, Landes and Posner have confused marginal costs and fixed costs. Profit-maximizing price is determined by marginal cost; because neither a damage award nor the expected value of an anticipated damage award has any effect on marginal cost, the price charged by the direct purchaser will be unaffected by the assignment to that purchaser of the cause of action for the overcharge. Consider a simple example: Company $\mathrm{X}$ receives (or anticipates) a check in the mail from an unknown benefactor. There is no reason to suppose that as a consequence of that windfall Company $X$ will lower the price of its products. Courts could, of course, order direct purchasers to lower prices over a period to redistribute recoveries resulting from the Illinois Brick rule, but that would simply be an awkward, cy pres method of obtaining the goal of compensatory justice-a goal more easily and precisely obtained by reversing Illinois Brick.
} 
Yet, there are discrepancies between actual commercial pricing practices and the strict assumptions of the marginal models. An analysis better rooted in commercial practice against which to check theoretical generalizations is therefore needed. Moreover, a method of investigation in particular cases is still important, if only to show how parties could challenge presumptions based on theory. Something more explicit than an abstract model is thus desirable in order to determine the behavior of particular firms in specific market situations.

In section $A$ of this part we review the deficiencies of the behavioral assumptions of the marginal-cost-pricing model and consider the extent to which these may weaken the inferences we have drawn from the theoretical analysis. There is an extensive empirical literature-mainly surveys of managers-which collectively shows that businesses seldom attempt actually to practice marginalcost pricing. We will attempt to explain why that is so and to gauge its significance for the use of marginal analysis in the passingon issue.

We then examine in section B the most common commercial pricing methods, markup and cost-plus pricing. Both of these are based upon costs, but we also go on to survey how managers may vary their pricing responses to take demand factors into account.

\section{A. Differences Between Commercial Reality and Neoclassical Assumptions About Pricing Practice}

Virtually every study of actual pricing behavior of businesses shows that managers do not typically follow the dictates of marginalcost pricing: ${ }^{68}$ This should come as no surprise: despite the formal elegance of price theory in microeconomics, those models provide few, if any, operational rules to guide actual pricing decisions. Although the models may tell us something about aggregate business behavior, they neither provide nor utilize norms or standards which are discernible to, and useable by, individual decisionmakers setting prices in a real market. In a commercial sense, the models

68 The seminal work challenging the descriptive validity of marginal-cost pricing is that of Hall \& Hitch, Price Theory and Business Behaviour, 2 Oxrond Econ. Papers 12 (1939). The Hall and Hitch study was based on interviews with 38 British businesses; the authors concluded that businessmen arrive at their prices as the sum of "full costs" plus some allowance for profit-in other words, cost-plus pricing. Further, confirming empirical studies were reported by J. DEAN, MANagerial Economics (1951); A. Oxenfeldi, Industrial Pricing and Market Practices (1951); and C. Saxton, The Economics of Pruce Determination (1942). For a survey of the literature on this issue, see J. BLAm, Economic Concentration 467-97 (1972). 
are extremely limited. Among the most important limitations of marginal-cost pricing are the following:

1. Marginal analysis assumes that individual firms are profitmaximizing (or, more generally, that the current discounted value of the firm is maximized) ${ }^{69}$ As to many decisions-for example, product design-there is no discernible explicit profit test, especially for firms with market power. For instance, there is simply no way to tell whether General Motors made more, or less, money by adding tail fins to its cars in the 1960s. Pricing decisions, however, are most intimately related to profits and, presumably, are rather rapidly and precisely tested by the market. Nevertheless, there is some doubt about whether pricing decisions are made, or at least always made, to maximize profits. Herbert Simon has argued that human cognitive limits may preclude serious efforts directed at maximizing profits. $^{70}$

Because of these limits, managers may develop a general norm about the lowest acceptable profit rate; as long as the firm is exceeding this rate, adjustments are not indicated. ${ }^{11}$ Furthermore, due to the separation of ownership from managerial control in large corporations, managers may behave to satisfy or maximize their own preferences rather than the interests of shareholders. If, for example, managers attach high status to large sales revenues, they might price below the profit-maximizing price in order to expand sales. Similarly, managers no doubt make some decisions (especially when market pressures are weak) with a view to minimizing potential criticism rather than to maximizing profits. ${ }^{72}$

60 Maximizing the value of the firm is equivalent to maximizing the present discounted value of the lifetime profits of the firm.

70 This reflects the concept of "Bounded rationality" introduced by Simon. "The capacity of the human mind for formulating and solving complex problems is very small compared with the size of problems whose solution is required for objectively rational behavior in the real world." H. Smon, Modexs of MAN 198 (1957) (italics in original). The implication is that, even if managers want to maximize profits, their limited capacity for rationality may prevent them from doing so.

71 Whereas profit maximizing means seeking, finding, and obtaining the highest possible level of profit, "satisficing," as this alternative policy is called, implies that so long as profit exceeds some specified threshhold level (a "target rate of return on investment"), managers will maintain their present course and policies. Only if profit falls below the threshhold (fails to "satisfice") will managers initiate remedial action. For an excellent review of choice behavioral models, see March, Bounded Rationality, Ambiguity, and the Engineering of Choice, 9 BELL J. Econ. 587 (1978).

72 Economists have long speculated and debated the appropriate "objective function" of the firm (what it is that managers attempt to achieve). Possibilities include size of the firm (employment), sales revenues, managerial status, minimum managerial risk, and, of course, profits. The chief advantage of selecting profits 
2. Marginal-cost pricing normally requires for its implementation an enormous quantity of high quality information. Not only must the firm have sophisticated cost data in order to link prices precisely to marginal costs, but it must also estimate the precise elasticity of demand (which is likely to change almost continuously) for each of its products. Only very large companies with extensive market-research capabilities could even consider developing information systems approaching this level of sophistication.

3. Economic models typically exclude critical non-price variables in the marketing mix, such as spending on sales promotion or advertising and building customer goodwill.

4. Marginal analyses seldom include the cost of price information or the effects of this cost upon pricing decisions. Simply providing price information (for example, publishing catalogues and price lists) may be costly. Also, customers may value price stability (that is, less frequent, if larger, price increases), and this phenomenon might cause managers to raise prices periodically rather than immediately in response to increases in costs.

5. One purpose of pricing is to cover the costs of the firm, but there are other, strategic, purposes served by pricing, most of which are excluded from marginal analysis. The more important of these include market pentration (introducing a product line into a new market area), increasing market share, and establishing brand-name identification or customer loyality. ${ }^{73}$ Thus, for strategic reasons, firms may not price at the profit-maximizing level, at least in the short run.

6. Marginal models neglect interdependence in production costs or demand among products of a multiproduct firm, yet most firms must constantly deal with these realities. On the demand side, multiproduct firms may deliberately price below marginal cost on some products as a strategy to increase sales of other products. For example, bread or milk may be used as "loss leaders" in a supermarket in order to increase the flow of customers to the store

as the firm objective is that it enables economists to derive deterministic results with analytical models.

73 Pricing, as taught in marketing-management courses by business schools, is one of four key ingredients in the "marketing mix," which also includes product design, communication (advertising, sales promotion), and distribution. Three widely cited texts in pricing, which present normative standards for commercial pricing policies, are R. Lynn, Pricing Poltcies and Marketing Manageanent (1967); Prucing Strategy (B. Taylor \& G. Wills eds. 1969); and I. Vernon \& C. Lamb, The Pricing Function (1976). 
and, consequently, the sales revenues from other products. Even more important is the interdependence among products on the supply side. A large share of the total costs of a multiproduct firm is not directly attributable to the production or sale of a specific product. Examples of such "joint costs" include salaries paid to top management, capital equipment used to produce more than one product (a cash register in a retail store), and capital investment in physical plant (the parking lot of a grocery store). By definition, it is impossible to relate these costs accurately to a specific product line, much less to a particular unit of the product line.

When joint costs exist-and they almost always do in a multiproduct firm-any cost-accounting assignment of a portion of the joint cost to a particular product is arbitrary. Moreover, the joint cost will not vary in a direct way with marginal increases or decreases in the production of any one product considered alone. Hence, when joint costs are encountered, marginal costs-the minute costs associated with the minute changes in the output of the product in question-are always less than average costs. ${ }^{74}$ Thus, if marginalcost pricing were literally and successfully practiced for products with joint costs, that pricing method would produce revenues below total costs and the firm would fail to earn a normal profit. Because hundreds of thousands of multiproduct firms (mainly retail stores and service establishments) do in fact earn normal profits, we know that their prices are not equal to marginal costs.

\section{B. Markup Pricing and Cost-Plus Pricing}

The numerous deficiencies of marginal-cost pricing and the power of commercial traditions and customs have their effects: very few enterprises actually attempt to practice it. The vast empirical literature on pricing practices ${ }^{75}$ establishes that most businesses ${ }^{76}$

74 Average costs, by economic definition, include a normal return on capital investment (alternatively stated, the cost of capital is part of average cost). Thus, by economic standards, if total revenues are exactly equal to total expenditures, the firm is earning a normal rate of profit. By accounting definitions (the kind used by most enterprises), capital costs are not included in total costs, so profits are defined as the difference between total revenues and total costs.

75 The best source of information regarding pricing practices within industries is trade journals, which contain surprisingly frank descriptions of these practices. That literature is, to put it mildly, voluminous. For exemplary review articles on commercial pricing policies, see Christopherson, Product Pricing in the Chemical Industry, Financial Analysts J., Nov.-Dec., 1977, at 54; Hampel, Pricing Policies and Profitability, Management Accounting, July, 1977, at 53; Knobloch, Pricing for Profit, Sales \& Marketing Managendent, Sept. 19, 1977, at 72; Monroe \& Della Bitta, Models for Pricing Decisions, 15 J. Marketing Research 413 (1978).

$78 \mathrm{We}$ are speaking in relative terms. There are, according to the Department of Commerce, more than ten million proprietorships, one million partnerships, and 
employ some variation of one of two basic methods: markup pricing or cost-plus pricing. In a survey of pricing practices, Alpert concludes that "markup pricing is probably the single most widely used approach in the setting of prices by wholesalers. Manufacturers, on the other hand, are more likely to use a closely related method of cost-plus pricing." 77 Most retail establishments use markup pricing, while most contractors use the cost-plus approach. ${ }^{78}$

In order to describe these pricing practices, it is necessary to distinguish between direct and indirect costs. A direct cost (loosely analogous to the variable cost dealt with in the theoretical literature) is one that can be related to the production of a specific product or group of products. In a manufacturing context, direct costs include product-specific production labor, raw materials, maintenance and depreciation costs of product-specific capital equipment, and product-specific selling expenses (such as sales commissions). Indirect costs in manufacturing include administrative overhead (including clerical, shipping, and other non-product-specific labor costs), managerial salaries, general selling expenses, and capital costs. In retailing or wholesaling, direct costs are invoice costs (for instance, the price paid for an item to the supplier); almost all other expenses, not being specific to any one product or group, are treated as indirect costs. ${ }^{79}$

Markup pricing is based upon the facts that, for wholesalers and retailers, the direct cost of a product is its invoice cost ${ }^{80}$ and few additional expenses can be directly attributed to any specific product category. The resale price is determined by a more or less standard markup over the invoice cost, which markup is intended to cover a reasonable portion of the indirect costs of the firm and also to yield a reasonable profit. The size of the markup for particular products or groups of products tends to be standardized in an industry or region and to become a matter of custom widely known to those in the trade. To illustrate, if an item costs $\$ 10$ per unit, and the

nearly two million corporations in the United States. U.S. DEP'T OF CoMnerce, Statistical Abstract of the United States 507 (1976). Many businesses, of course-if only a small percentage of the total-use other kinds of pricing methods.

77 M. Alpent, Pricing Dectsions 25 (1971).

78 For an excellent review of retail-pricing theory and empirical evidence regarding markup rates used by retail food stores, see L. Preston, Profts, Competition and Rules of Thumb in Retanl Food Prucing (1963).

79 The specification of direct costs depends entirely upon the sophistication of the information and accounting system utilized by the firm. The more data are kept, the more costs there are which can be assigned as direct costs. Hence, there is no single definition of direct costs.

80 Invoice cost is the unit cost paid by the retailer or wholesaler to its supplier. See L. Preston, supra note 78, at 5. 
standard markup in that product class is $50 \%$, the price would be set at $\$ 15$. The markup rate may vary within an industry from one product or group of products to another and may be varied by a particular firm to reflect current market conditions, inventory levels, profits, and a number of "subjective" factors decided by the price setter of the firm. Typically, though, markup rates closely adhere to a discernible standard and do not vary in the short run. ${ }^{81}$

In an important variant of the markup-pricing system, practiced widely at the retail level, ${ }^{82}$ the manufacturer (or, less frequently, the wholesaler) sets both the invoice cost and the resale price, thereby effectively determining the markup rate. ${ }^{83}$ For example, a clothing manufacturer might offer sweaters intended to retail for $\$ 40$ at an invoice price of $\$ 20.75$. If the retailer accepts the suggested retail price, it realizes a markup of $93 \%$. In order for suggested retail prices to gain wide acceptance, there must be a rough congruence between the markup rate implied by the respective invoice and retail prices and the markup rate common in that line of commerce.

It is important to note that characteristic of markup pricing which distinguishes it from cost-plus pricing: the firm makes no attempt to allocate indirect costs to each product line. Rather, it is assumed that at the appropriate mix of capacity (selling space), sales personnel, inventory, and advertising, the effective markup rates will produce revenues adequate to cover direct and indirect costs, including a reasonable profit.

By contrast, a cost-plus pricing system, such as that used by most manufacturers and contractors, involves a deliberate costallocation process. First, accounting information is used to allocate to each product or group all of the costs that can be associated with the production of one unit of that product; these are direct costs. Then, a share of all indirect costs incurred by the firm is also allocated to each product or group. Indirect costs may be apportioned equally among all product lines or in the same ratio in which any number of direct costs occur. For example, depreciation of a building may be allocated in a manner proportional to hours of direct labor.

81 Only as it becomes evident that current markup rates are inadequate (costs exceed revenues) or excessive (prices so high that business is lost) is it likely they will be modified. Such information takes considerable time to develop.

82 Weltzien, Infuence on Retail Prices, in Pricing Practices and Strategres 24 (E. Bailey ed. 1978). Weltzien contends that, due to the rise of discount retail stores and increased private labelling (that is, store brands), the influence of manufacturers and wholesalers on retail prices is waning.

83 Given the law regarding resale-price maintenance, manufacturers must be cautious in "suggesting" resale prices. It is nonetheless a common practice in many retail trades. See id. 24 . 
A hypothetical example will serve to illustrate the method more fully. A firm produces two products, $A$ and $B$. The direct costs of $A$ are $\$ 8$ per unit, those of $B, \$ 20$. The firm produces 200 units of $A$ and 100 units of $B$. Total indirect costs for the year (including a targeted profit) are $\$ 1,500$. If allocated at a fixed amount per unit of output, each unit would be assigned $\$ 5$ in indirect costs. Accordingly, the price of $A$ would be set at $\$ 13$ (\$8 in direct costs plus $\$ 5$ in indirect costs), while $B$ would be priced at $\$ 25$ ( $\$ 20$ plus $\$ 5) .84$ Alternatively, the firm might apportion indirect costs as a percentage of direct costs, in which case the price for $A$ would be set at $\$ 11.36$, and that for $B$ at $\$ 28.40 .85$ There are a number of other methods for measuring and assigning direct and indirect costs -actual practices vary widely from industry to industry and, on occasion, from firm to firm. Practices tend to be similar within industries, though: trade custom is a determinent of actual commercial practice. ${ }^{86}$

Let us now consider the effects of these alternative pricing techniques-markup and cost-plus-on the rate of passing on. We revert to the scheme and terminology of part $I$, in which a cartel (or monopolist) at the manufacturing level, $M$, sells to firms at level $R$, which resell to final consumer, firms or households at level $C$. We assume, for simplicity, that a price increase by $M$ does not affect the target rate of return for the firms at $R .{ }^{87}$ We also assume, initially, that $\mathbf{R}$ firms use a cost-based pricing system and that demand factors influence markup rates and the apportionment of indirect costs only over the long run. ${ }^{88}$

84 If apportioned per unit, total indirect cost is divided by total units to determine indirect cost per unit; in our example, $\$ 1500$ divided by 300 units (200 of $A, 100$ of $B$ ) equals $\$ 5$ per unit.

85 If apportioned as a percentage of direct costs, total indirect cost is divided by total direct cost to determine the percentage; in the example given, $\$ 1500 \div$ $\$ 3600=42 \%$, so total cost for $A$ is $\$ 8+.42 \times 8=\$ 11.36$, for $B$, total cost is $\$ 20+.42 \times 20=\$ 28.40$. Note that total revenue is $\$ 5100$ (200 $\times \$ 11.36$ for $A$, plus $100 \times \$ 28.40$ for $B$ ), which just covers total cost.

86 See, e.g., the authorities cited in notes $73,75, \& 77$ supra.

87 This assumption is realistic if $R$ is a competitive level. If it is not, adjustments like those suggested theoretically in part $I(C)$ might be worked out by reductions in the target rate of $R$ firms.

88 We are assuming that $R$ does not change its purchases from $M$ as a result of the price increase. That would be true if there were no lower-cost substitutes for $Q m$, or if $R$ 's production process was constrained by fixed factor proportions (that is, $X$ units of $Q m$ are required for every $Y$ units of output, $Q r$ ). To the extent that substitutes are available, the power of the cartel or monopoly at $M$ will be reduced, and the total amount of the overcharge will, over time, be reduced. Unless factor substitutions involved slips between variable and fixed costs (an unlikely consequence in most realistic situations), such substitutions by $R$ firms would not affect the rate at which the (now smaller) overcharge was passed on. 
Suppose first that the product manufactured by $M$ and sold to $R$ constitutes an indirect cost to $R .^{89}$ (Office supplies used in clerical functions would be an example.) What happens to pricing by $R$ if $M$ imposes a monopoly overcharge? If $R$ uses a markup pricing system, none of the monopoly overcharge will be passed on in the short run. Only if the increase in indirect costs forces $R$ firms over the long run to modify markup rates will the overcharge be passed on to consumers. By contrast, if $R$ uses cost-plus pricing, a monopoly overcharge which increases indirect costs will be passed on as soon as the firm recalculates indirect costs and reapportions them among units of output. That might be done annually or even more frequently. Suppose $R$ has direct costs of $\$ 1,000$ and indirect costs of $\$ 500$; then, because of a monopoly overcharge by $M$, indirect costs go up to $\$ 600$. If the firm produces 100 units, direct costs remain constant at $\$ 10$ per unit, while indirect costs increase from $\$ 5$ to $\$ 6$ per unit. As soon as the firm recognizes the indirect-cost increase, it presumably will raise its sales price from $\$ 15$ to $\$ 16$, constituting a $100 \%$ rate of passing on..$^{30}$

Consider next the effect of an increase in direct cost when a markup pricing scheme is used. An example might be a sale of canned goods to a supermarket. Imposing a monopoly overcharge, $M$ increases its invoice price from $\$ 10$ to $\$ 12$. The invoice price is a direct cost for $R$, which uses a markup rate of $50 \%$. R's price, $\$ 15$ before the increase, becomes $\$ 18$ after the increase. A price increase of $\$ 2$ from $M$ is transformed by the markup process to a $\$ 3$ increase for final consumers. In fact, as a general rule, the rate of passing on of direct costs under markup pricing is equal to $100 \%$ plus the markup rate of the firm. (In our example, the rate of passing on is equal to $100 \%$ plus $50 \%$ : the $\$ 3$ change in $P_{\mathrm{r}}$ equals $150 \%$ of the $\$ 2$ change in $P_{\mathrm{m}}$.)

Now assume the overcharge increases direct cost but that a cost-plus pricing method is used by $R$. A sale of radio tubes to a firm which assembles amplifiers is an example. There are two possibilities. If indirect costs are apportioned by a fixed amount per unit of output, the rate of passing on for a direct-cost overcharge

89 In most cases, it will be obvious whether a price increase affects direct or indirect cost. If an item is resold, then by definition direct costs are affected. When an item is used as an input into the production process, though, there is some ambiguity involved; depending on accounting techniques, what is treated as a direct cost of one firm (or industry) may be considered indirect cost by another.

90 Note that in a multiproduct firm, an increase in indirect cost will be passed on in the prices of as many products as the firm produces. It is these cases where the difficulties of determining and proving passing on are greatest. 
will be $100 \%$. In the two-product firm example given above, ${ }^{91}$ directs costs are $\$ 8$ for $A$ and $\$ 20$ for $B$, indirects costs are $\$ 5$ per unit, and prices are set at $\$ 13$ for $A$ and $\$ 25$ for $B$. If an overcharge imposed by $M$ raised direct costs for $A$ to $\$ 9$, then $R$ 's price for $A$ would be increased to $\$ 14-\mathrm{a} 100 \%$ rate of passing on. If indirect costs were apportioned relative to direct costs, however, then the $\$ 1$ increase from $\$ 8$ to $\$ 9$ in the direct costs of $A$ would also increase the percentage of indirect costs borne by $A$ and reduce the portion of indirect costs borne by $B$. The price for $A$ would therefore go up by the full amount of the overcharge plus the amount by which $A$ 's share of indirect costs was increased, a total increase of more than $100 \%$ of the overcharge. By contrast, the price for $B$ would be unaffected by the increase in direct cost and would be reduced on the new allocation since $B$ would then bear a smaller percentage of the unchanged indirect costs. In the example used above, the post-overcharge price of $A$ would be $\$ 12.55$ and that of $B, \$ 27.90$, compared to pre-overcharge prices of $\$ 11.36$ and $\$ 28.40$, respectively. For $\mathrm{A}$, this implies a passing-on rate of $119 \% .{ }^{92}$

Note that in no case of cost-plus or markup pricing thus far considered has the rate of passing on been less than $100 \%$. If we abandon our assumption that only cost factors are being incorporated into pricing decisions and assume instead that firms also include demand factors in setting specific prices, these results could change somewhat. How might demand factors come into play? In the short run, at least, a firm at $R$ might decide to absorb some of the overcharge imposed by $M$ for fear of losing customers. Thus, the "rigid application of cost-plus pricing margins [or markup rates] is typically modified by businessmen to incorporate subjective estimates of the price elasticity of demand, at various final prices .... However, this is frequently not done in any systematic way." 93

Whether systematically or not, firms do sometimes take demand considerations into account. Of course, if there was a monopoly overcharge on a product for which $R$ firms did not incur joint costs, each $R$ firm presumably would recognize that other $R$ firms

91 See text accompanying notes 84-85 supra.

92 When a firm uses cost-plus pricing, produces a large number of products, and apportions indirect costs as a percentage of direct cost, determination of passing on would be difficult. Actually, though, we have overstated the difficulty by implying in the example that an increase in direct cost of one product causes the firm to recompute the cost-plus percentage. If firms recompute that percentage periodically, not in response to each price change, the percentage does not change, and cost-plus is equivalent to markup pricing in that the rate of passing on is equal to $100 \%$ plus the cost-plus percentage.

${ }^{93} \mathrm{M}$. AtPERT, supra note 77, at 27-28. 
were experiencing the same cost increase. If, as would typically occur, all $R$ firms also used similar pricing methods, each would realize that others were likely to respond to the cost increase by passing it on. Hence, fear of loss to competing resellers would be greatly reduced for each $R$ firm. Nevertheless, a firm might alter its pricing practice in light of subjective judgments about demand. So, in our two-product manufacturing example with cost-plus pricing, a firm might face much more competition in the market for $A$ than $B$ and, accordingly, might respond to an overcharge by assigning less of its indirect cost to $A$ than to $B$.

In the perfectly competitive model, of course, prices are not set by anyone: they are dictated by the market. If competitive conditions-a large number of buyers and sellers, a homogeneous product, and perfect information-exist, then any single firm must charge the going market price if it wants to sell anything, no matter what its costs. As is widely appreciated, though, competition is seldom perfect. Prices often vary slightly among firms even in workably competitive markets. Still, many instances approach the ideal. If, for example, each of the retail stores in a market buys at the same price (and for most name-brand products that will be true) and uses the same markup rate (the function of trade custom), then they will "independently" arrive at the same "market" price.

To summarize, most businesses begin the pricing exercise on the cost side, measuring direct costs and apportioning indirect costs by a markup or cost-plus method. Demand factors are sometimes taken into account, usually in a subjective way. Put simply, very few businesses set prices by equating marginal cost to marginal revenue. The consequent indeterminacy of commercial pricing practices has been cited to support the claim that it is difficult to estimate the degree of passing on in a particular case. We will show in part III that the difficulty is overstated. It is possible, on the basis of theoretical insights reinforced by institutional knowledge, to make very reasonable estimates of passing-on rates, and to do so with limited amounts of data.

\section{RECONCILING THE THEORETICAL AND INSTITUTIONAL ANALYSES}

While the review of institutional practice in part II tends to reinforce the theoretical conclusions in part $I$, the possibility of subjective responses to demand and other such factors suggests a 
greater range of possible pricing responses than the theoretical models presuppose. In this part we evaluate the apparent variation and seek to reconcile the use of standard pricing techniques with the implications of the theoretical models described in part I. We show that, even though businesses may not intentionally price at marginal cost, market pressures-acting through inventories, investment levels, and firm entry and exit-will, especially in workably competitive markets, tend to bring prices into accord with costs (or, alternatively, bring costs into line with prices). We note a major exception to the tendency of markets to bring prices to marginal-cost levels-the multiproduct firm, an enterprise which sells a large number of different products which are "produced" in a common facility. The most obvious and frequently encountered example of a multiproduct firm is a retail store, but the term also describes most wholesale and service establishments, as well as many manufacturing firms. This exception does not weaken our theoretical conclusion about passing on, but strengthens it, for, as we will show, the marginal model understates the rate of passing on by multiproduct firms. Overall, this analysis of commerical pricing practices enhances the results of the marginal analysis: it shows that a large share of a monopoly overcharge will, in most cases, be passed on to indirect purchasers.

The standard defense of economists to attacks on the marginalprice model is that business enterprises need not consciously price at marginal cost in order for the model to be descriptive; rather, it is necessary only that, however prices are set, the results induced by those pricing practices and market forces be equivalent to marginal-cost pricing. If that sounds like a tortuous defense, consider the following analogy. When a quarterback tosses a sixty-yard pass to his flanker, he does not calculate the necessary trajectory (velocity of target, angle of inclination, force applied to trajectile). Nevertheless, the outcome might be fairly modeled as if he had made those calculations. Likewise, the price setter need not consciously calculate marginal cost and revenue, but we might still characterize behavior as if it did. The issue thus reduces to a simple question: Under what circumstances is either markup or cost-plus pricing equivalent to marginal-cost pricing? As we showed in part I, marginal analysis suggests a high percentage of a monopoly overcharge typically will be passed on in the short run and that a passingon rate approaching $100 \%$ will be the long-run norm. Thus, to the extent that market forces press for equivalence between the results suggested by marginal analysis and those achieved by conventional 
pricing practices, those instances in which the use of pricing conventions would seem to lead to passing-on rates exceeding $100 \%$ will be rectified, as will any instances in which subjective judgments about demand might tend to lead to a passing-on rate of less than $100 \%$.

We consider three possible cases in which the use of a conventional pricing method would lead to an equivalence of price and marginal cost, and a fourth in which reconciliation is not possible. In the first case, costs and demand are such that markup pricing is identical to marginal pricing. The conditions required are (1) that unit costs of individual products are constant, so that the marginal and average cost curves are flat and equal throughout the relevant range of output, and (2) that the demand curve facing the firm for that particular product is one of constant elasticity. If these conditions apply, then a price set by a constant markup over unit cost will always be the profit-maximizing price. Any shift in either cost or demand does not change the appropriate markup rate as long as the elasticities do not change. ${ }^{94}$ These are highly restrictive conditions, however, that seldom occur in the commercial world.

The second way by which markup or cost-plus pricing might be brought into equivalence with marginal-cost pricing is through inventory changes which signal the need for, and result in, price changes responsive to demand conditions. Suppose a firm normally uses a standard markup pricing scheme to determine product price and, initially takes no account of demand factors. If the price is above the "correct" (market-clearing) price, the firm's inventory of that product will rise above normal levels. (Alternatively stated, the turnover rate of that product will decline.) In that event, the firm may mark down the price or reduce the markup rate on that product in order to maintain inventory or turnover rate at the desired level. Similarly, if a price settler's subjective assessment of demand assumes that demand is more elastic than in fact it is, so that the price setter modifies its pricing method and absorbs part of an overcharge to avoid loss of sales, the inventory corrective will work in the other direction. The price setter, having set a price

94 Preston elaborates on the conditions required for markup pricing to be profit maximizing. If the two conditions given in the text obtain, then

[I] $M R=(1+1 / e) \cdot P$;

[2] $M R=M C=A C$; and

[3] $P=A C \cdot[1-1 /(1+e)]$,

where $M R$ is marginal revenue, $M C$ is marginal cost, $A C$ is average cost, $P$ is price, and $e$ is the elasticity of demand. Equation [3] states that if price is set by a constant markup, price is equal to marginal cost. See L. Preston, supra note 78. 
too low, will find turnover increasing and normal inventories too rapidly diminished. Thus, even though the price setter a priori makes no attempt to measure demand with precision and set price at marginal cost, demand-working through inventory-may have the effect of moving prices toward marginal cost. The responsiveness of prices will vary with the sophistication of the firm's inventory and sales-information system.

The third way by which markup or cost-plus prices can be brought into equivalence with marginal costs is through capacity adjustments-that is, through changes in the level of investment in productive facilities (such as manufacturing plants, wholesale warehouses, and retail selling space). Needless to say, these adjustments require time: in the economist's lexicon they are long-run adjustments. Companies do not-typically cannot-instantaneously change capacity in response to changes in prices, costs, or other market factors. Over the long run, however, the firms which make up an industry either do adjust their capacity or find that the market forces will do so through entry of new firms or forced exit.

If prevailing prices, as set by markup or cost-plus pricing methods, exceed marginal costs and inventory adjustments fail to revise prices sufficiently, there is an economic incentive for firms to seek to increase their shares of the market to capture some of the potential excess profit to be earned in the industry. ${ }^{95}$ The effort to gain a larger share will take the form of increased promotional activity, increases in capacity, and related activities, all of which increase costs. Firms will continue to have incentives to engage in such activities until costs are driven up to the point at which there are no longer excess profits to be gained. Thus, if prices are not driven down to marginal costs, costs will in the long run be driven up to price. This is a well-known theoretical result of "monopolistic competition" which characterizes most retail trades: because firms have some small degree of locational advantage (or product differentiation), excess capacity is induced and may persist over long periods. ${ }^{96}$ If prices are held artificially high by resale-price maintenance (as with liquor) or government regulation (as with financial

$95 \mathrm{We}$ are assuming that marginal cost is equal to average cost (that is, the industry is operating at an output level exceeding minimum optimal scale), so that a price exceeding marginal cost implies excess profit.

96 Monopolistic competition was conceived in Sraffa, The Law of Returns Under Competitive Conditions, 36 Econ. J. 535 (1926), and developed in E. Chambertain, The Theory of Monopolistic Competition (1933) and J. RobInSON, THE ECONOMIICS OF IMPERFEct CoMpetition (1933). For a modern treatment, see E. Mansfield, Mrcroeconomics (1979). 
depository institutions), ${ }^{97}$ the problem of excess capacity is exacerbated.

If, alternatively, existing markup rates lead to prices less than marginal costs, in the long run either firms will have to reduce capacity voluntarily (by using fewer or smaller stores), or some firms will be driven from the trade by bankruptcy. This is a powerful force at the retail level and is one reason why so many new business ventures fail. Because new retailers are likely to accept the traditional markup rates of their trades, almost irrespective of marginal costs and revenues, the market does the "equilibrating" through capacity adjustments.

Finally, there is the critical case of the multiproduct firm, in which inventory or capacity-cost adjustments will not function well as equilibrating forces. For reasons given earlier, marginal costs are less than average costs in virtually all multiproduct firms. Thus, it is not possible for markup prices to be identical to marginal costs: one of the two necessary conditions stated in our first case does not hold.

The second possibility-that inventory turnover rates will stimulate price changes so that marginal-cost pricing is approximateddoes exist for multiproduct firms. Even so, however, note the likely dynamics: absent a sophisticated demand-monitoring information system, and assuming that the overcharge imposed by $M$ affects all firms at level $R$, it is highly unlikely that imposition of the overcharge will cause any $R$ firm to modify its markup rate immediately. If $R$ does not change the markup rate, the rate of passing on will be $100 \%$ plus the markup rate, as already shown. Only if, over the longer run, a slower rate of turnover induces a change in the markup rate, will the rate of passing on be less (and even then, it may still be $100 \%$ or more). In any event, the initial, short-run response of the direct purchaser is to pass on more than $100 \%$; only if there exists some operative inventory adjustment mechanism will the passing on rate be reduced.

It is highly unlikely that capacity adjustment would play the equilibrating role within a multiproduct firm. If $M$ 's overcharge increases the price of a product which accounts for a small share of the total sales of a multiproduct $R$, the markup price used by $R$ could differ substantially from marginal cost over a long period without inducing any adjustment of the investment level in the industry. So, although the marginal model may be fairly descriptive

97 The "prices" of financial depositories are determined by government regulation of the interest rates those institutions can pay depositors or charge borrowers. 
of multiproduct firms if we abstract away from specific product lines (as by aggregating across specific products, measuring output in some homogeneous sense), the model is deficient if we are concerned with the price-cost relationship of a particular product.

This is a consequence of no small import because most wholesalers, retailers, and service establishments-the enterprises with whom consumers most often deal-are multiproduct firms offering a very large number of products. Even specialty stores typically carry at least several dozen different items; in grocery or department stores the number may run to the thousands. It is quite possible-indeed, probable-that markup rates would be unaffected by capacity adjustments or declining profit margins of such a firm. If so, then a rate of passing on exceeding $100 \%$ could well be maintained, even over the long run..$^{97 a}$

To summarize, the evidence suggests that businesses seldom set prices according to marginal costs as predicted by the economic model. In some cases, under very restrictive conditions, markup or cost-plus prices may be, coincidentally, equal to marginal cost. In other cases, in response to lagging (or excessive) turnover rates or unduly high (or low) inventory levels, prices may be marked down (or up), or the markup rate reduced (or increased), thereby equilibrating markup prices to marginal costs. Finally, and only over the long run, market forces may induce changes in profit rates and/or investment levels and thereby force prices into accord with marginal costs. These market forces will be strongest in the case of a single-product, competitive firm with little product differentiation and no significant barriers to entry. For a multiproduct firm, market-adjustment mechanisms may not be sufficient to equilibrate price to cost, with the consequence that the rate of passing on may exceed $100 \%$ even over the long run. That important exception aside, marginal analysis is confirmed as a fairly accurate guide for estimating the likelihood, speed, and rate of passing on. Moreover, it is quite feasible in particular cases to gather relevant, standardized empirical information about actual pricing methods from which the extent of passing on can be accurately determined.

97a The possibility of a rate of passing on exceeding $100 \%$ is critical in assessing the deterrent effect of alternative assignments of the cause of action for overcharge damages. Landes and Posner, for example, assert that deterrence is maximized by giving the cause of action to those purchasers most proximate to the violators, because these will most likely be aware of the violation. Landes \& Posner, supra note $61 \mathrm{a}$, at 608-15. That line of argument fails to recognize that direct purchasers may actually benefit from the violation by passing on more than $100 \%$ of the overcharge. Such purchasers may be loathe to give up this stream of certain revenue in exchange for the possibility of damage awards. 


\section{Determining the Rate of Passing On in Particular Cases}

The analyses above show the probability of a high rate of passing on in most cases. They also suggest ways in which passing on can be accurately evaluated-ways which should be neither too time-consuming, too expensive, nor too complex for use in litigation. While theory suggests general principles to guide investigation, institutional factors suggest how explicit, empirical investigations can be carried out. To these matters we now turn.

\section{A. Theoretical Guides to Measuring Passing On}

Economic theory suggests principles which constrain pricing behavior. These principles, together with information about commercial pricing practices, facilitate reasonable estimation of the rate of passing on in a specific situation in which an overcharge has been imposed. In presenting these general propositions, we cautiously note that they suffer the usual limitation of their genre: there are exceptions to every rule. Exceptions notwithstanding, the simplicity of these general rules is their most important message: reasonable estimation of passing on which will closely approximate the truth in the majority of cases requires no mystical powers or elaborate, extensive economic analysis. ${ }^{98}$ In many cases, making such estimates is a straightforward exercise. ${ }^{99}$

Before the incidence of an overcharge can be traced, one must be able to identify the distribution chain and follow transactions down the chain. Often, this presents no difficulty: the conventional manufacturer-distributor-wholesaler-retailer-consumer chain is likely to be obvious, as is the manufacturer-distributor-subcontractorcontractor-owner chain. If one starts higher up, above the manufacturer, with a raw-material producer or the manufacturer of a sub-assembly, the matter is slightly more complex, yet still manageable. Nonetheless, there are chains that become hopelessly obscure. When these are encountered, tracing beyond the point at which obscurity sets in is impossible.

98 We do not suggest that determining passing on is not exceedingly complicated in some cases. Our point is that, whereas some have suggested that is the usual, we think it is not. If the passing-on problem is thought difficult, compare this line of analysis to others commonly trod by courts-measuring the value of a human life, for example.

99 Useful for comparison is the well-developed theoretical literature on $\operatorname{tax}$ incidence. There is also an extensive body of empirical studies of tax incidence by public-finance economists. In most cases, the complexities of tax incidence make empirical analysis exceedingly more difficult than it is likely to be in most antitrust passing-on cases. For an extensive survey of tax-incidence theory and empirical studies, see Break, supra note 33 , at 119 . 
When the chain itself can be identified, however, tracing an overcharge is manageable. Subject to one condition, noted below, estimating the rate of passing on is entirely feasible, and in all instances, without condition, determining the rate from evidence of actual pricing practices is feasible. When estimates can appropriately be made, the factors that must be taken into account are few in number and, in any particular industry, the relevant facts are likely to be obvious or easily discovered. Thus, it is possible to develop a fairly simple, easily manageable methodology for making estimates of passing on which will be sufficiently accurate to serve as rebuttable presumptions. If courts follow the methodology, make the estimates, and announce the results as presumptions, the results will seldom be subject to successful challenge, though any party wishing to challenge them may do so on the basis of more detailed empirical evidence of the kind discussed in the next section.

The condition which must be met before estimates are feasible concerns the possibility of down-chain markets which are themselves cartelized or monopolized and which, consequently, will reduce the rate of passing on. In theoretical terms the problem arises whenever, to use the Supreme Court's language, "direct purchasers . . . sell in imperfectly competitive markets . . . " 100 In practice, it arises only when substantial market power is being exercised at two levels. ${ }^{101}$ Structural conditions consistent with substantial downchain market power will not occur routinely and can be identified when they do occur. In these instances, unless the possibility of an existing down-chain monopoly or cartel can be negated, no estimate of passing on would be sufficiently reliable to serve as a presumption. The party attempting to prove passing on would have to do so directly by means of more complete evidence of actual pricing practices, in the manner discussed in the next section.

There are five classes of factors which should be considered in making such an estimate of the rate of passing on: temporal relationships, pricing practices, directness of affected costs, supply, and demand. In any specific case, one or more of these factors may be determinative in the sense that the outcome will be certain whatever the nature of the other factors. For example, if the overcharge was imposed sufficiently long ago that long-run adjustments have been made, then a high rate of passing on will have been achieved, and the significance of other factors pales. Similarly, if supply is highly elastic, then elasticity of demand is irrelevant. On the whole,

100 Mlinois Brick Co. v. Mllinois, 431 U.S. 720, 742 (1977).

101 See part I(C) supra. 
though, the analyst should be guided by an examination of each of these factors. ${ }^{102}$ In this section we identify the factors and indicate the implications of each; in part $V$ we demonstrate their use.

\section{Temporal Factors}

a. Frequency of price changes. The more frequently price changes occur under the pricing conventions used in an industry, the sooner an overcharge increasing supply costs will be passed on to customers. The less frequently price changes are made, the higher the probability that the overcharge will be absorbed for an interval before it is passed on.

b. Duration of the monopoly overcharge. The longer the duration of the cartel or monopoly and the overcharge it imposes, the greater is the likelihood that the cost increase will be passed on to indirect purchasers. Firms may absorb a portion or, in some circumstances, even all of an overcharge in the short run (up to about a year), but in the long run prices must come to reflect costs.

\section{Pricing Factors}

a. Consistency of pricing practices. The more regular are individual pricing decisions (that is, the more rigidly a standard pricing policy is followed), the easier is the determination of the passing-on rate. At one extreme is a firm which uses the same percentage markup irrespective of product characteristics and supply or demand considerations; its passing-on rate is defined as $100 \%$ plus that markup rate. At the other extreme is a firm without a pricing policy, which sets prices subjectively or at whim.

b. Basis of pricing policy. The greater the extent to which price decisions are based upon supply costs, the more certain the rate of passing on can be determined by numerical operation. The more that demand factors play an important role in price setting, the more likely that the rate of passing on in the short run will be less than $100 \%$.

\section{Directness of Cost Factors}

a. Directness of cost. The more the overcharge affects direct cost, the sooner the pass on will occur, and the higher the rate of

102 In stating the probable effect of any one factor, we "hold constant" any other relevant factors. Thus, our discussion of each factor assumes "other things being equal." 
passing on will be. At the limit, direct costs will be reflected immediately, as in the case of retailers or wholesalers that price items as they arrive to reflect the actual cost of that stock of merchandise.

b. Assignment of indirect costs. In a multiproduct firm, when an overcharge increases an indirect cost spread over a large number of products sold to different classes of purchasers, the determination of passing on will be more difficult and rates of passing on will more likely vary among different products and, hence, among different indirect purchasers.

c. Computation of indirect costs. If an overcharge affects indirect costs, then the more sophisticated the pricing system (with respect to indirect costs) and the more frequently indirect costs are calculated and apportioned to products, the sooner a pass on will occur and the higher the rate of passing on will be. ${ }^{103}$ If there is a highly automated accounting system which closely monitors changes in indirect costs, a pass on will occur in the short run. At the opposite extreme, if the firm uses a crude cost-plus pricing system, the increase in indirect cost might not be passed on at all, or at least not for several years.

\section{Supply Factors}

a. Firm elasticity of supply. The more elastic the supply curve of the individual direct purchaser, the higher will be the rate of passing on. If it appears that the firm could expand output appreciably without increasing unit costs, then elasticity is high: irrespective of demand, the rate of passing on will be high. If direct cost is equal to invoice cost and the firm can buy as much of the cartelized or monopolized product from suppliers as it can sell, the firm has a perfectly elastic supply curve. In this case the rate of passing on will be at least $100 \%$. By contrast, if unit costs rise as output increases in the short run, the passing-on rate will be lower.

b. Industry elasticity of supply. The more elastic the supply curve of the industry (of direct purchasers), the higher will be the rate of passing on. If industry capacity can be adapted to output easily and quickly (as in the case of retail stores or service establishments without specialized or extensive capital equipment), if

103 The majority of firms using cost-plus pricing would recompute indirect costs at least annually because the requisite data need to be collected and computed for tax purposes anyway. 
there are no significant barriers to entry or exit of firms, and if there are no serious shortages of critical factors of production, then market forces are more likely to induce prices to equilibrate with costs so that firms are forced by market pressures to pass on cost increases.

c. Industry production technology. The greater the uniformity of production technique among firms in industry $R$, the higher will be the probability that a monopoly overcharge will be passed on because the costs of each firm will be similarly affected. The lower the potential for factor substitution for the price-fixed input, the higher will be the passing-on rate because firms cannot avoid the cost increase by changing factor-input combinations. Note that for resellers (for whom the output is physically identical to the pricefixed input) factor substitutability is zero.

\section{Demand Factors}

a. Firm elasticity of demand. The less elastic the demand curve of the individual direct purchaser, the higher will be the rate of passing on. ${ }^{104}$ The greater the competition among direct purchasers in the sale of their products, the more elastic demand will be. If some of their competitors do not have increased costs, ${ }^{105}$ then direct purchasers may have to absorb a cost increase in order to remain competitive in their markets. Alternatively, the larger the market share of firms whose costs are increased, the higher will be the probability of passing on.

b. Industry elasticity of demand. The less elastic the demand curve of the industry (of direct purchasers), the higher will be the rate of passing on. The fewer the readily available substitutes and the smaller the share of consumers' budgets taken by the product, the less elastic demand will be. The more constraining production technology is or the lower the cost of an input relative to total production cost, the less elastic will be demand of firms.

101 For a discussion of the determinants of elasticity of demand in a passing-on context, see Schaefer, supra note 5, at 887-900.

105 This might occur in the following situation: Suppose that $M$ is a regional industry producing components for $R$, which has a national market. If $M$ firms in one regional market conspire to fix prices, some $R$ firms would pay the higher price, others would not. In that event, the affected $R$ firms may have to absorb the cost increase in order to maintain a competitive price with the unaffected $R$ firms, at least in the short run. The losses occasioned by their competitive disadvantage would, sooner or later, drive these firms from the market. 
The use of these principles to make estimates about passing on requires sound judgment and a sense for economic relations, but arcane knowledge and esoteric techniques are not needed. In most situations the relevant factual information will be neither obscure nor complex: the analysis is fairly simple and straightforward, and the results are often obvious. In order to demonstrate this method of analysis, we review in the next part sixty-five government price-fixing cases. Before doing so, we discuss the empirical inquiry into passing on more fully.

\section{B. Measuring Passing On Empirically}

When managers make pricing decisions, they utilize one of a limited number of standardized, readily understandable pricing methods. The practice used by any single firm may develop and change somewhat over time but at any given time will be highly standardized and usually based upon industrywide or regional marketwide customs or conventions. Given these standardized practices, a fairly simple factual investigation will reveal the data needed for the evaluation of relationships like those identified in the preceding section. Indeed, a more detailed, yet manageable, inquiry will show the time at which, the manner in which, and the full extent to which a monopoly overcharge on any input factor is passed down the chain.

There will be occasions, nevertheless, when the process of tracing an overcharge to particular downstream purchasers will be daunting. If the direct purchaser makes a large number of products and the overcharge raises an indirect cost, a series of complex subchains may be initiated through which the overcharge cannot be traced or can be traced only at excessive cost. It is essential, then, to determine how far the chain of purchasers can be identified: a pass on can be traced no further down the chain than to those purchasers than can be identified as a class. We address these problems more fully in part V. Here it is sufficient to note (as we show in part VI) that most of these kinds of problems can be handled in conventional and sensible ways through the application of existing concepts.

We turn, then, to the cases which concern us: those in which the chain of distribution can be followed beyond the level of the direct purchaser. Often, it will appear quickly, clearly, and incontestably that the full amount of the overcharge was immediately passed on. When markup pricing is used, a full pass on of all 
overcharges on items classified by the direct purchaser as direct costs will take place as soon as the direct purchaser marks up the invoice price. Almost all retailers, wholesalers, and contractors price this way and mark up immediately. Such information could be obtained from any informed witness in a short deposition and could be easily verified with documents. In these cases-and they are numerous-dispute would be unlikely.

Further, there will not be much additional difficulty when markup pricing is used and the overcharge is on an item classified as an indirect cost. Evidence would then have to be obtained about when, following the imposition of the overcharge, markup rates were first reviewed and adjusted, and about how increases in indirect costs were dealt with. Thus would hardly be an unmanageable task.

Again, overcharges affecting direct costs are easily handled when cost-plus pricing is encountered: the inquiry would be much like that just envisaged. When such a pricing method is used, direct costs are recalculated periodically and prices then adjusted to reflect cost changes. The matter to be determined is simply how soon after imposition of the overcharge the next such adjustment took place. With this pricing method, indirect costs are also dealt with by standard techniques. If the overcharge imposed affects an indirect cost, the question to be answered is how frequently, and in what manner, either markup rates or costs are adjusted to reflect changes in these costs and when, following imposition of the overcharge, this was first done. None of these issues is particularly murky: these are run-of-the-mill litigation problems. The actual pricing practice used will leave its own clear, objective traces in the records of affected firms. Oral testimony from management about the processes used can thus be readily verified or impeached.

The last complexity is the possibility of subjective adjustments to reflect demand factors. In the great majority of cases this will not have occurred. When it does occur, moreover, that fact and its effect upon the passing-on rate can be easily determined from the evidence. Here, too, objective documentation will be available.

\section{Analysis of Passing On in Recent Price-Fixing Cases}

In the preceding sections, we used economic theory and institutional knowledge about commercial pricing methods to show that when a seller at a high level on a production-distribution chain imposes a monopoly overcharge, direct purchasers will, as a rule, pass it on to indirect purchasers. We have presented general economic principles which might guide the examination of passing on 
in specific cases, thus facilitating presumptive judgments about passing on even without empirical review. Finally, we have also shown that through empirical investigations of specific pricing situations the accurate determination of passing-on rates in actual markets will often be well within the capacity of courts.

We now put these claims to the test. In this section we present economic facts from sixty-five recent price-fixing cases brought and won by the Antitrust Division of the Justice Department to illustrate the processes used in the investigation of passing on. Although it is not feasible for us to complete a comprehensive empirical investigation of any of these cases, we complete (or, in some instances, nearly complete) an estimate of the extent of passing on using the factors described in part IV(A). We demonstrate that the analysis of passing on involves a sequence of quite manageable inquiries, each of which has the potential for providing a dispositive answer to the ultimate question-what ought a court do in each instance about passing on? Last, by drawing inferences from the aggregate results of inquiry into these cases, we find further support for the conclusion that in many cases indirect purchasers bear all or most of the costs of a monopoly overcharge.

The cases for which data are presented in the Table in the Appendix were brought by the Antitrust Division under section 1 of the Sherman Act. ${ }^{108}$ All were criminal cases either won at trial or settled by a plea of nolo contendere between January, 1963, and December, 1972.107 Data about these cases were derived from the indictments or complaints and related court records, the press releases accompanying case filings, and factual memoranda and supporting documents prepared by the Antitrust Division staff which investigated the violations. In cases for which data are omitted from the Table, the relevant facts were not available.

The cases are listed in the first column of the Table by the same numbers that are used in the CCH Trade Regulation Report ("Blue Book").108 The second column sets forth the name of the product for which the price was fixed, designated in accordance with the Census Bureau's Standard Industrial Classification system. The information in the next four columns (the territorial scope of the conspiracy, the number of conspirators, the total number of firms

10615 U.S.C. $\$ 1$ (1976).

107 This list of cases was first presented in Hay \& Kelley, An Empirical Survey of Price Fixing Conspiracies, 17 J.L. \& Econ. 13, 17-28 (1974).

108 Summaries of these cases can be found in [1961-1970 Transfer Binder, U.S. Antitrust Cases] Trade Reg. Rep. (CCH) II 45,063-45,070 and 4 Trade Reg. REP. (CCH) IT 45,070-45,072. 
in the market, and the percentage of total market sales made by the conspirators) is taken directly from Hay and Kelley. ${ }^{109}$ These data, which describe the relevant market and size distribution of firms in the industry, ${ }^{110}$ would be relevant to either an empirical or theoretical analysis of passing on.

Taking that data as given in the Table, the passing-on analysis can begin. Whether one is proceeding empirically or theoretically, a sequence of questions must be asked. The first four questions, discussed in section A, apply to either type of inquiry. Who are the direct purchasers? Are the direct purchasers also final purchasers? Can the final purchasers on the distribution chain be identified as a class? Can they be identified as individuals? Based upon the answers to these questions, a judgment is made whether it is possible or practical to trace any passing on. If not, the inquiry stops. If it does appear practicable, the inquiry proceeds.

\section{A. Inquiries from Which It Can Be Determined Whether It Is Possible to Trace an Overcharge}

The first question-who are the direct purchasers?-is always easy to answer. In our Table, the seventh column lists the class or classes of purchasers that bought the price-fixed product directly from the conspirators. ${ }^{111}$ The conspirators, of course, would stand in the place of the $M$ firms (the manufacturers): these are the antitrust-law violators that impose a monopoly overcharge. In order for passing on to be a relevant issue, there must be a distribution chain below $M$-at least two sequential purchasers, one (or more) to stand in the position of the $R$ firm (the reseller), and one (or more, if the chain has split into two or more branches) to stand in the position of $C$ households or firms, the final purchasers (or consumers). If there is only one sale from $M$ to $C$ (as was the case, for example, in case no. 1930 in the Table, in which class rings were sold by the conspirators directly to student consumers), there can be no passing-on problem. In that kind of case each direct buyer pays the full overcharge and has no alternative to absorbing it. ${ }^{112}$

109 Hay \& Kelley, supra note 107, at 29-38.

110 "In most cases the data are taken from the last year in which the conspiracy was fully operative." Id. 19.

111 Hay and Kelley left this column empty "[i]f the buyers were a very heterogeneous group, or if their identity was simply not known." Id. 20. We have filled in those spaces [1744, 1748, 1751, 1818, 2036] with the general term "industrial users" or with information from the case summaries. See note 108 supra.

112 A prospective purchaser can avoid the overcharge by not purchasing the price-fixed product. This accounts for the allocative effect described in part I, see 
In the eighth column, we come to the second inquiry in the analysis-is the direct purchaser the final purchaser? When there are two or more classes of direct purchasers indicated in the seventh column, there may be two answers to this inquiry: one class of direct purchasers may be final purchasers and another not. In many instances, whether purchasers in a particular class (students buying rings, contractors buying linoleum) are direct purchasers will be a conceptually simple question easily answered from the available empirical data. In deciding whether purchasers in a particular class are final purchasers, however, we must sometimes make a judgment having policy significance. We have used a standard which is simple to apply and responsive to the functional purpose: no purchaser that uses the product as an input for a product or service sold at a market-determined price is treated as a final purchaser of that product, regardless of whether the product is transformed or incorporated into, for example, a larger assembly before being resold. Any such purchaser has the potential capacity to pass the overcharge on. Hence, the inquiry should be pursued if feasible. We have classified as final only those purchasers that either consume the product (such as a household purchaser of bakery products) or that pass on the product but not at a marketdetermined price. The latter category would include non-pricing institutions such as government agencies or public schools.

When direct purchasers are the consumers of a product, they are easily identified. Examples in the Table include liquefied petroleum gas sold to households [1756]; ${ }^{113}$ refuse-collection service sold to households [1763], fuel oil sold to households [1928], auto repairs sold to car owners [2156], and overhead garage doors sold to households [2211]. When direct purchasers are non-pricing institutions, they can also be identified readily enough without particularly difficult problems of evidence or judgment. Consider case no. 1749, for example: strictly speaking, metal library shelves are passed on to the users of library services. They are an input into the production of library services, but because the direct purchasers -schools, colleges, and government agencies-do not charge customers of library services market-determined prices which reflect the costs of providing those services, there is little question that a cost increase is not passed on. Hence, we classify these non-pricing

notes $45-46$ \& accompanying text-that is, the loss of economic welfare attributable to the reduction in sales of the price-fixed product.

113 Throughout this section, numbers within brackets, e.g., [1847], refer to the Blue Book number of the case as listed in the Table. 
institutions and agencies as final purchasers even though they may not literally be the consumers of the product in question. ${ }^{113 a}$ The institutions we have so classified include schools and colleges; local, state, and national governmental units; hospitals; ${ }^{114}$ and the military. Note, however, that when one of these institutions resells the product at a cost-based price, we do not classify it as the final purchaser. For example, the military installations which were the first purchasers of nonpremium beer [1847] resold that product at a cost-based price in military exchanges and recreational facilities. We therefore treat the consumers of the beer as the final purchasers. Of course, we do not have complete data on all of these cases, and it may be that there are some products or services that we have concluded were not passed on at a market-based price which, in fact, were resold on such a basis. Our point here is merely that these issues are neither arcane nor particularly complex: with manageable amounts of data, these classifications can be made with a high degree of confidence.

At this juncture, three points should be emphasized. The first is the ease of determining whether the first purchaser is the final purchaser. All that need be asked is whether the direct purchaser resells the product (whether in the same form or transformed by a production process) to someone else. If so, the direct purchaser is not the final purchaser and the issue of passing on must be pursued. The second is the relatively small share of cases $(12.3 \%)$ in which all direct purchasers are final purchasers. The effect of the Illinois Brick ${ }^{115}$ ruling, accordingly, would be to deny a remedy to final purchasers in the vast majority of cases $(87.7 \%$ ) without ever raising the issue of passing on. The third is that when the direct

113a Supporters of the Illinois Brick rule argue that to maximize deterrence, the cause of action for an overcharge must be assigned to that level of the distribution chain at which the number of purchasers is smallest, the organization costs are lowest, the level of sophistication is greatest, and the financial incentive of each purchaser to sue is largest. They routinely assume that these indicia identify direct purchasers. See, e.g., Landes \& Posner, supra note 61a, at 608-15. In cases like many of those in our sample, in which the final purchasers are government agencies or other nonpricing institutions, the weight of that deterrent argument supports granting the cause of action to indirect purchasers. Illinois Brick itself is instructive: the Attorney General brought that action on behalf of 700 local government entitiesall final purchasers of the price-fixed product.

114 Hospitals represent a difficult choice in designating final purchasers. Many hospitals are nonprofit organizations whose prices do not cover the costs of service (indeed, they often lack the requisite cost data for even computing such prices). On the other hand, hospitals are increasingly employing modern management and pricing techniques (partly in response to insurers who will pay for only "the cost of service"). In those cases, the users of hospital services are more likely to be the final purchasers.

115431 U.S. 720 (1977). See text accompanying notes 9-14 supra. 
purchasers are found to be the final purchasers, no further inquiry is needed: there is no passing on.

Thus, in eight of the sixty-five cases we reviewed, inquiry terminates at this stage. In four of these eight cases, the direct purchasers are consumers: these involve class rings [1930], gasoline [1951], auto repair [1994], and retail shoes [2192]. In the four other cases, the direct purchasers are public institutions: these concern metal library shelves [1749], liquid asphalt [1860], school construction [1909], and athletic equipment [2009]. These buyers suffered the economic loss resulting from the overcharges and thus ought to have a private action for redress. ${ }^{116}$

In sixteen of the sixty-five cases, some of the direct purchasers are final purchasers; others are not. ${ }^{117}$ Seven of these cases involve the sale of food products both to final consumers (such as schools and hospitals) and to retail stores and/or restaurants which resell the products at a market-determined price. The application of Illinois Brick in these cases, by limiting availability of the private remedy to direct purchasers, would grant all direct purchasers a pro rata share of the recovered overcharge, even though some may have passed the overcharge on while others could not.

Perhaps the most anomalous result under present law is illustrated by the case involving overhead garage-door openers [2211]. The only ultimate consumers are households: such consumers may buy the product either directly from a manufacturer for self-installation or indirectly from a service firm which also installs the product. Based on the economic characteristics of the case, there is every reason to believe that consumers bear the cost of the price conspiracy regardless of whether they buy directly or indirectly from the conspirators. Yet, Illinois Brick mandates that these two groups of consumers be treated differently: there is full recourse for one group, none for the other.

In twenty-four of the sixty-five cases, then, some or all of the direct purchasers are final purchasers, so the issue of passing on need not be raised for those purchasers. Further analysis need be pressed only with respect to those direct purchasers that are not final purchasers. In the sixteen mixed cases, the further analysis applies only to that group of direct purchasers that uses the product as an input for a commercial activity. For example, in the garage-door-

116 These cases come out correctly under the Illinois Brick rule; they would also come out correctly if that rule were overridden. Upon analysis, they involve no passing-on problem.

117 See case nos. 1743, 1754, 1756, 1763, 1802, 1880, 1928, 1963, 1970, 1997, $2034,2156,2189,2211,2246, \& 2278$. 
openers case, further analysis is needed only to determine whether contractors passed on the cost increase to the indirect purchasers, households.

Having determined that there is a possibility of passing on in fifty-seven of the sixty-five cases (those in which some or all of the direct purchasers are not final purchasers), we want to estimate the probability of passing on in those cases. We are interested in both the process and the results: we want to illustrate the method of determining passing on, and we want to know the frequency with which a high rate of passing on occurs.

The third inquiry in the analytical process is, then, to identify the class of final purchasers of the product involved in each case. Based on the material available to us, we have, in the ninth column of the Table, classified as high, low, or medium the ease of identifying the class of final purchasers. (In the same column we classify in the same way the relative ease of identifying individual purchasers once the class has been identified; this responds to the fourth inquiry, yet to be discussed.) If we cannot readily identify final purchasers even as a class, then further analysis of passing on becomes a very difficult, perhaps intractable, problem. The third inquiry, then, is another possible stopping point. When it appears that the first (or any subsequent) purchaser uses the product as an input for other products which are passed on at a price, but that the production-distribution chain is so multilineal, fractured, or convoluted as to make tracing through to the next step unfeasible, the inquiry, quite simply, must end. ${ }^{118}$

In nine of fifty-seven cases, we have classified the "ease of identifying final purchasers as a class" as "low." That does not necessarily mean that a court could not identify final purchasers as a class, because parties to a litigation might be able to provide the court with more extensive information than we possess about these industries. Even so, there will no doubt be a minority of cases in which it will not be possible to make a reasonable identification of the final purchasers, usually because the cost increase is passed on through a large number of different products to different kinds of users.

118 Contrast this standard with the much narrower one, based entirely on pricing policy, which is implicitly suggested by In re Beef Indus. Antitrust Litig., 600 F.2d 1148 (5th Cir. 1979). Because it is our view that the appropriate stopping point should take account of the distribution structure, not solely the pricing method used, we do not think that even an open-ended construction of the passing-on exception, like that suggested by the Beef Industry litigation, adequately responds to the problems presented by Illinois Brick. 
The identification of final purchasers as a class is most difficult in cases involving industrial products which are sold to manufacturers that use them as inputs into their respective production processes. Examples of this sort are the cases involving rolled-steel pipe flanges and rings [1744], steel castings [1751], carbon-steel sheets [1796], and drill-jig bushings [1890]. Identification of final purchasers as a class is also difficult when the direct purchasers are small-business establishments providing many different types of goods and services to consumers, such as linen supplies [2032], liquefied-petroleum-gas delivery [1756], and refuse collection [1763]. Such cases are the stuff out of which horrendous hypotheticals are constructed by opponents of any change in the Illinois Brick rule. ${ }^{119}$ Such cases do exist, but the sound response is not to say that, because hard cases exist, we ought never to examine passing on. Rather, when these cases are encountered-and they can be identified readily enough-one should terminate the inquiry.

In the nine cases in which we were unable to identify final purchasers as a class, we have not attempted to estimate the rate of passing on. Rather, we have in the last column stated that the "probability of a high rate of passing on" is "indeterminate." Again, that means neither that a court with more data could not identify the class and then determine the passing-on rate nor that direct purchasers ought to be given standing automatically because final purchasers cannot be identified. It may be feasible to identify one or more levels of passing on or to identify some, but not all, final purchasers. Suppose, for example, that further information showed that the major purchasers of carbon-steel sheets [1796] were household-appliance manufacturers. This would suggest that households purchasing those appliances constitute one important class of final purchasers. Carbon-steel sheets might be used for many other purposes as well, no one of which represents a significant share of total sales. If so, two purchaser classes might be designated, the first consisting of direct purchasers of carbon-steel sheets (except appliance manufacturers), and the second of purchasers of household appliances. The point is that inquiry is usually manageable and any difficulties can often be resolved, at least in part.

In six cases it was possible to identify a class of final purchasers of a significant share, but not all, of the output of the conspirators. In these cases we have designated "ease of identifying final purchasers as a class" as "medium." It still makes sense to continue

119 See, e.g., 1978 Senate Hearings, supra note 15, pt. 2, at 313-14 (statement of Dorsey D. Ellis, Jr.). 
the passing-on analysis to determine whether it is likely that a large share of the price increase was passed on to the final purchasers so identified. In the case of industrial linen supplies sold to gasoline stations and automobile dealers [2025], for example, it is apparent that consumers of gasoline and automobiles would be the largest groups of final purchasers, though there may be other groups not easily identified. Admittedly, there is some ambiguity in these fifteen cases in which we have characterized the ease of identification of a class of final purchasers as either "medium" or "low," but these represent only $26.3 \%$ of the fifty-seven cases in which it is possible to estimate passing on.

Consider some illustrations of the identification of final purchasers as a class. In twenty-two of the forty-seven cases in which it was easy to identify the final-purchaser class, the product involved is a consumer product sold through retail outlets or service establishments. Examples include bed springs [1748], women's swimsuits [1778], milk [1880], bread [1963, 1997, 2182], and meat [2278]. Another fifteen cases in which class identification was easy involve contractors as the direct purchasers. Examples include lineoleum installation [1773], fabricated structural steel [1779], concrete pipe [1885, 1888], and ready-mix concrete [2035, 2124, 2136]. Complicated economic analysis is not required to discern that in both of these types of cases-retail goods and contracting services-the ultimate consumers of the goods or services are the final purchasers. There may or may not be actual passing on of price increases by direct purchasers to these final purchasers, but there can be no doubt regarding the feasibility of passing on.

In instances in which final purchasers have been identified as a class, we must turn to the fourth inquiry in the sequence: how difficult would it be to identify class members as individuals? Once final purchasers have been identified as a class, capacity to identify them individually is not necessarily a prerequisite to compensation in a legal regime which authorizes an overcharge suit on their behalf. As we shall show more fully in part VI, either a parens patriae or class action might be authorized and a cy pres remedy designed which would benefit class members more or less commensurately with the injuries they individually suffered. Thus, even when it would be very difficult to identify specific individuals, as often will be the case, the passing-on inquiry need not stop.

While not a prerequisite for private action, the relative ease of identifying individual final purchasers is important. The more difficult their identification, the less likely it is that individual pur- 
chasers will bring private actions against antitrust-law violators. Even if suit were successfully brought on their behalf, the inability to identify individual final purchasers would necessitate a cy pres distribution of the judgment.

Of the forty-eight cases in which it was easy to identify all or a significant portion of the final purchasers by class, in twelve it was also relatively easy to identify individual final purchasers. Eleven of these cases involve contractors as the direct purchasers, ${ }^{120}$ and the other involves apartment owners [1928]. In all of these instances ( $21 \%$ of the cases in which passing on may have occurred), the indirect purchasers that may actually have suffered the loss-government agencies, corporations, and individuals who hired contractors, and apartment residents and owners-were in a position to protect their own interests. As a general proposition, the identification of individual final purchasers will be relatively easy when there are relatively few, large transactions between direct and final purchasers (as with construction projects and contracting services), or a longterm business relationship between the direct and final purchasers (as in the case of apartment owners). In any randomly selected group of overcharge cases, there will likely be-as in our samplea significant number of this type.

In most cases we examined, though, identification of individual final purchasers was difficult because the number of transactions and purchasers was large, and the size of the particular transaction was small. Usually, when "ease of identifying final purchasers as individuals" is rated "low" (twenty-nine cases) or "medium" (seven cases), the direct purchasers are retail stores or service establishments that sell to a large number of customers without establishing longterm business relationships with many of them. Examples include cases involving resale book matches [1883], dairy products [1925, 2034, 2189], and bread [1963, 1997, 2182]. The identification of individual final purchasers is not a prerequisite for private action, though. It is important to reiterate that in forty-two of the fiftyseven cases in which the direct purchasers are not the final purchasers, the identification of final purchasers as a class was relatively easy, and in six other cases, it was possible to identify at least a significant number of final purchasers as a class. In the thirty-six of the forty-eight cases in which final-purchaser classes could be readily identified, redress for any overcharge passed on would have to be on a cy pres basis. \& 2211.

120 See case nos. 1773, 1779, 1842, 1885, 1887, 1888, 1957, 2035, 2124, 2136, 
It is these forty-eight cases, then-twelve in which final purchasers can be identified as a class and as individuals and thirty-six in which they can be identified only as a class-that further analysis of passing on remains relevant. As shown in part IV(B), a complete empirical analysis would often involve nothing more onerous than gathering information about highly standardized and readily understandable pricing policies and how they were applied in particular situations. However, we lack the data to demonstrate that for our sample cases. We turn, then, to the additional inquiries which would be involved in completing the analysis by drawing on the general principles outlined in part IV(A).

\section{B. Inquiries from Which the Rate of Passing On Can Be Estimated} When the Final Purchasers Have Been Determined as a Class

The purpose of this analysis is not to estimate precisely the rate of passing on. Such an analysis would require more business facts for the cases than we possess. Rather, we seek to determine with a reasonable degree of certainty whether there was in each case a high probability of a very high rate of passing on. To make such an analysis in any actual case, one would inquire about the five factors enumerated in part III; the length of the conspiracy, pricing methods, the directness of costs affected by a monopoly overcharge, the elasticity of supply, and the elasticity of demand. For the cases in our study, however, we have no actual data regarding the first two sets of factors: we know neither the actual duration of the price-fixing conspiracy in each case nor the frequency of price changes in the respective industries (though, in inflationary periods one can reasonably expect frequent price changes in virtually all industries). Nor do we have any specific information regarding actual pricing practices in each case.

In a litigation context, of course, all such information would be available to the court. Proof of the price-fixing conspiracy would be part of the plaintiff's case: evidence showing when as well as how it was accomplished would be essential. If the Court deemed it appropriate to rule on passing-on questions in a pretrial motion proceeding, the parties could cite, and the court could use, the product of the discovery process for facts about when the conspiracy developed (or, in appropriate cases, could accept for purposes of the particular motion allegations about the time the conspiracy began). Evidence about the pricing method used by alleged conspirators would be even more readily available and, thus, easy to obtain and present to the court. 
To deal with our lack of specific information about duration and pricing methods, we make reasonable, but conservative, assumptions about both the duration of the offense and the pricing practices employed by the direct purchasers. We assume that the violation continued for at least one year before the case was brought: it seems highly unlikely that the government would have learned of the alleged violation, investigated it, and started proceedings in less time. Because the longer the cartel is operative the greater the rate of passing on, our assumption is conservative in that it tends to understate the likely extent of passing on. As for pricing method, we assume that firms used the one common in their trade (for example, markup pricing by retailers or cost-plus pricing by contractors). The institutional literature cited in part II ${ }^{121}$ indicates that this assumption is correct in the overwhelming majority of instances. Given these assumptions, our estimate of the probability of a high rate of passing on depends upon the remaining three factors: whether the product for which the price has been increased by the conspiracy at $M$ is a direct cost to the $R$-level firms which use the product as an input in their operations; the elasticity of supply; and the elasticity of demand. ${ }^{122}$

This leads us, then, to the third specific inquiry in the passing-on analysis: how direct is the cost of the cartelized product when viewed as an input to the productive or commercial processes of firms at the level of distribution one step below the conspirators? As we showed in part IV(A), the more direct the cost which is increased by the overcharge, the higher is the probability of a high rate of passing on. In thirty-three of the forty-eight cases, the costs affected by the fixed prices were very direct. In the tenth column of the Table, we have classified these as "high." In six cases, costs were moderately direct (designated "medium" on the Table), and in nine cases, the cost was relatively indirect (designated "low" on the Table).

The empirical concept of directness of costs is roughly equivalent to the theoretical concept of variability of costs. When direct

121 See sources cited in notes $68,73,75,77 \& 78$ supra.

122 The estimates we completed are conservative in two senses. First, we have very limited information relative to the amount of data readily available to or easily obtainable by a court in an actual case. If we were able to make confident estimates about the rate of passing on with such limited information, then a court should be able to do so with even greater confidence. Second, we have been conservative in our estimates of the probability of high passing on rates: if there is any reasonable doubt, we have posited the conservative (that is, lower) estimate. As a consequence, the estimates presented in the Table may actually understate the frequency of high passing on rates. 
costs are increased by an overcharge, it is likely that all or a significant part of the increase will be passed on. Nevertheless, we cannot conclude on the basis of high directness alone that there is a great likelihood of a high rate of passing on. Rather, these cases become prime targets for further inquiry. The remaining question, pursued below, is whether, despite high directness, unusual elasticities prevail which tend to reduce this rate of passing on.

Examples of the thirty-three cases clearly displaying high directness are linoleum installation [1733], in which the work is done by subcontractors for contractors (who treat the subcontractors' work as a direct cost of performing their general contracts), gasoline [1849] sold to retailers who resell it to the motorists, and steel products [1818] sold to businesses that utilize them in further industrial operations. Most of the high-directness cases involve either sales to firms that resell, though perhaps with some further processing, ${ }^{123}$ or sales to contractors. ${ }^{124}$ A few [for instance, 1800, 1928] involve sales to firms that do extensive additional processing.

In the nine cases in which the overcharge imposed by the pricefixing cartel is on items regarded by the $R$-level firms as indirect costs, we could not, on that basis alone, confidently draw any inference about the likelihood of either a high or low passing-on rate. If the data were available, we would turn at this point on an evaluation of the relationship between the length of time the cartel had existed and the frequency with which, under the prevailing pricing method, it made a price response to changes in direct costs. The longer a conspiracy is operative, the higher the probability of a high passing-on rate; the more frequently indirect costs are computed and markup or cost-plus percentages modified, the sooner the cost increase will be passed on. Lacking data on these matters, we assumed a year-long price conspiracy and the use of typical industry pricing systems. Using these conservative assumptions, we estimated that the likelihood of a high rate of passing on was low in all nine cases involving low directness. Thus, in all of these cases, our inquiry ends at this point: there is no need to consider elasticities.

Note that more information would likely suggest a different result in some of these cases. Despite low directness, overcharges would be passed on to the final purchasers in any case in which the conspiracy lasted long enough for direct purchasers to make long-

123 See case nos. 1778, 1847, 1849, 1880, 1883, 1925, 1963, 1970, 1997, 2104, $2182,2189,2277, \& 2278$.

${ }^{124}$ See case nos. 1773, 1779, 1842, 1885, 1887, 1888, 1921, 1957, 1965, 2034, $2035,2124,2136,2211, \& 2243$. 
run adjustments. In some cases-for example, sales of welding electrodes to transportation- and chemical-industry firms [1802]many purchasers would likely have sophisticated information systems which would speed such adjustments. Thus, in any instance in which the conspiracy lasted significantly longer than a year, the rate of passing on would increase rapidly despite low directness. Indeed, some pricing systems would probably reflect some of the costs we labeled indirect even in the short run.

We tried to be similarly conservative in spanning the information gap in the six cases in which affected costs were moderately direct. In these we made cautious "judgment calls" by labeling the probability of a high rate of passing on as "medium" in five cases and "low" in the sixth. Bed springs sold to mattress manufacturers [1748] is an example. In an industry that typically uses cost-plus pricing moderated at times by demand factors reflected through inventory, increases in a material cost like this one would often be responded to in the short run, but on occasion the response would be delayed. Having no more pricing information, and assuming the conspiracy to be in effect for no longer than a year, we judged the likelihood of a high rate of passing on to be medium. We made that judgment, however, subject to one condition: if in any of these situations we found supply to be highly inelastic (an unlikely but possible circumstance), we would reduce our estimate of short-run passing on from medium to low.

In the thirty-nine cases in which costs were of either high or medium directness then, we proceeded with our analysis. We thus ask whether supply is elastic or inelastic, and whether the direct purchasers face an elastic demand curve.

When highly direct costs are affected by a price-fixing conspiracy, the likelihood that most of the overcharge will be passed on is great unless one of two unusual conditions prevails: either supply or demand is highly inelastic. Only in such unusual situations might the direct purchaser absorb some part of the overcharge in the short run.

We determined supply elasticities on the basis of the general characteristics of the industry. Although the presumption is that a cartelized industry is marked by excess capacity which will increase supply elasticity, we did not rely on the presumption. Rather, taking into account such factors as ease of entry, likely start-up time, and the ease and speed with which capacity could be increased, we estimated whether supply could be increased without increasing costs. 
In twenty-seven of the thirty-two cases involving highly direct costs, the supply curve of the direct purchasers (both as individual firms and as an industry) were very elastic: expansion of output would not raise unit costs. When, as in these cases, direct costs are increased by price-fixing and supply is highly elastic, the almost certain consequence is a very high rate of passing on even in the short run. (The only possible counter-indicator would be very inelastic demand.) Thus, in twenty-seven of the cases the probability of a high rate of passing on in the short run is clearly high.

Case no. 1773, linoleum installation for contractors, will serve as an example. The $M$ firms here, the conspirators, are subcontractors who made bids to general contractors, the $R$ firms in our model, for linoleum work. General contractors universally treat the costs incurred on such contracts as direct costs and thus reflect them in full in their own bids-that is, in setting their own prices. There can be no serious question that overcharges in cases like this are passed on immediately and in full in the overwhelming majority of instances.

In only five of the thirty-three cases in which affected costs were highly direct did analysis of supply elasticity suggest that the probability of high short-run passing on was either medium or low. In the case of commercial baking flour [1800], for example, supply would be moderately inelastic in the short run, as plant expansion requires at least a year or so (though, even here, inelasticity of demand suggests short-run passing on). Similar factors suggested medium supply elasticity, and hence, only a medium likelihood of a high short-run passing-on rate, for steel products [1818], fuel oil [1928], brass plumbing [1965], and wholesale meat [2278].

In virtually all of the twenty-eight cases in which high directness of costs and high elasticity of supply strongly indicate a high passing-on rate even in the short run, the analysis of passing on is simple and requires very little empirical evidence. One class of these cases involves consumer goods in which the direct purchasers are retail stores: women's swimsuits [1778], nonpremium beer [1847], gasoline [1849], milk [1880], book matches [1883], dairy products [1925, 2034, 2189], bread [1963, 1997, 2187], bakery products [1970, 2277], and snack foods [2104]. The other class of these cases includes those in which the price-fixed goods or subcontracting services are purchased directly by contractors, which in all probability pass on the higher costs as part of their prices: linoleum installation [1773], fabricated structural steel [1885, 1887], cement installations [1887], plumbing fixtures [1921], plumbing contract- 
ing [1957] maple floors [2034], ready-mix concrete [2035, 2124, 2136], overhead garage doors [2211], and plumbing supplies and services [2243].

Our final inquiry concerns demand elasticity. It will be recalled from part IV that this factor would indicate a low, short-run rate of passing on only if the elasticity of demand were found to be very high. In none of the thirty-eight cases with high or medium directness and high supply elasticity did this unusual demand condition prevail. As shown in the twelfth column of the Table, demand elasticity appears low in the overwhelming majority of cases, though in a few (such as women's swimsuits [1778]) it is medium. Hence, in none of these cases did demand factors suggest that we moderate our tentative conclusion, reached on the basis of other factors, about the likelihood of passing on.

We present no detailed, empirical proof of a high rate of passing on in these cases; that is not the purpose of this exercise. Rather, we argue that by application of economic theory, knowledge of commercial pricing practices, and a very modest amount of information, one can be reasonably certain of a high degree of passing on even in the short run. Thus, a presumption of passing on is plainly warranted in these cases. A party seeking to challenge the presumption ought to bear the burden of presenting explicit, empirical evidence to refute the presumption. Certainly, given the resources and intelligence available to the court, such a determination, at least in these cases, would require very modest judicial effort.

Note also that in the twenty-eight cases in which a very high rate of passing on was highly likely even in the short run, a party could quite easily obtain and present empirical evidence to refute the presumption if, in fact, passing on did not occur. Consider, for example, the pricing response of general contractors to an overcharge imposed by subcontractors [for example, 1773]. Any instance in which a general contractor absorbed the overcharge portion of the subcontractor's bid would immediately appear from the general contractor's working papers used to compute the bid.

In cases in which the analysis leads to an inference that the likelihood of a high rate of passing on in the short run is low, the presumption ought to be that the direct purchaser has borne the costs of the overcharge. This presumption would govern unless evidence were introduced to show that the overcharge was imposed over a period sufficiently long that the direct purchasers (the $R$ firms) had already made long-run adjustments and thus passed on, 
or unless other explicit empirical evidence were introduced which warranted a finding that passing on occurred despite the theoretical basis for assuming that in the short run it would not occur.

The theoretical analysis nonetheless will not provide such a clear picture in some cases-that is, the probability of a high rate of passing on in the short run will appear to be medium, as it did in ten of our cases. In these instances no presumption about passing on in the short run is warranted: the burden of proof remains wherever it was placed at the outset. Any party seeking to prove or disprove short-run passing on must undertake a more particularized evidentiary inquiry.

In part IV(B), we suggested that a complete evidentiary and empirical analysis of passing on would not be unduly difficult, and we emphasized that such an analysis would involve no concepts which were unusual or would present any difficulty to a court. Courts (or litigating parties) might for these reasons prefer to do such a straightforward analysis of actual pricing practice and its consequences in all cases in which final purchasers can be determined instead of using the approach set forth in this section.

We emphasize, nonetheless, that the method of estimating which we have proposed is deeply rooted in empirical and institutional realities. The presumption with which it ends is validated not merely by theory but also by experience. The value of estimating in this way lies in its potential for reducing the time required to determine passing-on issues. The methodology does require the court in some cases to take evidence and make judgments on supply and demand elasticities-unfamiliar concepts for most courts-but it does not require that precise information about these elasticities be known or even knowable. Elasticities become relevant only in those instances in which there is already a very strong basis for inferring a very high rate of passing on. The purpose of the inquiry into elasticities is only to determine whether either of two very unusual conditions prevail-conditions which would be rather easily recognizable.

Let us, then, summarize the results of the demonstration in this section. We have reviewed all of the covert price-fixing cases won by the government in the period from 1960 to 1972. In fifty-seven of those sixty-five cases, all or a large share of the purchases were made by firms or individuals who were not the final purchasers, so that passing on was a possibility in nearly ninety per cent of the cases. In nine of the fifty-seven cases, however, we were unable to specify, on the basis of very limited information, the final purchasers 
as a class, so that we made no attempt to estimate the degree of passing on. Of the remaining forty-eight cases, we estimated, on the basis of directness of costs and elasticity of supply and demand in each case, that the probability of a high rate of passing on in the short run (one year or less, depending on the frequency with which changes in direct costs are reflected in pricing) was high in twentyeight cases, medium in ten cases, and low in ten other cases. In the long run (more than one year, depending on the time needed in the particular industry to make adjustments on account of changes in indirect costs), as we argued in part II, we would expect the rate of passing on to be high in virtually all cases.

\section{Passing On: The Requisites of a Balanced Policy}

The prior parts of this Article lead ultimately to the crucial policy issue: is Illinois Brick sound law or should Congress act to annul that case and establish a more balanced procedure for dealing with passing on? In the sections which follow, we evaluate the implications of our analysis for the issues which are most salient in the Illinois Brick opinion.

\section{A. Judicial Capacity: The Implication of Analysis and Experience}

Three relevant propositions may be derived from the prior parts of this Article: first, when final purchasers can be identified, either by class or individually, it is well within the range of normal judicial inquiry to determine the extent to which an upstream overcharge has been passed on to that class or those individual purchasers; second, at the point in the chain at which it ceases to be possible to identify purchasers even by class, inquiry about passing on should be aborted; and third, it is relatively easy to determine when purchasers can be identified and when they cannot. Given these propositions, doubt that courts can handle passing-on evidence -the concern that Justice White thought the most compelling reason for barring such evidence ${ }^{125}$-simply vanishes.

The Court in Illinois Brick explicitly recognized that some distribution chains are long. ${ }^{126}$ It is also true that some chains are complex-so complex, indeed, as to frustrate efforts to identify final and, at times, intermediate purchasers. The Court, however, without considering chain complexity, erroneously inferred from chain length alone that it is difficult to determine whether passing on has

125 See Illinois Brick Co. v. Illinois, 431 U.S. 720, 731-33 \& 732 n.12 (1977). 126 Id. $740-41$. 
occurred.127 Rigorously considered, these are two separate, if related, problems. One is whether the distribution chain, however long, is sufficiently simple and clear that an overcharge, if passed on, can be traced; the other is whether an overcharge was passed on. Because of chain complexity the first of these problems sometimes presents insolvable difficulties, but the instances in which difficulties are present are readily distinguishable from those in which they are not. The evidence will quickly disclose how far the chain can be followed before any overcharge, if passed on, becomes (if ever it does) an indirect cost of a multiproduct firm. The second processdetermining how far an overcharge is passed down a chain, to the extent the chain itself is discernible-is an entirely separate inquiry and, contrary to the Court's unsupported factual conclusion, presents problems of manageable magnitude.

When final purchasers can be determined individually, it is patently clear that a court can decide whether, and the extent to which, an overcharge has been passed on to those purchasers. It will be recalled from part $\mathrm{V}(\mathrm{A})$ that these cases tend to be construction-contract cases or cases involving long and continuing business relationships, all of which are likely to involve relatively large claims by identifiable final purchasers. Even if it were essential to measure precisely the amount of the overcharge absorbed by each intermediate and final purchaser, the techniques for empirical inquiry are entirely adequate. Indeed, given the routine character of pricing decisions, courts (and lawyers) will typically find tracing an overcharge a more boring than perplexing task. It is, perhaps, a worthy goal to protect courts from tedium, but surely not at the cost of depriving parties injured by a blatant wrong from appropriate redress. With judicial capacity plainly existing, reluctance to exercise that capacity is not an appealing foundation for national policy.

There is, of course, a question whether the advantages achieved by making the inquiry outweigh the costs, but in the cases we are now considering-suits in which a firm must prove both violation an injury-the potential value of redress is considered much as is the value of any other claim in a treble-damage action. There is

127 Id. 741-44. Seemingly, the Court also thought that the only, or at least primary, way to determine the amount of an overcharge is by measuring elasticities of demand, a task it thought difficult. Id. 742. As we have shown, direct empirical evidence may be used, and theoretical estimates depend not on measuring elasticities of demand but on looking at a variety of readily determinable factors (including, in some instances, whether elasticities of supply or demand have certain extreme, readily identifiable characteristics). 
no reason to suppose these cases less worthy of judicial attention than any others.

Moreover, it is easy to overestimate both the tedium and the cost that would be involved in a passing-on investigation on behalf of identified final purchasers. As shown in part $V(B)$, reliable, simplifying presumptions can be predicated upon a rather limited inquiry into industry structure and practice; further, these presumptions would do substantial justice in most cases and could be rebutted when wrong. Also, whether or not presumptions were used, a court in its discretion could keep the passing-on inquiry within reasonable bounds during the pretrial and trial. Even if there are, say, ten distribution levels, the factual issue at each is simple. If judicial involvement begins, and the adversary positions regarding passing on are particularized, at an early stage, a reasonable discovery program can be developed and administered which will assure that passing-on issues, as well as others, are dealt with efficiently. ${ }^{128}$ Judicial experience during the years between Hanover Shoe ${ }^{129}$ and Illinois Brick fully confirms this conclusion. In numerous cases, both trial and appeals courts, with the specific factual content of a particular case before them, have expressed confidence in the capacity of a trial court to trace the overcharge..$^{130}$ In some, the courts thought the evidence of a pass on to be unmistakably clear. ${ }^{131}$

Simplifying devices should, of course, be used. ${ }^{132}$ Often, claims of several buyers at the same and different distribution levels will

128 See generally Natronal Commission for the Review of AnttrRust LaW and Procedures, Report to the President and the Attorney General $\$ 1$, at 17-23 (1979) [hereinafter cited as REview of ANTIIRUsr].

129392 U.S. 481 (1968).

130 E.g., West Va. v. Chas. Pfizer \& Co., 440 F.2d 1079, 1086-88 (2d Cir.), cert. denied, 404 U.S. 871 (1971); Armco Steel Corp. v. North Dakota, 376 F.2d 206, 210-11 (8th Cir. 1967); In re Sugar Indus. Antitrust Litig., 73 F.R.D. 322, 350-55 (E.D. Pa. 1976); Bray v. Safeway Stores, Inc., 392 F. Supp. 851, 862-65 (N.D. Cal. 1975); Midway Enterprises, Inc. v. Petroleum Marketing Corp., 375 F. Supp. 1339, 1344-45 (D. Md. 1974); cf. In re Master Key Antitrust Litig., [1973-2] Trade Cas. $\{74,680$ (D. Conn. 1973), appeal dismissed, 528 F.2d 5 (2d Cir. 1975). There are also numerous other cases ruling that indirect purchasers might pursue an overcharge cause of action, thus implicitly endorsing the view that trial courts could handle the factual issues. These cases are collected in 1978 House REPORT, supra note 4, at 47-53.

131 West Va. v. Chas. Pfizer \& Co., 440 F.2d 1079 (2d Cir.), cert. denied, 404 U.S. 871 (1971) (drugs sold by manufacturer to wholesalers, then marked up and sold to retailers, then marked up and sold to consumers); Armco Steel Corp. v. North Dakota, 376 F.2d 206 (8th Cir. 1967) (steel plate sold to contractors and marked up).

132 See, e.g., Carnivale Bag Co. v. Slide-Rite Mfg. Corp., 395 F. Supp. 287, 292 (S.D.N.Y. 1975) (enumerating procedural devices available to aid consolidation of all suits arising from the same claim). 
be consolidated.133 When cases have been consolidated, courts can try the issue of liability and the total amount of the overcharge first, and leave passing-on and allocation questions to be tried only if liability and the fact of an overcharge are established. When litigated, allocation issues need not be particularly difficult. Allocation among different distribution levels is susceptible to both theoretical and empirical investigation; allocation among purchasers at any one level can be simplified by presuming that the sum allocable to that level is itself allocable among particular buyers in a manner proportional to their total purchases. Fair, sensible presumptions of this character which save time and resources while preserving substantial justice, are appropriate judicial responses to complexity. ${ }^{134}$

Note, too, that cases in which individual final purchasers are identifiable are likely to be those in which either a class or parens patriae action would be appropriate. Illinois Brick itself typifies one pattern. The State of Illinois and over seven hundred of its state and local agencies alleged that concrete-block manufacturers had cartelized to impose an overcharge aggregating $\$ 3$ million on block sold to subcontractors doing work for contractors on public buildings. In such a situation, the passing-on issues are not particularly difficult, and it is likely that the claims of all final purchasers can be heard in a single suit. This may not always be possible, however. In some instances a single, final purchaser with a large individual claim might be motivated to sue alone or to opt out of any pending class action, but, if several individual actions were initiated, they could be consolidated for pretrial and eventually tried together. ${ }^{135}$

Litigation problems are different when the class of final purchasers is known but, because numbers are large and individual

133 Actions on behalf of consumers can be brought as parens patriae actions under Title III of the Hart-Scott-Rodino Antitrust Improvements (Hart-Scott-Rodino) Act, 15 U.S.C. $\$ \$ 15 \mathrm{C}-15 \mathrm{H}$ (1976), or, in some circumstances, as class actions under rule 23 of the Federal Rules of Civil Procedure. See L. Sulcrvas, supra note 2 , at $\$ 249$. Suits by individual or class claimants at the same or different levels can be consolidated for pretrial or trial when in the same district, FED. $R$. Crv. P. 42, transferred on motion from one district to another to facilitate consolidation, 28 U.S.C. $\$ 1404$ (1976), or transferred and consolidated for pretrial at the initiative of the Judicial Panel on Multidistrict Litigation, id. $\$ 1407$.

134 Although legislation is hardly necessary to facilitate such case management by the courts in the interest of efficiency, the bill introduced by Representatives Rodino, Sieberling, and Hughes on February 8, 1979, to overrule Illinois Brick would specifically provide such power in a new section $4 \mathrm{I}$ of the Clayton Act. H.R. 2060, 96th Cong., Ist Sess. 1979). See generally ReVIEW of AnIrTRusT, supra note 128.

135 See note 133 supra \& accompanying text. 
transactions small and nonrecurrent, it is difficult or costly to identify individual final purchasers. In these circumstances, individual actions by single purchasers will not occur. Under present law, the only means for bringing suits on behalf of these final purchasers are consumer class actions, the utility of which has been greatly reduced by restrictive judicial interpretation, ${ }^{136}$ and parens patriae actions. Moreover, even when an action is brought to a successful conclusion on behalf of such purchasers, very few of them will claim the proceeds: some form of cy pres remedy is essential.

We do not challenge the soundness of Eisen $v$. Carlisle b Jacquelin, ${ }^{137}$ which limits the situations in which consumer class actions are feasible. Whatever one might conclude about the utility, fairness, and feasibility of consumer class actions, there is no doubt that Congress, aware of (and perhaps sharing) judicial reluctance to countenance such actions, has made a deliberate choice to authorize and encourage parens patriae actions to vindicate consumer interests in these kinds of situations. ${ }^{138}$ Neither can there be doubt that Illinois Brick frustrates that congressional choice. Given that overcharges can be traced with ease in a large portion of cases (a fact the Court has failed to perceive), and given the intent of Congress in enacting the Hart-Scott-Rodino Act, the argument is compelling that parens patriae suits are the appropriate way to protect the public when vast overcharges have been thinly spread among a large class of consumers.

Such suits provide all or most of the advantages of consumer class actions yet avoid all or most of the deficiencies which make the latter problematical. Like consumer class actions, they are an efficient means of aggregating large numbers of small overcharge claims and could be utilized not merely to require wrongdoers to disgorge, but also to develop cy pres remedies that substantially reimburse individuals actually injured. Unlike consumer class actions, however, parens patriae actions are fueled not by the incentive of large legal fees but by the incentive of state attorneys general to enhance the public welfare. ${ }^{138 a}$

136 See L. SuldrvaN, supra note 2, at $\$ 249$ (a).

137417 U.S. 156 (1974).

138 The legislative history of Title III of the Hart-Scott-Rodino Act convinces us that Congress was trying to create a more effective remedy for injured consumers. See, e.g., H.R. Rep. No. 94-499, 94th Cong., 1st Sess. 3-8 (1975) (Antitrust Parens Patriae Act).

138a Landes and Posner, who stand aloof on the frictionless plane of price theory when arguing about the incentives of direct purchasers to seek windfalls, wander wide-eyed into the institutional underbrush in their eagerness to discredit the potential of parens patriae suits to deter violations. See Landes \& Posner, supra note $61 \mathrm{la}$, at $612-13$. Whereas they portray corporate managers as rational profitmaximizers, without a shred of evidence they freely fantasize that state attorneys 
Yet, even if one concluded that no action of any kind could vindicate the interests of final purchasers when these purchasers can be identified only by class, the argument for legislation to overrule Illinois Brick would still be forceful. There would remain a large number of cases in which passing on occurred, in which the victims, the final purchasers, were readily identifiable as individuals, and in which the overcharge passed on to these purchasers would be both substantial in amount and easily traced. The conclusion that other, quite different cases might present litigation problems lends no support to a rule which deprives affected purchasers in such relatively easy cases of all possible redress for serious losses.

There is a related position-though it has more to do with judicial custom than capacity-sometimes pressed to bolster the claim that courts lack the ability to trace an overcharge: it is the rather mystical assertion, originally attributable to that realist, Justice Holmes, that courts terminate analyses after "the first step." ${ }_{139}$ The truth is that, throughout the history of judicial inquiry, courts have both cut inquiry short and pressed it farther, depending upon which course was most responsive to prevailing perceptions of policy. If the common-law tradition has bearing, a useful distinction may be perceived between tort and contract concepts. With limited exceptions, courts tend to limit liability for breach of contract to parties that participated with the defendant in the transaction but to extend liability for tort as far as causalities can be efficiently traced. Cartelization, after all, is a blatant, deliberate tort with potential for financial harm as great as or greater than many other business torts. From the perspective of judicial tradition, the argument for tracing an overcharge through the distribution chain from, for example, a manufacturer to ultimate consumers, is quite as strong as that for holding the same manufacturer liable to the same consumers for a product defect. Indeed, if the law were to make distinctions between these cases, it might more logically treat the cartelist-or monopolist-who knowingly imposes a tortious overcharge more severely than it does the hapless manufacturer which is well-intentioned but wanting in care.

\section{B. Duplicative Liability and Compensatory Justice}

The concept of "duplicative liability" requires definition. The majority opinion in Illinois Brick seems to fear that if down-chain general will bring "headline-grabbing, scapegoat-seeking lawsuits against politically unpopular corporations." Id. 613.

139 See Southern Pac. Co. v. Darnell-Taenzer Lumber Co., 245 U.S. 531, 533 (1918). 
plaintiffs are permitted to recover, violators might be forced to disgorge more than the statutory damages of three times the total amount of the overcharge. ${ }^{140}$ Such a result might accurately be called "excessive liability," and we shall use this designation when we refer to it.

As a practical matter, to allow down-chain plaintiffs to sue would create no risk of excessive liability. An overcharge is first paid by a plurality of direct purchasers-that is, by all of the initial customers of the monopolized or cartelized industry. Each of these firms then sells to its own customers, multiplying the aggregate size of the buyer group, and so on at each succeeding distribution stage. An aggregate recovery equal even to the full amount of the overcharge trebled could result only if suits were successsfully brought on behalf of all direct purchasers or, if any one direct purchaser did not recover, by all subsequent purchasers in the chain beginning with any nonrecovering direct purchaser. Has any cartel or monopolist ever been forced to account so comprehensively for its overcharge? The question itself underscores the triviality of the risk. Yet excessive liability implies a recovery even larger than this-that is, larger than the maximum recovery that the statute authorizes. Not only would the full overcharge imposed on all direct purchasers have to be recovered and trebled, but also total recoveries in at least one chain would have to exceed three times the amount of the overcharge to the direct purchaser in that chain. An unbiased observer would hardly place this risk very high on any agenda of national policy concerns.

The risk of duplicative liability, then, if it is to be taken seriously at all, must be taken to imply a more limited risk-that in one or more chains beginning with a direct purchaser, there may be successful suits by purchasers at two or more vertical levels which are duplicative in that they are predicated, at least in part, upon inconsistent findings about the extent of passing on. We shall use the designation "duplicative liability," therefore, to refer to this occurrence.

Picture, for example, a cartelist, $M$, that imposes an overcharge of ten dollars on each of one hundred resellers, $R$, each of which resell to ten consumers, $C$. Now assume that one of the resellers sues and recovers three times ten dollars (on the theory that it paid the full overcharge) and that a down-chain consumer also sues and recovers three times one dollar (on the theory that the overcharge was fully passed on, one tenth to each of the ten consumers). This state 
of facts would involve no excessive liability as we have defined that term. Excessive liability would occur if all resellers sued and recovered three times ten and, in addition, one or more down-chain consumers sued and recovered three times one. On the other hand, a recovery of three times ten by even one primary purchaser followed by a recovery of three times one by a consumer lower in that primary purchaser's chain would involve duplicative liability, as we have defined it, inasmuch as the first recovery presupposes no passing on and the second presupposes $100 \%$ passing on.

One might argue that duplicative, as distinguished from excessive, liability ought not concern us, that lack of symmetry is more an aesthetic than a policy deficiency. We reject that position, however. A satisfactory system of justice would avoid the windfall resulting from overlapping liabilities, even though the violator has not yet disgorged an amount approaching the total overcharge. We do not, however, find in this demand of compensatory justice any warrant for selecting primary purchasers as the presumptive victims of all overcharges-the ones to whom the cause of action should alone be assigned. (Indeed, because a high rate of passing on is the rule, not the exception, any group to be chosen presumptively ought to consist of the last identifiable purchasers in the chain, not the first.)

Our conclusion, rather, is that duplicative liability, though a concern, can be effectively avoided through adjudication. Because tracing an overcharge is far simpler than the Court has supposed, the risk of inconsistent findings is correspondingly smaller. The Court has spoken as though the risk of inconsistent decisions about passing on is peculiarly high because of factual complexity. In many instances, the opposite will be true: evidence will be very clear, and sequential trials, even if independently conducted, would likely lead to consistent results.

Some risk of inconsistency does, of course, remain, but it is no greater than that inevitably incurred when common questions are presented in any series of litigated cases. The risk can be handled by the customary methods for reducing inconsistent findings.

Such means are numerous. The four-year limitation statute will give protection in some cases. ${ }^{141}$ If the first suit is at all delayed, it may soon become too late for competing claimants to sue. This protection will not always be available, however. Of greater significance, then, are the numerous devices which can bring potentially inconsistent passing-on claims into a single proceeding

14115 U.S.C. $\$ 15(b)(1976)$. 
which will foreclose inconsistent results. Transfer and consolidation for pretrial at the direction of the Judicial Panel on Multidistrict Litigation will often be available. ${ }^{142}$ A consolidated trial involving all or a representative group of plaintiffs may be appropriate. ${ }^{143}$ Courts and parties may also make use of interpleader. ${ }^{144}$ Moreover, in appropriate cases, a court might require an overcharge award to be held in escrow pending the outcome of other suits in progress or about to be started..$^{145}$ Lastly, res judicata and collateral estoppel will in many circumstances bind a party with respect to liability, the total size of the overcharge, or the amount of the overcharge allocable at different levels. ${ }^{140}$

During the period between Hanover Shoe and Illinois Brick, courts successfully used some of these devices. ${ }^{147}$ As far as we are aware, there is not a single credible claim that any defendant was ever held to duplicative liability. The risk, then, is not merely one that can be adequately handled case by case, it is one that judicial experience shows to be easily managed.

There is, furthermore, an equally important concern about compensatory justice which Illinois Brick ignores. Granting the overcharge cause of action solely to direct purchasers would achieve a

14228 U.S.C. $\$ 1407$ (a) (1976).

143 Id. $\$ 1407(\mathrm{~h})$. Section 4 of S. 300 , the pending bill to overrule Illinois Brick, would amend this section to permit the Judicial Panel on Multidistrict Litigation to consolidate any related civil actions arising under the Clayton Act, including suits by direct and indirect purchasers, for trial as well as pretrial. See 1979 SENATE REPORT, supta note 18, pt. 2.

14428 U.S.C. $\$ 1335$ (1976); FED. R. Crv. P. 22(1). As the Court noted in Illinois Brick, although a defendant for its own reasons may neglect to interplead competing claimants, they may be joined (individually or as a class) as necessary, though not indispensable, parties. 431 U.S. at 738-40. See Comment, Standing to Sue in Antitrust Cases: The Offensive Use of Passing On, 123 U. PA. L. Rev. 976, 997-98 (1975).

145 There seems little doubt that a court, under its general authority to administer federal statutes in a manner doing substantial justice, could on motion after verdict order an appropriate remittitur, even in a jury case, if duplicative recovery rendered a verdict excessive. See Dimick v. Schiedt, 293 U.S. 474, 476-85 (1934), and cases cited therein. Although a decision to delay judgment or execution of verdict pending the outcome of a case not yet concluded is more extreme in form, it would be predicated upon essentially the same theory. Doubt about judicial power to use the escrow device could be resolved by appropriate provision in the legislation to overrule Illinois Brick. A recent report states that a bill containing such a provision is under consideration in the House Judiciary Committee. See New House Proposals Emerge to Reverse Illinois Brick, [1979] 926 ANTITRust \& Trade Reg. Rep. (BNA) A-7 to -8.

146 Cf. Parklane Hosiery Co. v. Shore, 99 S. Ct. 645 (1979) (allowing offensive use of collateral estoppel under certain circumstances).

147 See cases cited in note 130 supra. 
just result if, but only if, direct purchasers were the ones actually bearing the burden of the overcharge. To the extent that direct purchasers pass the overcharge on to down-chain buyers, it is blatantly unfair to deny all redress to those down-chain purchasers. Supporters of Illinois Brick recognize this dilemma and try to avoid it by suggesting that much of the overcharge is ultimately borne by the direct purchaser, ${ }^{148}$ but earlier parts of this Article show that this response cannot withstand examination. Theoretical economics and practical information about pricing practices suggest that even in the short run massive passing on is the rule and that in the long run it is well nigh inevitable.

When passing on is asserted affirmatively by a down-chain purchaser, the claimant ought to bear the burden either of proving the overcharge empirically or of proving the facts upon which a presumption of passing on can be based. When the plaintiff can prove that it is a final purchaser, the further process of proving the overcharge will be straightforward enough. In some instances, however, the distribution chain will become complex and obscure. Especially when the overcharge is on a product the price of which is classified as an indirect cost, the process of tracing may become extremely difficult and, at some point in the chain, uncertain or even speculative in outcome.

When difficulty reaches this stage, inquiry should stop: buyers at or below these points in any chain should be denied the right to try to show that passing on took place. Under the rubric of standing to sue, many courts prior to Illinois Brick handled the problem presented by obscure chains in essentially this way; standing to assert a claim based on passing on was allowed, as far down the chain as the impact was discernible, ${ }^{149}$ and, at the point at which tracing became speculative, standing was denied.150

The ideal of compensatory justice, then, is simply not within the reach of the judicial machinery in the instances in which passing on may or may not have occurred, but in which final purchasers cannot be manageably identified either as individuals or as a class.

148 E.g., 1978 Senate Hearings, supra note 15, pt. 2, at 315 (statement of Dorsey D. Ellis, Jr.).

149 E.g., In re Western Liquid Asphalt Cases, 487 F.2d 191 (9th Cir. 1973), cert. denied, 415 U.S. 919 (1974). For an interesting discussion of existing doctrine and its applicability in passing-on contexts, see Berger \& Bernstein, supra note 5 .

150 E.g., Mangano v. American Radiator \& Standard Sanitary Corp., 438 F.2d 1187 (3d Cir. 1971). 
When the defendant can prove that the direct purchaser did pass on, and when those ultimately injured cannot be identified, we must choose among allowing the cartel or monopoly to retain the overcharge, assigning the overcharge to the primary purchaser without inquiry into whether or not passing on occurred, or assigning it to the lowest identifiable purchaser on the chain, provided that the purchaser can prove that the overcharge was passed to its level.

Our method of inquiry, described in part IV(A), implicitly rejects choosing the first of these alternatives. We now make that rejection explicit. To allow the violator to show passing on defensively when there is no serious risk of duplicative liability would be to grant a windfall to the violator-an aggravated violation of the ideal of compensatory justice and a gratuitous sacrifice of the deterrent effect of the treble-damage remedy. To allow primary or subsequent-but still intermediate-purchasers to recover, even though further passing on is suspected might or might not sacrifice compensatory justice, but it would be a less serious imposition on compensatory justice than allowing the wrongdoer to keep his gain, and the deterrent effect of the treble-damage remedy would remain intact.

Our choice between the direct purchaser and intermediate down-chain purchasers to whom the overcharge can be traced is to grant the remedy to the latter. The choice is between a firm that both paid and passed on an overcharge, and a firm that paid and may or may not have passed it on. The principle of compensatory justice suggests at least a weak preference for the latter and, for reasons explained in the next section, we think that choice will in many circumstances have the greatest deterrent impact. Instead of following the Holmesian dictum, which advocates stopping at the first step, we think courts should be ready to trace the overcharge as far as they reasonably can. For these reasons, legislation to overrule Illinois Brick should make clear that when a primary (or midchain) purchaser sues for an overcharge, the defense that the plaintiff passed on should be available only in instances presenting a real risk of duplicative liability. If plaintiff establishes that possible plaintiffs farther down the chain are barred by the statute of limitations or have been served as necessary parties, yet have not appeared and asserted a claim or otherwise can be shown not to threaten duplicative liability, the reason for allowing the passing-on defense is eliminated. In such circumstances the goal of deterrence and the lack of any threat to compensatory justice should result in rejection of a passing-on defense. 


\section{Passing On and the Deterrence of Violations}

The majority in Illinois Brick concluded that assigning the cause of action for an overcharge solely to the direct purchaser would provide greater deterrence than would granting relief to purchasers (even when down-chain) that actually suffered the loss. ${ }^{151}$ The majority thus resolved what might be termed an issue of legislative fact-an issue upon which it had little, if any, reliable empirical information. ${ }^{152}$

Direct purchasers have often sued in the past and sometimes recovered large damages. ${ }^{153}$ One must infer, moreover, that these purchasers are encouraged to sue by Illinois Brick and would, to an indeterminate extent, be discouraged from suing by a rule which requires them not only to prove the offense and the overcharge but also to defend against efforts by defendant or other claimants to show that not all of the overcharge stayed in their hands. Neither of these observations, however, warrants the conclusion that Illinois Brick aids deterrence.

Information about the number of direct purchasers that have sued in the past tells us nothing about their importance or significance as private attorneys general unless we also know (or make assumptions about) the total number of overcharges to be found in the economy and, thus, about the percentage of all violators that are sued by direct purchasers. Like the Court, we are without data on this matter, and without data, claims either way about the effectiveness of primary purchasers as antitrust enforcers pass wide

151 Thus, the majority read Hanover Shoe as "resting on the judgment that the antitrust laws will be more effectively enforced by concentrating the full recovery for the overcharge in the direct purchasers" and, in part for this reason, declined to permit down-chain purchasers to prove passing-on. 431 U.S. at 735.

152 It is unfortunate that there is so little accessible data regarding the relationship between government and private antitrust actions. Such information would be valuable not only for the present needs-evaluating the deterrent effects of alternative policies-but would be of enormous value in the allocation of resources within antitrust enforcement agencies. In a proposal for a research project which would collect and analyze such data, M. Block, H. Demmert, \& F. Nold supra note 56, at 35 , present preliminary evidence showing that private actions are surprisingly infrequent when the government has already won a case against conspirators. Of the 49 price-fixing cases won (by verdict or nolo contendere plea) by the government in the period 1971 to 1976 , private actions against the conspirators have been brought in only 18 cases. In its most immediate bearing on the deterrent effects of Illinois Brick, this evidence suggests that even when presented with the facts of a successful government action, which can be introduced in trial by private plaintiff, direct purchasers-who would almost certainly learn of the violation through their trade publications-often lack incentive to sue.

153 Cases are collected in Handler, Changing Trends in Antitrust Doctrines: An Unprecedented Supreme Court Term-1977, 77 CoLuM. L. REv. 979, 1000-01 (1977). 
of the mark. ${ }^{154}$ Moreover, were it assumed that an inference can be drawn from the existence of past direct-purchaser suits, the plausible inference would be that these purchasers are little deterred by the risk of competing claimants farther down the chain. In suits started before Illinois Brick, direct purchasers faced that risk but sued anyway.

By contrast, the contention that legislative overruling of Illinois Brick would inevitably deter direct-purchaser suits to some extent is supported by the conventional marginal analysis of theoretical economics. ${ }^{155}$ It is the net effect of Illinois Brick that is important, however, and there is reason to believe that legislative reversal would have a relatively small deterrent effect on suits by direct purchasers and a much larger and more significant effect in encouraging suits on behalf of down-chain purchasers.

The deterrent effect of overruling Illinois Brick on suits by direct purchasers would not be a smooth, continuous function, so that each marginal addition to the difficulty of the litigation would deter some marginal number of potential direct-purchaser plaintiffs. Common sense and experience both suggest that a party that is likely to litigate in the hope of recovering, say, a million-dollar overcharge, is likely to do so within a fairly wide range of predictions or expectations about the risk and difficulties of the lawsuit.

One concern of any potential plaintiff will be the anticipated cost of the suit. At the beginning of any complex case, this is ex-

154 Landes and Posner claim to present evidence supporting their argument that direct purchasers are the most vigorous enforcers. The only data they offer, Landes \& Posner, supra note $61 \mathrm{a}$, at 629 (Table 1), show that the ratio of private antitrust actions to private civil actions and the ratio of private antitrust actions to government antitrust actions have both increased during the period 1960-1978. Statistical machinations notwithstanding, Landes and Posner fail to substantiate their claim because their data do not discriminate between actions brought by direct purchasers and those brought by indirect purchasers, or even between overcharge actions and actions by competitors, franchisees, or others making antitrust claims wholly unrelated to the passing-on problem.

Impression-supporting information, such as that collected by Professor Handler, supra note 153 , cuts both ways. Indirect purchasers were plaintiffs in almost two-thirds of all private treble-damage actions brought since 1960 , and were the only plaintiffs in about 25\% of all cases. Antitrust Enforcement Act of 1979: Hearings on S.300 Before the Senate Comm. on the Judiciary, 96th Cong., 1st Sess. 12 (1979); 1979 Senate Report, supra note 19, at 16. Moreover, there are some significant overcharge cases in which primary purchasers were discernibly less aggressive enforcers than downstream buyers. E.g., West Va. v. Chas. Pfizer \& Co., 440 F.2d 1079 (2d Cir.), cert. denied, 404 U.S. 871 (1971). Given that the recent parens patriae legislation opens up significant new potential for enforcement by states on behalf of consumers, there seems little doubt that the vigor and frequency of enforcement by (and on behalf of) downstream buyers will increase.

155 But see 1978 House Hearings, supra note 15, at 192-95 (statement of Richard A. Posner). 
tremely difficult to estimate beyond saying that the costs will be high. It is unlikely that the presence or absence of a passing-on defense will be a key factor in a decision to sue. The gestalt concern is whether the estimated potential recovery is large enough to pursue through complex litigation. Anyone who considers himself a potential plaintiff at all is likely to remain one within a fairly wide variation of estimates about the likely size of the recovery. A direct purchaser that has suffered substantial losses is not likely to give up at the outset upon learning that recovery will be limited to three times those injuries and will not include injuries suffered by others. Whether the probability of success makes the effort and expense worthwhile involves numerous complex questions concerning liability and damage calculation. It does not seem likely that the addition of a passing-on issue will often prove critical in the calculations of a potential plaintiff with real and substantial losses.

Conceivably, some potential plaintiffs will give up solely because of the passing-on defense, but these may not be particularly important ones. They are likely to be those that know that they have in fact passed on all of the overcharge and that, if they sued, would be doing so as bounty hunters seeking a windfall. Wholesalers or retailers in some of the antibiotic cases are, perhaps, pertinent examples. ${ }^{156} \quad$ Few such purchasers sued before Illinois Brick and experience suggests that those who do sue are likely to be "tag along" plaintiffs seeking a windfall settlement. It is possible that the Illinois Brick result will encourage more such direct purchasers to sue, but that expectation does not necessarily make Illinois Brick more attractive. Potential plaintiffs without real injury are seldom likely to be the only (or even the most likely) plaintiffs unless the operative rule of law precludes suit by parties actually injured.

Remember that the deterrent effect of Illinois Brick on suits by down-chain purchasers is absolute: given Illinois Brick, none of them will sue. Legislation which overrules that case would therefore likely encourage more overcharge enforcement cases than it would discourage. There are situations in which granting the cause of action solely to direct purchasers effectively forecloses any private suit. Often, direct purchasers pass on all or substantially all of the overcharge. This will be especially so in the cases which are socially more harmful-those in which the monopoly or cartel is well entrenched and direct and other purchasers have made longterm adjustments. If the ongoing relationship between the direct

158 See, e.g., West Va. v. Chas. Pfizer \& Co., 440 F.2d 1079, (2d Cir.), cert. denied, 404 U.S. 871 (1971). 
purchaser and the potential defendant has any value to the direct purchaser (and often it will have), the direct purchaser will to that extent be deterred from suing. (Indeed, even in cases in which the direct purchaser absorbs a significant part of the overcharge, it may often be deterred by the risk of being cut off entirely.) It is true that some direct purchasers that suffered little or no real loss -for example, wholesalers in the antibiotic cases ${ }^{157}$-have brought suit in the past, but this does not diminish the force of our concern. The instances in which direct purchasers do sue tend to be those in which the cartelized product is peripheral rather than central to the direct purchasers' business needs, and in which the direct purchaser deals with several sellers at the cartelized level. Then, the direct purchaser is likely to have convenient alternative ways to. continue to meet its need for supplies: it can withstand disruption of its relationship with the violator. ${ }^{158}$ Many direct purchasers, however, are in long-term, ongoing supply relationships with a single firm (or a few) and are extremely dependent upon supplier continuity and goodwill. An automobile or television dealer serves as an example. Such a direct purchaser is highly unlikely to sue its supplier unless the relationship has been independently disrupted. ${ }^{158 a}$ In numerous instances, then, if down-chain purchasers have no cause of action, no suit is likely to be brought.

Direct purchasers do have one advantage as potential enforcers: they are closer to the violation and thus may be in a better position to be aware of it. ${ }^{159}$ Yet, there are limits to the significance

$157 \mathrm{Id}$.

158 Even in these situations direct purchasers may well be deterred. For example, if $A$, a distributor or wholesaler, brings an antitrust complaint in an effort to stop an antitrust violation by $B$, a manufacturer of one product in which $A$ deals, $A$ may find that $C, D$, and $E$, suppliers of other products in which $A$ deals, begin to look for alternative distribution outlets.

158a Landes and Posner claim that "the idea that purchasers are bashful about suing their suppliers is today unrealistic, almost quaint," Landes \& Posner, supra note $61 \mathrm{a}$, at 614 , but citing evidence that direct purchasers bring suits does not substantiate that claim. Because the total number of violations is unknown, there may be many cases in which direct purchasers do not bring actions against violators. Managers do not typically regard disruptions in supply as costless-they recognize that long-term supply relationships and business reputation have significant economic value not to be frittered away on antitrust actions unless the potential damage award is substantial. Moreover, the Landes-Posner analysis assumes that potential plaintiffs will treat every dollar of profit identically, whether earned by selling their products, recovering demonstrable losses (that is, monopoly overcharges not passed on), or windfall gains (that is, recovery of monopoly overcharges which had been passed on). We refuse to accept this characterization of managerial mentality in American society.

Posner).

1591978 House Hearings, supra note 15, at 193 (statement of Richard A. 
of propinquity. If the overcharge item represents a relatively small part of the direct purchaser's total cost, that purchaser's sensitivity may well be quite low and if it represents a very large part of cost, a dependency relationship is likely to dampen enthusiasm for a suit. Moreover, if the cartel or monopoly has been operating very long, direct purchasers will have made long-run adjustments (involving reduced capital investment) and will be earning normal returns (on the smaller capital that remains). Also, if Illinois Brick is overruled, a direct purchaser suffering from a violation but deterred from bringing suit, has alternative recourse: it can notify the Department of Justice or a state attorney general, or it can gossip to down-chain purchasers which, not being under dependency constraints, may sue. Illinois Brick forecloses the latter response. ${ }^{160}$

In any event, judicial experience during the years before Illinois Brick suggests that down-chain purchasers do identify violations and that, before being stifled by that case, were becoming increasingly vigilant as private attorneys general. ${ }^{101}$ In many important cases, these buyers played a significant role. ${ }^{162}$ Furthermore, cutting off down-chain purchasers frustrates a significant movement in antitrust enforcement which has been growing for some time and which Congress, in the Hart-Scott-Rodino Act, ${ }^{163}$ sought to foster and encourage-suits on behalf of the states and their subdivisions as down-the-line purchasers and, in parens patriae actions, on behalf of state residents as ultimate consumers. The increasing skill and sophistication of state attorneys general in antitrust is one of the

160 If the fact that information may be accessible to direct purchasers makes necessary a bounty to direct purchasers, there are more selective ways to grant one than by offering three times the overcharge, as does the Illinois Brick rule. Congress could legislate to provide an appropriate bounty for the provision to the Department of Justice of information leading to successful criminal or civil proceedings against the violator. This approach would encourage any party with information to report it and would not deprive any injured party of incentive to sue. Cf. I.R.C. $\$ 7623$; Treas. Reg. $\$ 301.7623$ (1959) (providing for payments to those who inform about Internal Revenue Code violations).

161 See note 154 supra.

102 Illinois v. Ampress Brick Co., 536 F.2d 1163 (7th Cir. 1976); In re Western Liquid Asphalt Cases, 487 F.2d 191 (9th Cir. 1973), cert. denied, 415 U.S. 919 (1974); Armco Steel Corp. v. North Dakota, 376 F.2d 206, 210-11 (8th Cir. 1967); South Carolina Council of Milk Producers, Inc. v. Newton, 360 F.2d 414 (4th Cir.), cert. denied, 385 U.S. 934 (1966); In re Plywood Antitrust Litig., 76 F.R.D. 570 (E.D. La. 1976); In re Master Key Antitrust Litig., [1973-2] Trade Cas. I 74,680 (D. Conn. 1973), appeal dismissed, 528 F.2d 5 (2d Cir. 1975). We are expressing here an impressionistic view. The incomplete data are no more logically compelling on our side of the argument than they are on Professor Handler's. See notes 153 \& 154 supra.

16315 U.S.C. $\$ \S 15 \mathrm{C}-15 \mathrm{H}(1976)$. 
most hopeful signs for the free-enterprise system. ${ }^{164}$ Illinois Brick does more than reduce state enforcement of the federal law: it also discourages states from refining and vigorously enforcing their own antitrust laws and thus destroys the hope that, as they become more aware of the advantages of free-market competition, they will consider the potential advantages of deregulation at the state level.

To summarize, if the law is serious about deterring monopoly pricing, then it is surely counterproductive to designate as the only possible private attorney general the purchaser likely to have the least incentive to sue and the greatest incentive to accept the status quo. Yet, Illinois Brick does precisely that.

\section{ConcLusron}

Our analysis uncovers the misapprehensions that underlie the Illinois Brick decision and brings into focus several of the deficiencies in the policy established by that decision. There is simply no credible argument that courts cannot handle passing-on issues. Clearly, they can. When they fail to do so, they sacrifice the desideratum of compensatory justice. Nor is there any credible basis for concluding that antitrust enforcement is invigorated by the rule of Illinois Brick: more likely its effect is quite the opposite. Congress, therefore, should pass legislation overruling Illinois Brick in the interest of deterring cartelization and monopolization and compensating the actual victims of these offenses.

164 See, e.g., 1978 House Hearings, supra note 15, at 36-43 (statement of Bruce E. Babbitt). 


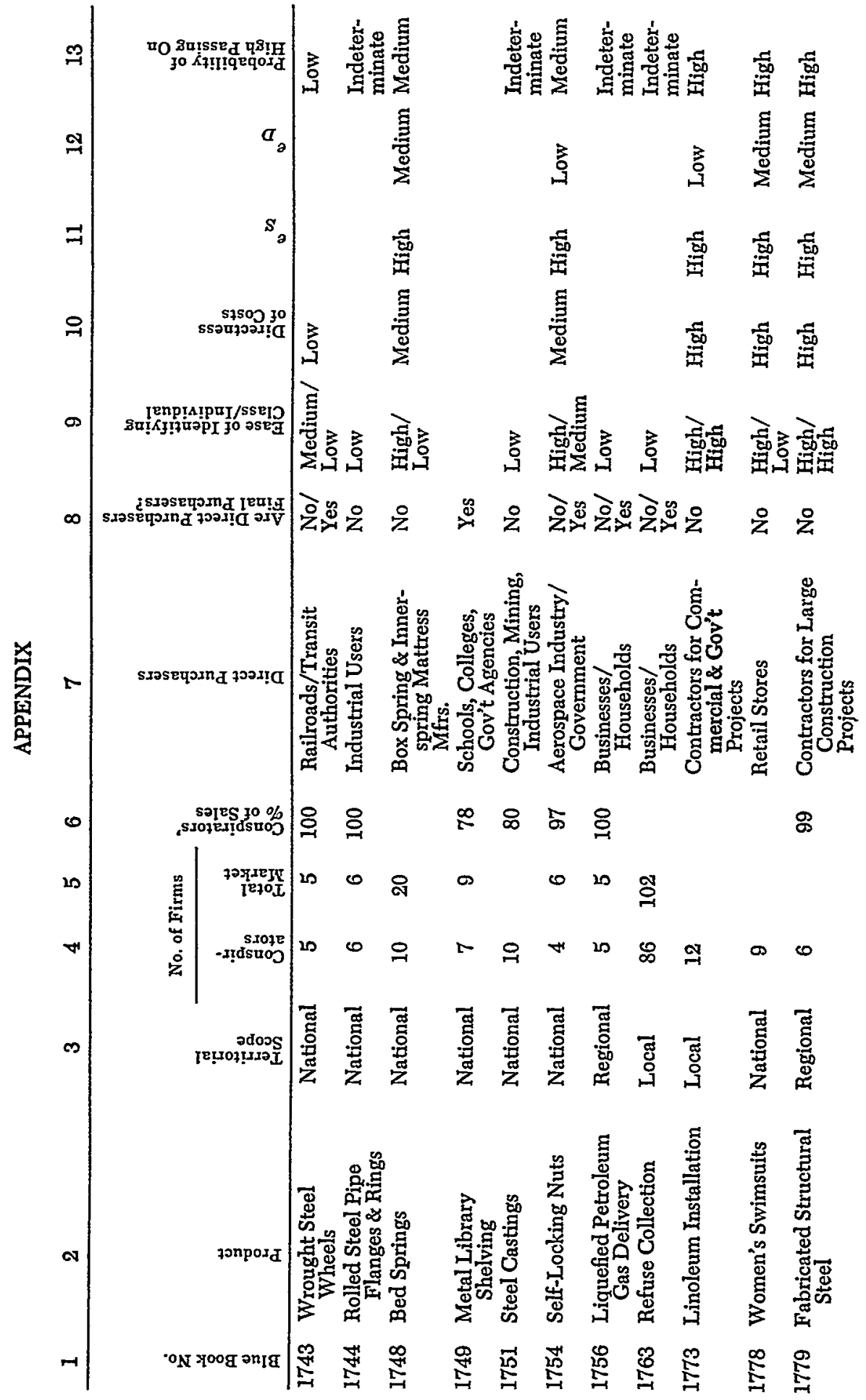




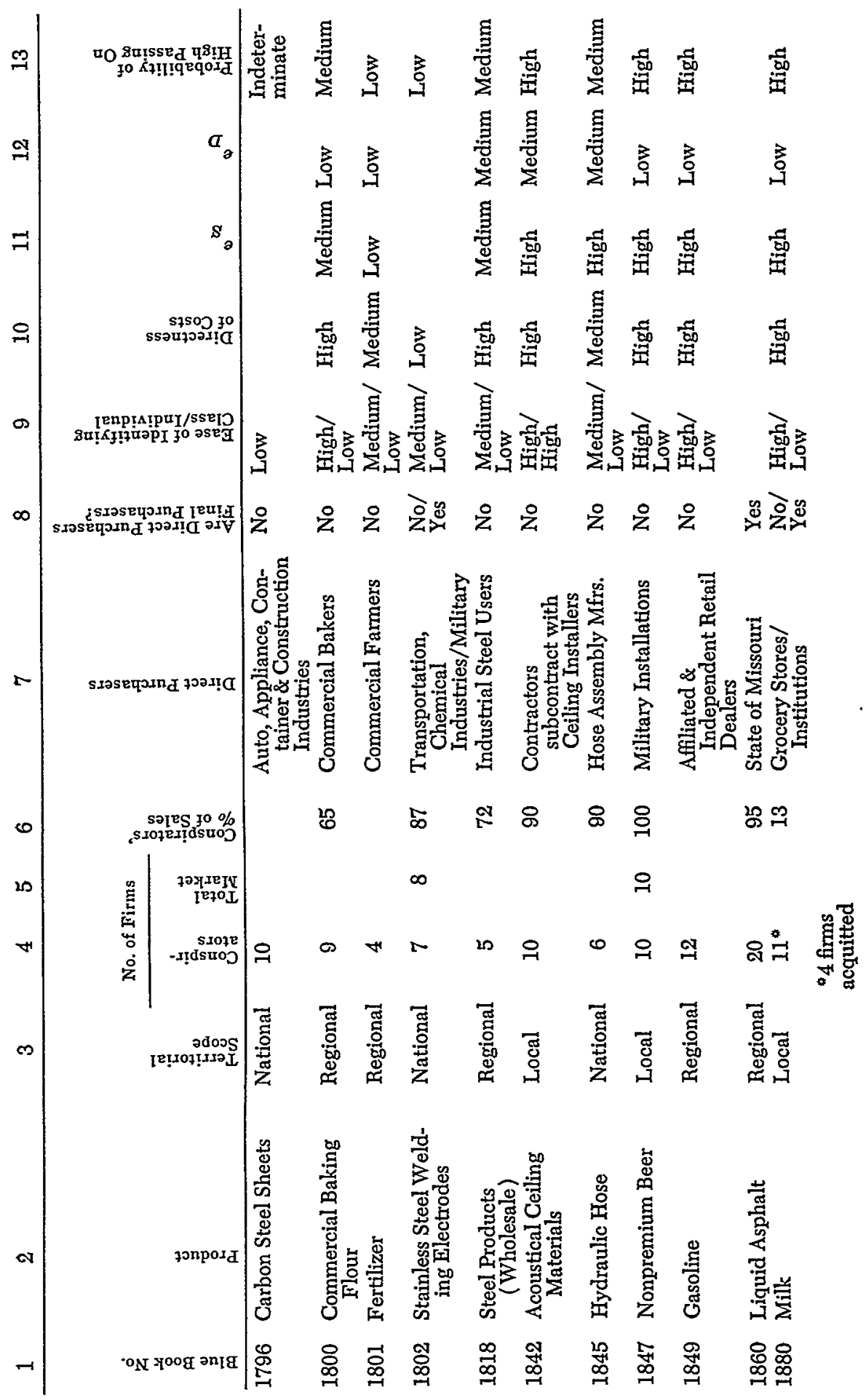




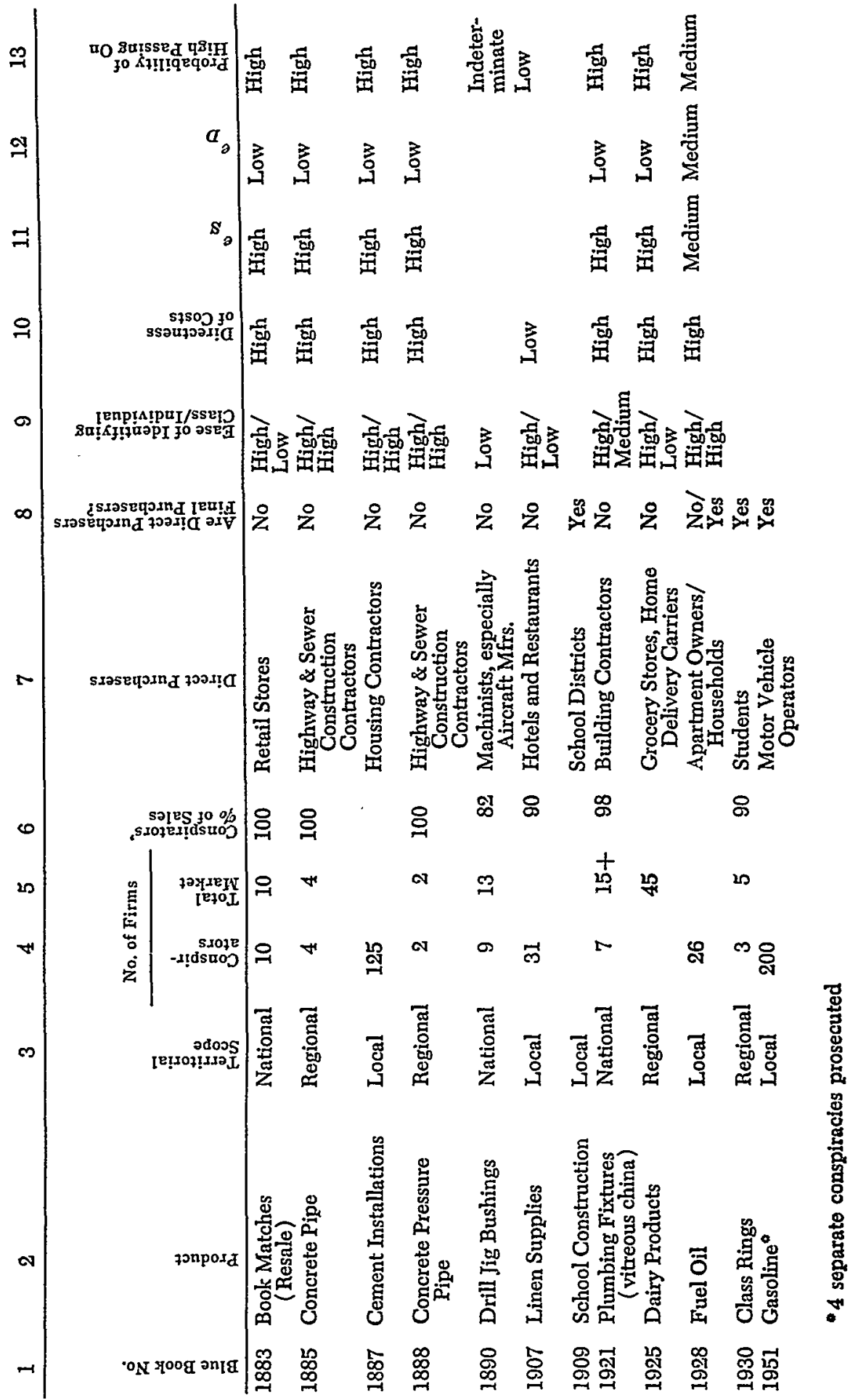




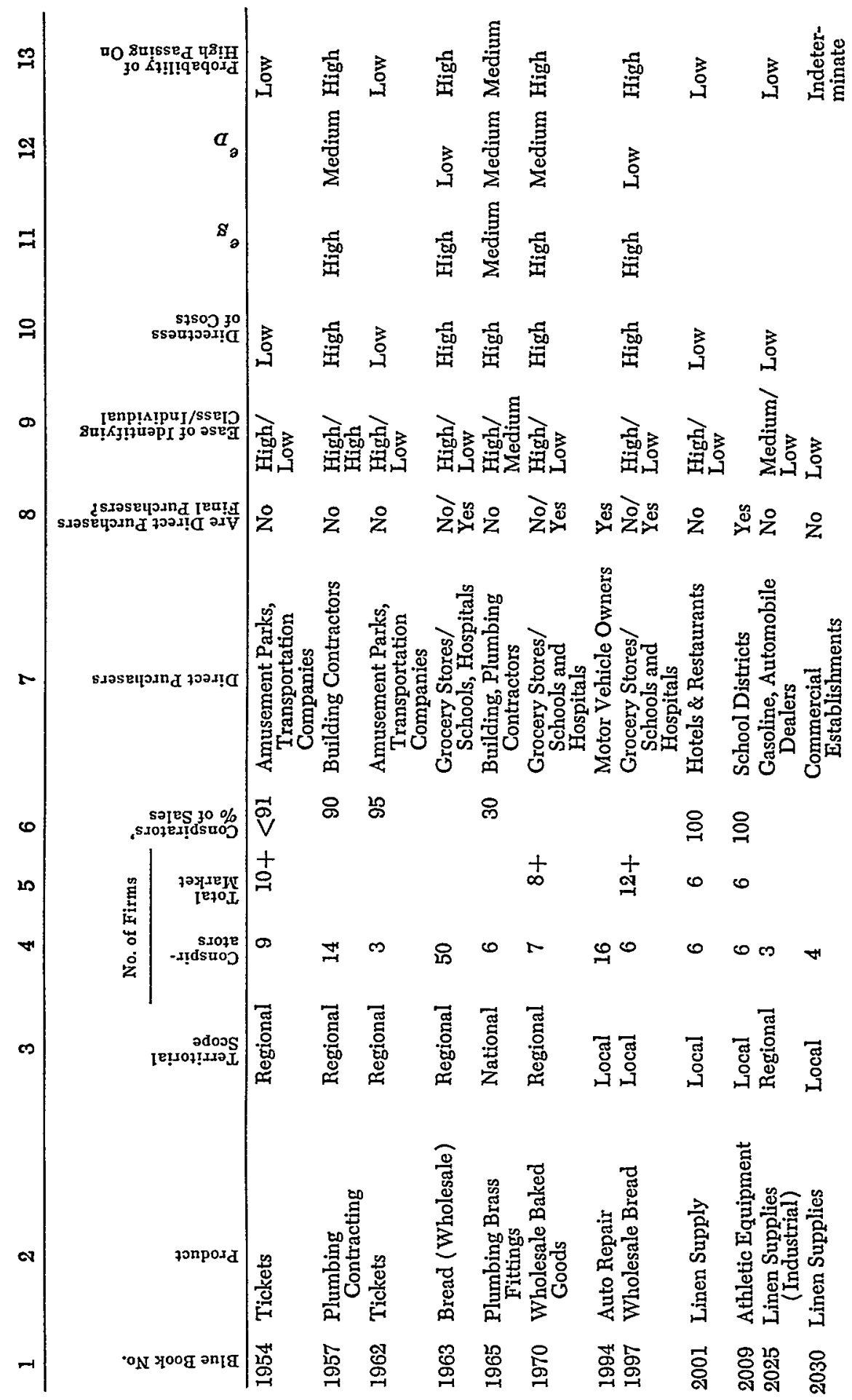




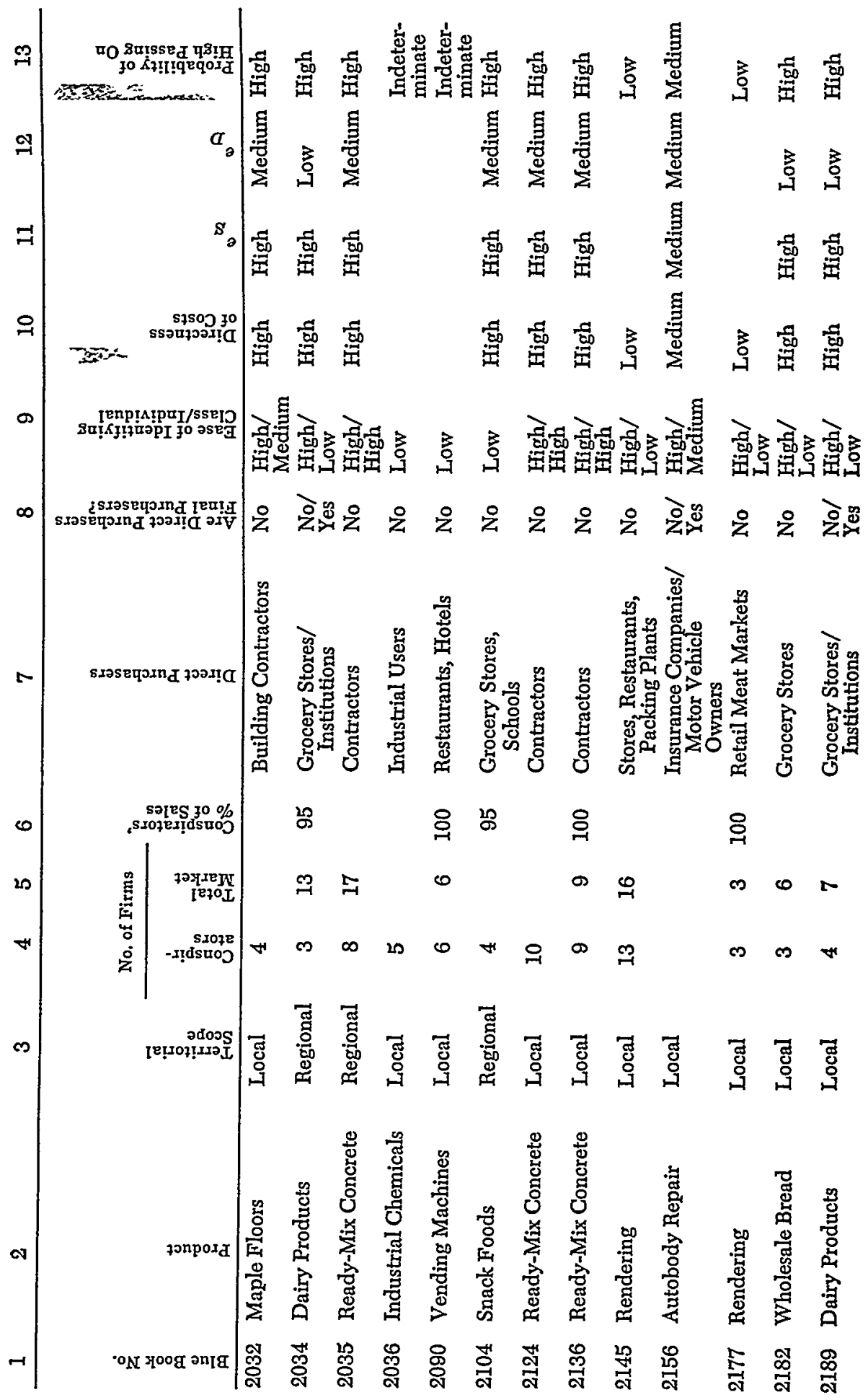




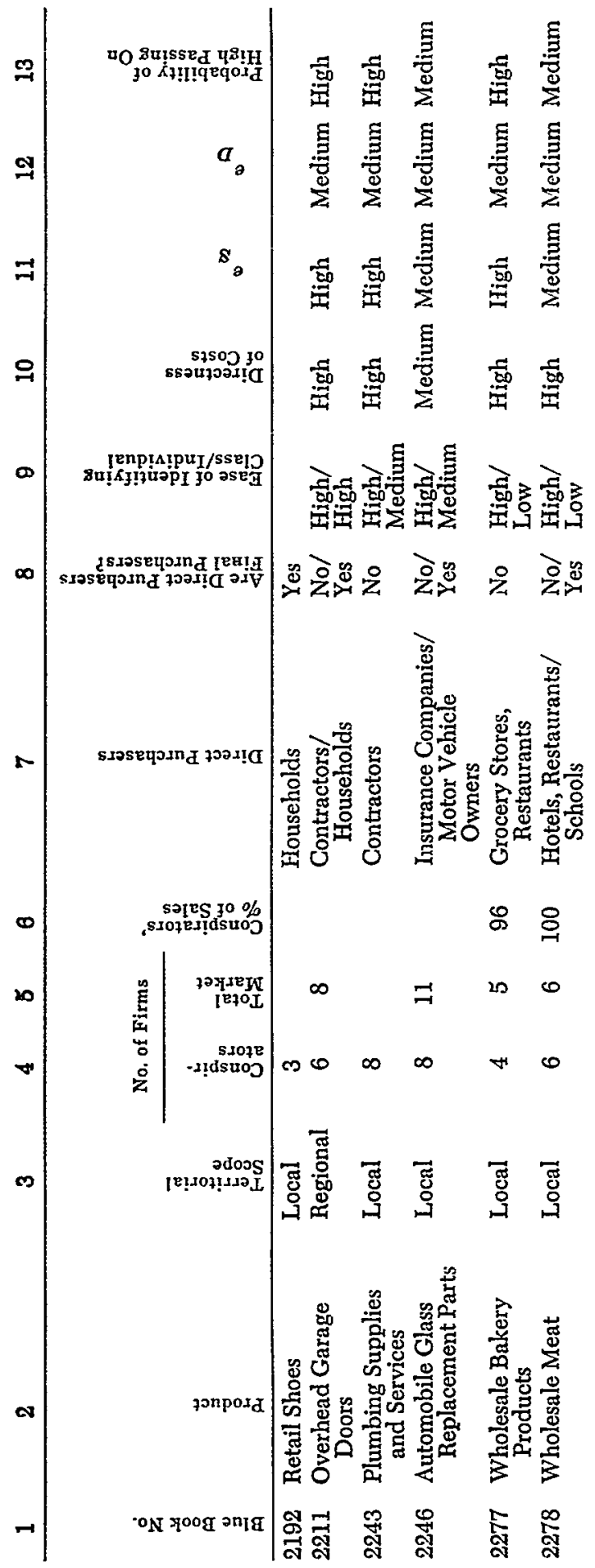

